\title{
Wann tritt die Geburt ein?
}

\section{(Vorausbestimmung des Geburtstages und nachträgliche Bestimmung des Schwängerers.)}

Von

\section{Friedrich Sehatz.}

(Mit 29 Curven.)

(2. Fortsetzung zu Band 72, S. 168-260 und Band 80, S. 557-680.)

Die normale (häufigste) Dauer der Schwangerschaft und ihre Construction.

Die Dauer der menschlichen Sehwangerschaft ist keine gleichmässige, sondern, wie in Tabelle 1 gezeigt ist, sogar eine recht ungleichmässige. Da man aber doch eine Normallinie haben muss, nach und mit welcher man sich technisch kurz verständigen kann, so muss man eine bestimmte Normaldaner annehmen bezw. vereinbaren. Die Juristen thun dies ihrem Bedürniss entsprechend durch eine vereinbarte Höchst- und Niedrigstgrenze, also in Form einer Zone - Empfängnisszeit: 181. bis 302. Tag -. Die Mediciner bedürfen einer sehärferen Bestimmung und nehmen besser eine einzige Normallinie, von welcher aus alle Abweichungen nach oben und unten leicht und bestimmt angegeben werden können.

- Ich meine, dass die Gynäkologen dazu am besten die Zahl 273 Tage nehmen. Damit soll aber durehaus nicht gesagt sein, dass die Schwangerschaftsdauer von 273 Tagen die allein normale, $=$ allein richtige oder auch nur die richtigste sei; alle Tage von 260 bis 280 sind, was die Reife der Frucht betrifft, nicht normwidrig und, wenn dabei die Construction der Schwangerschaftsdauer eingehalten wird, ebenso richtig.

Für die Schwangerschaftsdauer 273 Tage als technische Normallinie führe ich folgende 7 Gründe an:

1. 273 Tage entsprechen der ziemlich allgemein angenommenen Nägele'schen Wahrscheinlichkeitsberechnung: Die Geburt erfolgt $3 / 4$ Jahr und 1 Woche nach Beginn der letzten Menstruation. 
Wenn, wie gewöhnlich angenommen wird, die Empfängniss eine Woche nach Beginn der letzten Menstruation zu setzen ist, so bleiben für die Dauer der. Schwangerschaft 39 Wochen $=273$ Tage.

2. Die Zahl 273 Tage $=39$ Wochen $=9$ Kalendermonate $=3 / 4$ Jahr $(3 / 4$ Jahr sind genauer 273,94 Tage $)$ stellt gewissermaassen eine von der Natur gegebene runde Zahl dar, mit der und von der aus leicht zu rechnen ist.

3. Die Schwangerschaftsdauer von 273 Tagen trifft wirklich recht häufig auf den Tag zu. Man darf freilich nur bis zum Beginn der Geburtswehen, nicht bis zum Austritt des Kindes rechnen und darf die Mühe nicht scheuen, auch sonst richtig zu rechnen.

Es ist nicht überflüssig daran zu erinnern, dass dasjenige Vierteljahr, welches man der Kürze der Rechnung halber gewöhnlich vom ganzen Jahre abzieht, richtig 92 Tage haben muss, um von 365 Tagen 273 Tage zu ergeben; das abzuziehende Vierteljahr muss dazu immer zwei lonate von 31 Tagen haben. Es ist dies nur der Fall, wenn es das 3. oder 4. Vierteljahr des Kalenders ist. Ist es das erste Vierteljahr mit seinen 90 Tagen oder das zweite (oder das erste bei Schaltjahr) mit seinen 91 Tagen, dann muss ausser dem Vierteljahr noch 2 resp. $1 \mathrm{Tag}$ mehr abgezogen werden. - Solchen naiven Schnitzer macht sogar der Kalender selbst (ich weiss nicht, nach welchen Papstes Vorgang). Vou Mariä Verkündigung 25. III. bis Weihnachten 25. XII. sind 275 Tage, weil vom 25. XII. bis 25 . III. = nur 90 Tage von 365 abgezogen sind. Mariä Verkündigung müsste also richtiger auf 27. III. gesetzt werden. Dagegen rechnet der Kalender von Mariä Empfängniss 8. XII. bis Mariä Geburt 8. IX. etwas richtiger. Das sind 274 Tage, weil das von 365 Tagen abzuziehende Vierteljabr 8. IX. bis 8. XII. 91 Tage zählt. - Wenn in das abzuzjehende Vierteljahr die Enden der 3 Monate Februar, März und April fallen, so müssen sogar 3 Tage mehr als diese 3 Monate abgezogen werden, weil Februar, März, April nur 89 Tage zählen. Umgekehrt ist, wenn das abzuziehende Vierteljahr etwa von Mitte November bis Mitte Februar läuft, gar keine Correction nöthig. - Ein Uebersehen dieser Verhältnisse verursacht oft hässliche Täuschungen und Rechnungen.

4. Die durchschnittliche Dauer der Schwangerschaft, aus grösseren Reihen berechnet, ist allerdings etwas geringer als 273 gefunden worden, z. B. von Issmer und Sehlichting vom Conceptionstermin ab 268,2 bezw. 269,9, von Ahlfeld 269,91 Tage. Dass diese Durchschnittszahlen um 3-5 Tage kleiner sind, liegt daran, dass in den verrechneten Reihen eine grössere Zahl zufälliger Frühgeburten als zufälliger Spätgeburten enthalten sind (s. unten). Das rechnerische Mittel wird schon dadurch unter 273 herabgedrückt. Besonders gesehieht dies aber weiter dadurch, dass sehr viele (44 pCt.) Conceptionen erst 6-10 'Tage nach Beginn der Menstruation eintreten. Wir werden später sehen, dass bei 
primärem Abstand zwischen Menstruationsbeginn und Empfängniss bei angioneurasthenischen Personen eine gegenseitige Anziehang und Verschiebung zwischen den Menstruations- und Schwangerschaftsmonaten bis zur gegenseitigen Deckung stattfindet. Dann gestaltet sich die Schwangersehaftsdauer so, als ob die Empfängniss in der Mitte zwischen Beginn der Menstruation und der Conception stattgefunden hätte und sie ist um die Hälfte des primären Abstandes, also von 273 auf $270-268$ Tage verkürzt, während die Construction der Schwangerschaftsdauer dabei doch 273 Tage beträgt und letztere auch wirklich 273 Tage betragen würde, wenn die Empfängniss bei Beginn der Menstruation oder wenn wenigstens keine Verschiebung stattgefunden hätte.

Aus diesen Gründen folgt nun an sich noch nicht, dass normal oder meist die Dauer gerade 273 Tage sein müsse. Man wird diese Zahl aber um so lieber als Normale annehmen, wenn zugleich auch 5. die. Curve, welche, wie Curve 1, die Häufigkeit der Schwangerschaftsdauer nach den einzelnen Tagen ausdrückt, bei oder um 273 die höchsten Spitzen zeigt.

6. Da bei der Menstruationsperiode 28 (oder besser 27,3) Tage als Norm geiten, obgleich sehr viele Fälle längere oder kürzere Periode zeigen, so wird auch das entsprechende zehnfache Multiplum gern als Schwangerschaftsdauer angenommen werden, besonders wenn es sich zeigt, dass solches zehnfache Multiplum häufig wirklich eine gewisse Beziehung zur Schwangerschaftsdauer hat.

7. Der Hauptgrund für die Zahl 273 als Normale für die Schwangerschaftsdauer ist aber die Construction der Schwangerschaftsdauer, indem die meisten meteorischen und zugleich physiologischen Monatsperioden, nämlich die von $21 \cdot 22,75 \cdot 27,3 \cdot$ $30,3 \cdot 34 \cdot 39$ Tagen, und besonders gerade die häufigsten $21 \cdot$ $27,3 \cdot 30,3 \cdot$ mit einem ihrer Multipla bei 273 Tagen abschneiden, nämlich

$273=13 \times 21$ (kurzer [elektrischer?] Monat),

$273=12 \times 22,75(22,8=$ vierte Halbtheilung des Jahres $)$, $(275=11 \times 25)$,

$273=10 \times 27,3$ (periodischer Mondmonat und elektrischer Monat), $273=9 \times 30,3(30,4=$ Sonnenmonat $=$ Kalendermonat $)$,

$(272=8 \times 34)$,

$(273=7 \times 39)$.

Um die normale Dauer der Schwangerschaft practisch zu finden, darf man - wenigstens zunächst - nur solche Fälle benützen, bei welchen die Empfängniss zur normalen Zeit erfolgt ist, d. i. kurz 
vor oder bei Beginn einer Menstruation, also zu der Zeit, welche bei den Thieren im Naturzustand allein zur Empfängniss benützt wird.

Bei Empfängniss zu anderer Zeit stellen sich, wie wir sehen werden, unter gewissen Umständen durch gegenseitige Anziehung der dann mehr oder weniger von einander entfernten Perioden Verscbiebungen derselben gegen einander und damit Verkürzungen oder Verlängerungen der Schwangerschaftsdauer ein, welche, wenn nicht genügend bekannt und berücksichtigt, jede genauere Berechnung unmöglich machen können. - Bis ich dieses erkannte, habe ich oft die grössten Schwierigkeiteı gehabt, die Fälle einigermaassen richtig zu deuten. Ich musste oft meine Zuflucht nehmen zu Verkürzungen oder Verlängerungen, welche die Perioden (Monate) gegen die Geburt bin erleiden sollten. Ich habe solche Verkürzungen und Verlängerungen der Wehenperioden in der Arbeit "Schlechte Wehen und die centrale Steuerung der Wehenthätigkeit" theilweise als Ante- und Postponiren der Wehenreihen aufgefasst und beschrieben.

Seit es mir gelungen ist deren Ursachen zu finden, könnten allerdings auch solche Fälle für die Erkenntniss der normalen Schwangerschaftsdauer herangezogen werden. Ich will dies aber hier nur ausnahmsweise und nur dann thun, wenn ich für die betreffenden Stellen einfacheres Beweismaterial, d. i. Fälle mit Empfängniss am Beginn der Menstruation nicht habe.

\section{Die Construction der Schwangerschaftsdaner.}

Seit je haben verschiedene Aerzte die Schwangerschaftsdauer als ein (zehnfaches) Multiplum der Menstruationsperiode und die Geburt als die nach so langem Ausbleiben um so stärker auftretende Menstruation angesehen. Man musste diesen Gedanken aber verlassen und hat ihn immer wieder verlassen; denn wenn auch eine Anzahl Fälle recht gut zur Hypothese passt, so passen doch noch viel mehr garnicht.

Schliesslich ist die Hypothese aber doch ganz richtig, nur freilich nichtin solcher Einfachheit.

Ich will hier gleich der Uebersicht halber zusammenhängend formuliren, wie sie etwa lauten muss und will die Beweise dafür daran anschliessen.

Allerdings ist die Șchwangerschaftsdaner normaler Weise immer ein Multiplum eines physiologischen Monats, und zwar dasjenige Multiplum, das mit seinem Monatsende in die Reifezone der Frucht fällt. Sie kann also recht wohl auch das zehnfache Multiplum des periodischen Mondmonats sein: $10 \times 27,3=273$ und wenn, wie recht häufig, die Menstruation schon vor der Schwangersehaft diesen Monatstypus eingehalten hat, so trifft die alte einfache Regel zu. Aber:

1. Der physiologische Monat kann eine ganz andere Länge 
haben und sein Multiplum muss dann auch ein ganz anderes sein, um bis in die Reifezone der Frucht zu gelangen, z. B. $13 \times 21$ $=273 ; 12 \times 22,75(23)=273(276) ; 11 \times 25=275 ; 9 \times 30,3$ $=273 ; 8 \times 34=272 ; 7 \times 39=273$. Das Multiplum braucht dann aber nicht gerade bei 273 zu enden, z. B. $10 \times 25,9=259$.

2. Die Menstruation braucht vor der Schwangerschaft nicht den gleichen physiologischen Monat eingehalten zu haben wie in derselben, sondern einen anderen. - Während der Schwangerschaft gilt der Blutdruckmonat, vom tiefsten Minimum zum tiefsten Minimum gerechnet, als Menstruationsmonat.

3. Die Schwangerschaftsdauer wird aber nicht von nur einer Periodenreihe (Periodicität) bestimmt, sondern von $z$ weien. Während der Schwangerschaft laufen nämlich immer zweierlei physiologische Monatsreihen nebeneinander (concurrirende Periodicitäten) und treffen sich am Ende der Schwangerschaft in derselben. Phase wieder, in welcher sie sich bei der Empfängniss befunden baben, z. B. $10 \times 27,3=13 \times 21=273$. Dieses Wiedertreffen bestimmt den Beginn der Geburt. Die Schwangerschaftsdauer ist also nicht, wie man bisher annahm, das Multiplum nur eines physiologischen Monats, sondern zweier, manchmal sogar dreier verschiedener, aber in ihren Summen gleich langer Multipla.

\section{Die beiden ,concurrirenden Periodicitäten".}

Ich benutze zur Darlegung des Mechanismus der beiden concurrirenden Periodicitäten zuerst nur die beiden häufigsten und häufigst vereinten Periodicitäten:

$$
273=10 \times 27,3 \text { und } 273=13 \times 21
$$

und zeige zunächst, wie sich jede möglichst vollkommen und für sich allein an der Blutdruckeurve darstellen kann.

Der oben (Bd. 72, S. 223) mitgetheilte Fall 170, dessen (dort fälschlich mit 169 bezeichnete) Curve 13, weil dort zu stark verkleinert, ich nochmals wiedergebe, hat 25. XII. bei Beginn der Menstruation empfangen und kam 25. IX., d. i. nach 273 Tagen zur Geburt. Der Fall hatte die Menstruation vor der Schwangerschaft regelmässig 28 tägig (jedenfalls nur 27,3 tägig) und ist die ganze zweite Hälfte der Schwangerschaft, also 5 Monate lang, in der Klinik beobachtet worden, so dass nur die ersten 5 Monate unbeobachtet waren. Die letzten 5 Monate sind an der Blut- 


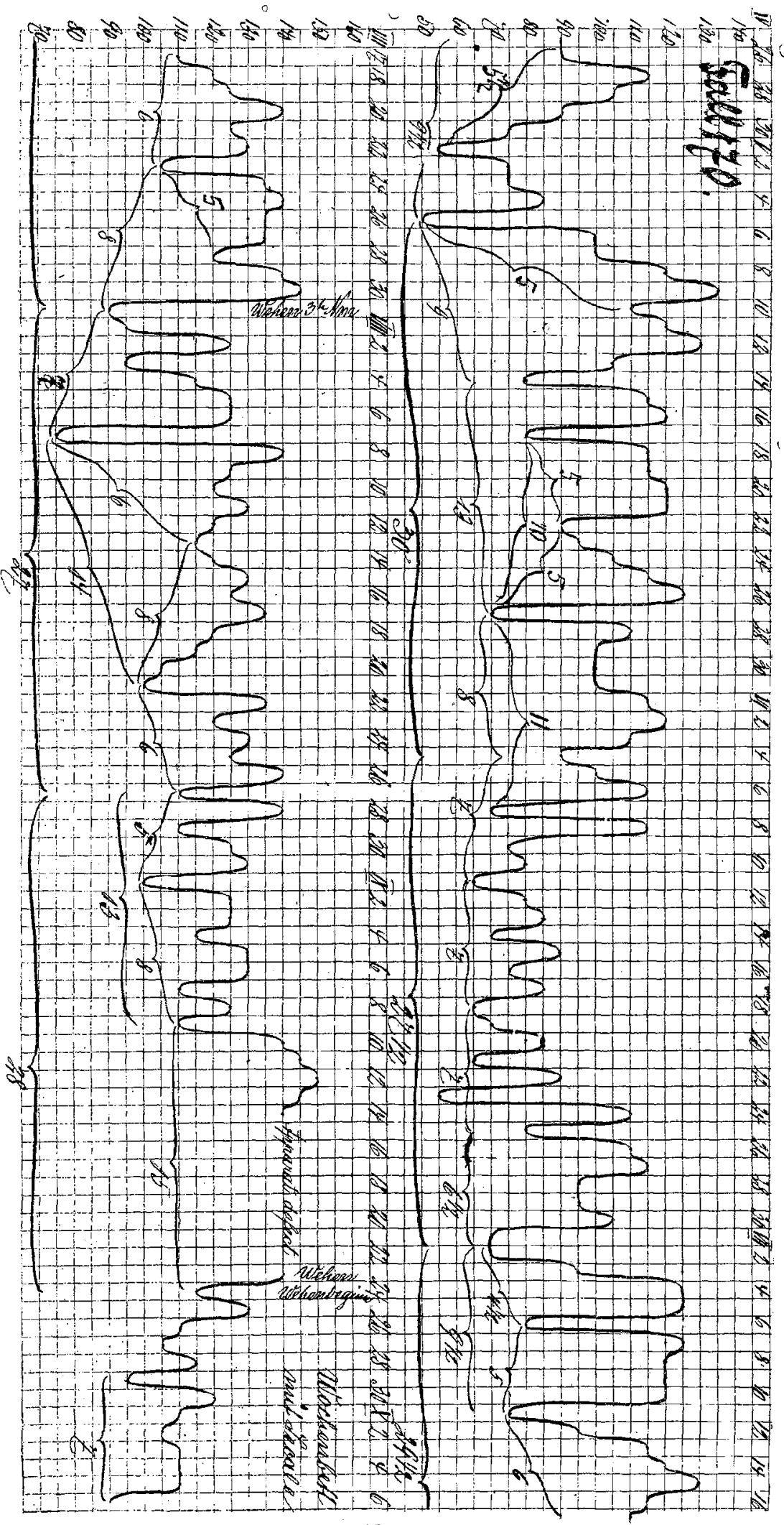


druckcurve $30 \cdot 271 / 2 \cdot 291 / 2 \cdot 27 \cdot 28$, d. i. $\frac{142}{5}=$ durchschnittlich 28,4 Tage lang. Die ersten 5 Monate waren dagegen, vom 25. XII. bis $5 . \mathrm{V} .=\frac{131}{5}=$ durchschnittlich 26,2 Tage lang. Beiderlei Monatslängen gleichen sich áber gegenseitig aus $142+131$ $=\frac{273}{10}$ zu je 27,3 Tagen.

Solche zeitweilige Abweichungen, welche sich wieder ausgleichen, sind überhaupt nicht selten, und können ein Gesetz nicht discreditiren, sondern beweisen sogar die zwingende Kraft desselben. Wodurch hier die zeitweiligen Abweichungen erzeugt sind, kann man nur vermuthen. Wahrscheinlich hat die reichliche Arbeit und Bewegung im Dienst die 5 ersten Honate der Schwangerschaft um je 1 Tag verkürzt und während der grösseren Ruhe in der Klinik wurde umgekehrt jeder Monat durchschnittlich um 1 Tag verlängert, und zwar der erste wegen der schnellen Veränderung gegen den letzten draussen sogar gleich um 4 Tage - 30 gegen 26,2.

Abgesehen von diesen zeitlichen Abweichungen erkennt man den 4 wöchentlichen Periodentypus mit Halb- und Vierteltheilung der Monate an der Curve ganz deutlich und rein:

$$
\frac{9 \cdot 13 \cdot 8}{30} \cdot \frac{7 \cdot 7 \cdot 7 \cdot 61 / 2}{271 / 2} \cdot \frac{91 / 2 \cdot 6 \cdot 6 \cdot 8}{291 / 2} \cdot \underbrace{7 \cdot 6 \cdot 8 \cdot 6}_{27} \cdot \underbrace{5 \cdot 8 \cdot 15}_{28} .
$$

Ganz ebenso zeigen den rein 4 wöchentlichen Periodentypus die Fälle 202 Misck (Bd. 80, S. 563) 203 Seedorf (Bd. 80, S. 565) und die weniger lang beobachteten. Fälle 171 und 172 (Bd. 72 S. 228).

Der Fall 201 (Bd. 72, S. 561) zeigt gleich reine 28 tägige Periodenbildung und unterscheidet sich nur dadurch, dass er von Mitte zu Mitte des Blutdruck-(Menstruations-)Monats läuft.

Diesen Fällen mit rein 27,3 (28) tägigem Periodentypus stehen gegenüber die Fälle mit rein 21 tägigem Periodentypus, z. B.

Fall 243. 1903/4. Geburts-No. 72. Kesch, 35jähr., $166: 89 \mathrm{~cm}$ lange, $62^{1} / 2 \mathrm{~kg}$ schwere, gracil gebaute, mässig ernährte, blonde $1 \mathrm{Igr}$, ist seit dem 16. J. 24 tg., 6-7tg., reichlich mit Kreuzschmerz menstruirt,

a) hat vor $6 \mathrm{~J}$. in $10 \mathrm{St}$. grosses M. geboren,

b) hatte die letzte Menses Mitte V. wie sonst, will 1. VI. (2. Pfingsttag) empfangen, 12. $\mathrm{X}$. die ersten Bewegungen und 8. l. dentliche Senkung des Uterusgrundes gefühlt haben, was jedenfalls richtig ist, weil es mit der Curve stimmt. Schwangerschaftsweben 30. I.

Diese Curve zeigt zunächst die Besonderheit, dass die grosse Blutdruckwelle vom 8 . I. bis 19. II. volle 6 Wochen umfasst: 201/2. Tage Aufstieg, 21. Tage Abstieg der Minima. Sie zeigt auch im Uebrigen fast durchweg Theilung nach dem 21 tägigen Periodentypus. 
Schatz, Wann tritt die Geburt ein?
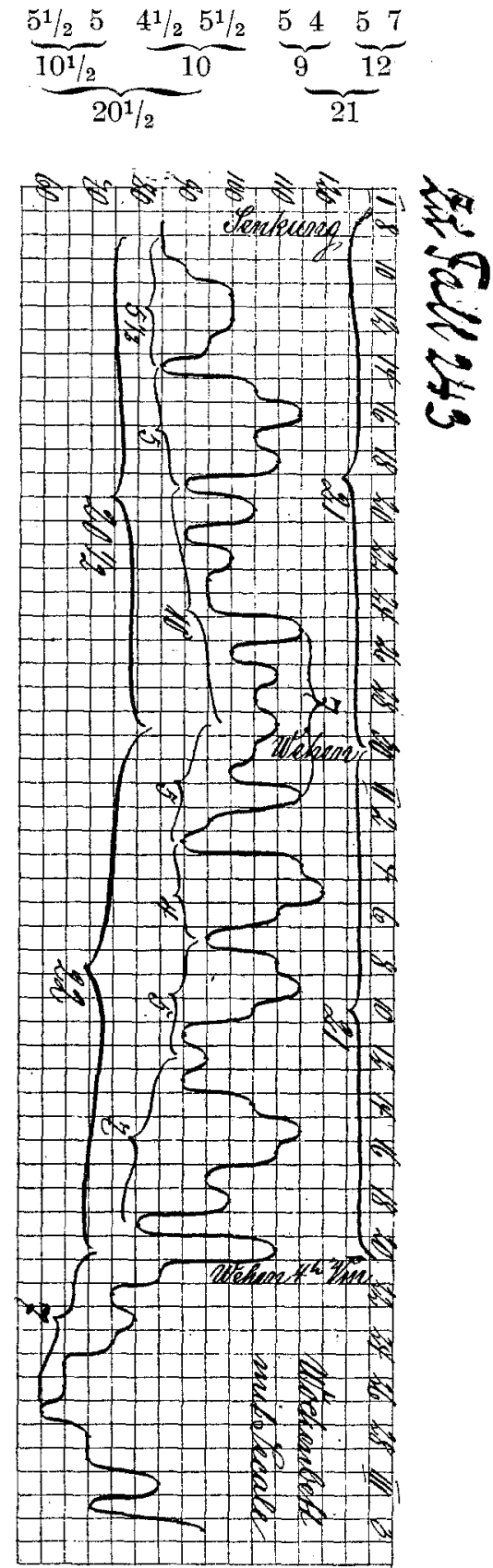

Da die Senkung des Uterusgrundes 8. I. und die Schwangerschaftswehen 30. I. auch mit der Curve stimmen, so passte alles zur Bestimmung des Geburtstages auf den 20. II. - nur nicht der angegebene Con- 
ceptionstermin. In Rücksicht auf die 6 Wochen lange ungetheilte Blutdruckwelle (s. unten) hielt ich es allerdings für wohl möglich, dass die Geburt erst 1. III., d. i. 273 Tage nach dem 1. VI., eintreten würde. Aber die Schwangerschaftswehen sprachen dagegen, und die Geburtswehen trafen entsprechend den Schwangerschaftswehen wirklich 21. II. 4 Uhr Nachm. ein, betrugen von $71 / 2$ Uhr Vorm. ab 7, 6, 6, 5, $6,8,7,7,7,8,6,5,4,6,4,3,4,5,6,6,8,8,7,7,6,8,9,7,4$. Die Blase sprang erst vor der Vulva. K. $51 \mathrm{~cm}, 3030 \mathrm{gr}$. (Plac. $585 \mathrm{gr}$. mit wenig Kalk).

Zweifellos hat die K. am 2. Pfingsttag cohabitirt, aber sie hatte schon am Sonntag vor Pfingsten 24. V. oder am 23. V. - 2 Tage nach Beginn der Menstruation, die also erst nach Mitte Mai eingetreten war - empfangen gehabt.

Insofern passt also der Fall nicht ganz hierher. Er erfüllt nicht ganz die oben aufgestellte Bedingung, dass die Empfängniss kurz vor oder bei Beginn der Menstruation, also am Beginn des Menstruationsmonats stattgefunden haben soll. Aber der Fall kann trotzdem und soll hier verwerthet werden, weil ich einen andern eben solange beobachtete mit 21 tägigem Periodentypus nicht habe, bei welchem die Empfängniss gerade zu Beginn des Menstruationsmonats stattgefunden hat, und weil sich dieser Fall als angioneureustenischer bezüglich der Blutdruckmonate gerade so verhält, wie wenn die Empfängniss bei Beginn der Menstruation erfolgt wäre.

Die Schwangerschaftsdauer ist constrairt deutlich $13 \times 21$ $=273$ Tage.

An diesen Fall 243 schliessen sich als ebenfalls normal und mit rein 21 tägigem Perioden(Monats)typus an die nur kurz beobachteten Fälle 173 und 174 (Bd. 72 S. 229, 230) und die länger beobachteten Fälle 205 Güls., 206 Mik., 207 Koch., 208 Jel., 209 Bre. (Bd. 80 S. 571-579).

Diese beiden hier einander gegenübergestellten Arten Normalfälle mit deutlich ausgeprägtem 27,3tägigen Monatstypus und $10 \times 27,3=273$ tägiger Schwangerschaftsdauer einerseits und mit deutlich ausgeprägtem 21 tägigen Monatstypus und $13 \times 21=$ ebenfalls 273 tägiger Schwangerschaftsdauer anderseits sind die beiden Endglieder einer langen Reihe zwischenliegender Fälle, bei welchen die beiden genannten Monatstypen vereinigt und durcheinander arbeitend erkennbar sind. In Wirklichkeit arbeiten immer beide, wenn auch in recht verschiedener Weise mit- und durcheinander.

Selbst bei den vorgeführten „Normalfällen mit nur einheitlichem Monatstypus" zeigen sich doch auch kleine Anzeichen des zweiten (concurrirenden) Monatstypus, z. B. in Fall 170 zwischen den fast ausschliesslichen 4 wöchentlichen Monaten mehrfach die Periodentheile 5 und 11 des 21 tägigen Monats, und in Fall 243 zwischen den fast ausschliesslichen 3 wöchentlichen Monaten die Periodentheile 7 des 27,3 tägigen Monats.

Dadurch wird es höchst wahrscheinlich, dass überhaupt bei jeder Schwangerschaft zwei solche Perioden(Monats)typen - zwei 
Periodicitäten - vorhanden und wirksam sind, wenn sie auch nicht stets beide oder wenigstens nicht beide gleich stark in Erscheinung treten, der eine also mehr oder weniger latent bleibt.

Es ist dies eine so auffallende Erscheinung, dass sie zuerst auf Zweifel stossen wird. Ich muss also möglichst gutes und viel Beweismaterial vorführen.

Zunächst führe ich als Wahrscheinlichkeitsbeweis den Umstand vor, dass nicht selten der vor der Schwangerschaft vorhandene Monatstypus bei Lintritt der Conception in den andern Monatstypus umspringt und nach der Geburt - oft schon im Wochenbett in den ersteren zurückspringt.

Es ist durchaus wahrscheinlich, dass da der vor und nach der Schwangerschaft vorhandene Monatstypus auch während der Schwangerschait neben dem neueingetretenen Typus, wenn auch latent, so doch in (gewisser) Wirkung bleibt.

So springt der vor der Empfängnis vorhandene 4 wöchentliche Typus mit der Empfängnis in den 3 wöchentlichen um, bei Fall 173 Alb. (Bd. 72 S. 229), Fall 185, 1048 (Bd. 72 S. 242), Fall Wollg. (s. später unter "Einfluss des Vaters auf die Dauer der Schwangerschaft") Fall 244 Krüg., Fall Dans. (s. unten unter "Suchen des Erzeugers") und der vor der Empfängnis vorhandene 3 wöchentliche Typus springt mit der Empfängniss in den 4 wöchentlichen über wie bei Fall 245 Weiss. Bei den beiden letzten Fällen springt der in der Schwangerschaft eingetretene Monatstypus nach der. Geburt wieder zu dem vor der Schwangerschaft dagewesenen zurück. Ebenso bei Fall 247 Schwa. und bei Fall 25301.

Fall 244. 1904/5. Geburts-No. 19. Krüg., 22jähr., $151: 80 \mathrm{~cm}$ lange, $671 \frac{1}{2} \mathrm{~kg}$ schwere, kräftig gebaute, gut genährte, dunkelblonde

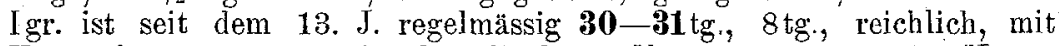
Kreuzschmerzen menstruirt, hat die letzte Menstruation 10.-13. II. gerínger als sonst gehabt und hat vom 15. I. ab cohabitirt. Sie gebar K. $51 \mathrm{~cm}, 3300 \mathrm{~g}, 10$. XI. 7 Uhr 40 Min. Vorm., nachdem die Wehen 4 Ubr Vorm. begonnen und von 6 Uhr ab betragen hatten: $6,6,7,6$. Keine Schwangerschaftswehen, aber Senkung des Uterusgrundes 21. X. Nittags bemerkt, also Wehen jedenfalis von früh $a b$, d. i. 20 Tage vor Beginn der Geburtswehen.

Die Curve zeigt 21 tägigen Periodentypus. Die Senkung am 21. X. (20 Tage vor Beginn der Geburtswehen) entspricht ganz diesem Typus, denn die Wehen, welche diese Senkung bewirkt haben, werden länger als 1/4 Tag gedauert haben. Beginn der Schwangerschafts- und der Geburtswehen werden 20-21 Tage von einander entfernt sein. Die Schwangerschaftsdauer ist also jedenfalls $13 \times 21=273$ und die andere Periodicität, welche den Knotenpunkt mit bildete, $9 \times 30^{1 / 3}$ $=273$, weil diese Periodicität vor der Schwangerschaft bei der Men- 
struation da war. Die Empfüngniss wird unmittelbar vor der veränderten Menstruation 10. bis 13. II., also wohl 9. oder 10. II. erfolgt sein.

Die Vorausbestimmung des Geburtstages war leicht und sicher, nachdem die Curve den 21 tägigen Periodentypus verrathen hatte. Dann wies die Senkung auf 3 Wochen später hin, und dorthin wies auch der letztmögliche Empfängnisstermin kurz vor der veränderten Menstruation.

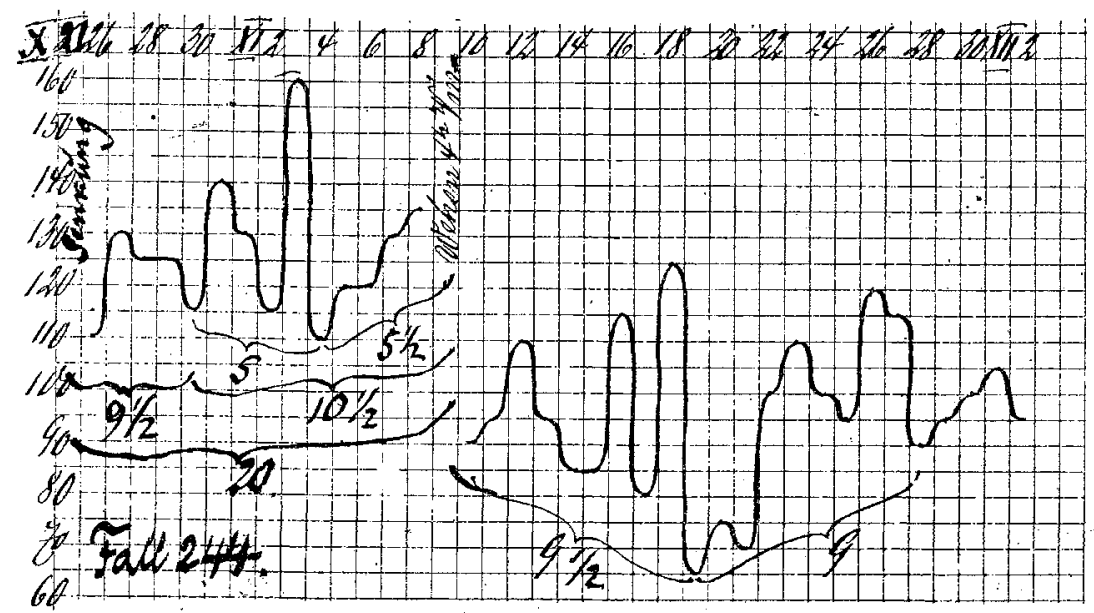

Hier sprang die vor der.Empfängniss $30 \frac{1}{3}$ tägige Menstruations-Periodicität mit bezw. nach der Empfängniss in die 21 tägige um, wirkte aber neben dieser in der Schwangerschaft als zweite Periodicität weiter mit zur Erzeugung des Knotenpunktes, welcher den Geburtstag und damit die Dauer der Schwangerschaft bestimmte. $9 \times 30,3=13 \times 21=273$.

Fall 245. 1903/4. Geburts-No. 67. Weiss, 29 jähr., $155: 89 \mathrm{~cm}$ lange, $63 \mathrm{~kg}$ schwere, kräftig gebaute, gut genährte, dunkelblonde II gr., ist vom 14. J. regelmässig, 22 tg., 3 tg., reichlich, mit Leibschmerz menstruirt,

a) hat vor $8 \mathrm{~J}$. in $20 \mathrm{Std}$. reifen K. geboren,

b) hat die letzte normale Menstruation Ende IV., die nächste nur 1 tg. 20. V. gehabt, sogleich 20. V. concipirt und die Senkung des Uterus nach Mitte I bemerkt.

Sie gebar M., 505/2 cm, $3100 \mathrm{~g}$ (Plac. $520 \mathrm{~g}$ ); 20. II. 2 Uhr $50 \mathrm{Min}$. Vorm., nachdem die Wehen 18. II. $10 \mathrm{Uhr}$ Nachm. begonnen hatten, die Blase 2 Stunden darauf gesprungen war und die Wehen von da $a b$ betragen hatten: $4,7,6,5,8,7,7,6,6,7,8,4,7,8,7,8,8,8,8$, $7,7,8,7,6,7,8,6,6,4,4,4,5,3,2,3,7,5,4,4,5,4,3,3,3$, $3,6,5,6,5,6,4.5,6,7,6$.

Da hier die Conception sicher bei Beginn der Menstruation stattgefunden hatte, so konnte man sicher annehmen, dass die Menstruations(Blutdruck-) und die Schwangerschafts-(Wehen-)periodicitäten beisammẹn geblieben sind, und dass, sei es, dass sie 21- oder 27,3tägig wären̆, 
die Geburt am 273. Tage eintreten werde, d. i. 18. II. Die Senkung des Uterusgrundes passte zur 27,3 tägigen Periodicität, und die kurze Blutdruckcarve ebenfalls, wenn man den 273. Tag, d. i. 18. II., als Geburtstag ansah.

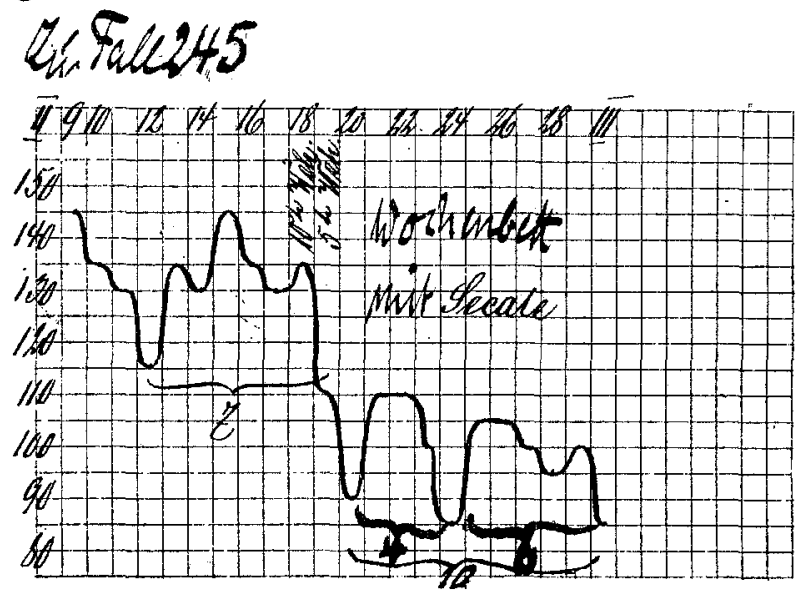

Hier ging offenbar der vor der Schwangerschaft vorhandene 21(22?) tägige Periodentypus mit und in der Schwangerschaft in den 27,3 tägigen über und kehrte nach Ende der Schwangerschaft sogleich zu dem 21 tägigen zurück. Die Schwangerschaftsdauer war die ganz normale: $10 \times 27,3=13 \times 21=273$ Tage.

Das gleichzeitige Arbeiten der beiden Perioden(Monats)typen während der Schwangerschaft tritt aber auch sichtbar und beweisend an der Blutdruckeurve zu Tage:

a) Dadurch dass in der Blutdruckcurve bei den Maximis der eine, und bei den Minimis der andere Periodentypus vorherrscht.

b) Dadurch dass der 27,3tägige Blatdruckmonat in den 21tägigen umspringt oder umgekehrt.

c) Dadurch dass der 27,3tägige Monat nach den Periodentheilen des 21 tägigen $10 \cdot 5$ und der 21 tägige nach den Periodentheilen des 27,3tägigen Monats $14 \cdot 7 \cdot 3 \frac{1}{2}$ getheilt wird.

d) Dadurch dass man die Blutdruckeurve sowohl nach dem einen wie nach dem andern Typus eintheilen kann.

e) Dadurch dass in manchen Fällen die Blutdruckmonate nach dem einen (27,3tägigen), die Schwangerschafts(Wehen)monate aber nach dem andern (21 tägigen) Typus arbeiten, oder umgekehrt.

f) Dadurch dass der Uebergang - das Umspringen - von einem Typus zum andern bei den Wehenmonaten früher oder später erfolgt, als bei den Blutdruck(Menstruations)monaten. 
ad a) An der Blutdruckeurve herrscht bei den Maximis der eine, bei den Minimis der andere Perioden(Monats)typus vor.

Fall 246. 1905/6. Geburts-No. 56. Schwa., 24jähr., $168: 91 \mathrm{~cm}$ lange, $73 \mathrm{~kg}$ schwere, mittelkräftig gebaute, hellblonde I gr., hatte die Menstruation vom 16. J. ab regelmässig 28-30tg., 4-8 tg. reichlich, mit Schmerz, hatte die letzte Menstruation 16.-24. IV. wie sonst und hat empfangen in der Woche vom 24. IV. ab. Sie gebar M., $49 \mathrm{~cm}$, $3200 \mathrm{~g}$ (Plac. $470 \mathrm{~g}$ ), 2. II. Vorm. 2 Uhr 50 Min., nachdem die Wehen 1. II. $10 \mathrm{Uhr}$ Vorm. begonnen und von $11 \mathrm{Uhr}$ Nachm. betragen hatten: $5,6,6,8,8,7,7$.

Das Kind ist offenbar normal lang (273 Tage) getragen. Es soll in der Woche 24-30. IV. empfangen sein. Rechnet man von Beginn der Geburt 1. II. Abends 273 Tage zurück, so kommt man auf den 3. V. Abends als Empfängnisstermin, d. i. 17 Tage nach Beginn der letzten Menstruation. Es ist fraglich, ob die Cohabitation erst da oder doch, wie angegeben, schon in der Woche 24.-30. IV. stattgefunden, aber da kein Ei vorgefunden hat. Letzteres ist mir wahrscheinlicher. Das Ei wird aus der Zwischenovulation 1. V. stammen und von dem Sperma der Cohabitation 24. - 30. IV. befruchtet sein. Die Sehwangerschaft ging also erst vom 1. V. ab mit einer Dauer und Construction $10 \times 27,3=13 \times 21=273$.

An der Blutdruckcurve zeigt sich die Periodicität $10 \times 27,3$, besonders bei den Maximis, die Periodicität $13 \times 21$ besonders bei den Minimis.

Während der Schwangerschafi, wo man bei den Minimis 2 mal einen Blutdruckmonat von 19 Tagen gesehen hatte, musste man meinen, dass die 2. Periodicität $7 \times 39$ sein möchte. Dann war die Geburt 2 Tage früher zu erwarten, und dies stimmt auch besser mit der Cohabitation. Der letzte Monat von 21 Tagen zeigt aber, dass doch $10 \times 27,3=13 \times 21$ richtiger ist.

ad b) Der vierwöchentliche Monat springt während der Schwangerschaft in den dreiwöchentlichen um oder umgekehrt.

Fall 247. 1903/4. Geburts-No. 151. Schwa., 24jähr., $163: 85 \mathrm{~cm}$ lange, $701 / 2 \mathrm{~kg}$ schwere, gracil gebaute, gut genährte, brünette Igr., ist seit dem 15. J. regelmässig $\mathbf{3}$ wöchentlich 2 tg., nicht reichlich mit Schmerzen menstruirt, will die letzte Menstruation 10. IX. wie gewöhnlich gebabt haben, gebar M., $50 \mathrm{~cm}, 3300 \mathrm{~g}$ (Plac. 550), 26. VII. $4 \mathrm{Uhr}$ Nachm., nachdem die Wehen 8 Uhr Vorm. begonnen und von 101/2 Uhr ab betragen hatten: $5,6,6,7,9,9,8,9,10,9$.

Die Conception wird jedenfalls 6 Wochen nach der angegebenen letzten Menstruation stattgefunden haben vielleicht bei oder bald nach der da (22. X.) fälligen Menstruation. Die Schwangerschaftsdauer war jedenfalls die normale und das 2 malige Ausbleiben der Menstruation 1. X. und vielleicht auch 22. X. durch Wechsel des Aufenthaltsortes bewirkt. 

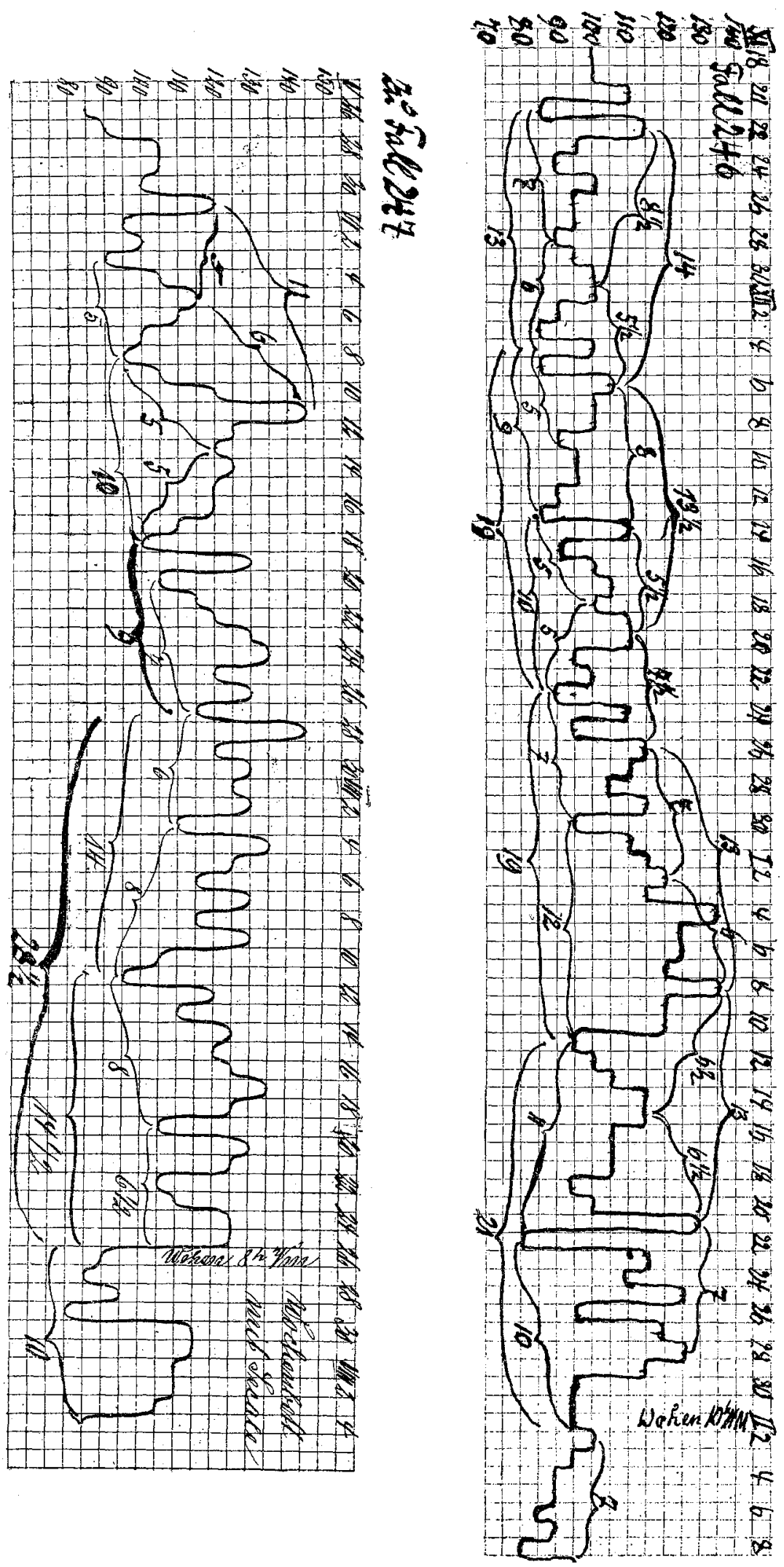
Die beiden Jetzten Halbmonate von 14 und 141/2 Tagen können sehr wohl als zu einem 28 tägigen, letzten Schwangerschaftsmonat zusammengehörig angesehen werden. Jedenfalls ist für diese Zeit der 28 tägige Periodentypus zweifellos: Freilich ist auch dabei die Theilung der Halbmonate nicht ganz gleich: $6 \cdot 8 \cdot 8 \cdot 67 / 2$. Im vorletzten Schwangerschaftsmonat ist dagegen nach einem Uebergang von 7 oder 9 Tagen der 21 tägige Periodentypus deutlich vorhanden $5,10(5,5)$. Wahrscheinlich wurde noch weiter zurück dieser 21 tägige, schon vor der Schwangerschaft vorhandene Typus noch mehr eingehalten. Die Schwangerschaftsdauer und ihre Construction war $13 \times 21=10 \times 27,3$ $=273$ Tage, und es arbeiteten die beiden Periodentypen so mit einander, dass vom vorletzten zum letzten Schwangerschaftsmonat der von vor der Schwangerschaft bis dahin vorhandene 21 tägige Periodentypus in den 28 tägigen überging, um übrigens gleich nach der Geburt im Wochenbett wieder zum 21 tägigen zurückzukehren.

Im folgenden Fall ist zwar Beginn und Ende der Schwangerschaft nicht sicher festgestellt, aber der 21 tägige Periodentypus ist an der Blutdruckeurve wie bei den Wehen deutlich und ist zeitweilig in den 28 tägigen umgesprungen.

Fall 248. 1904/5. Geburts-No. 171. Brı., 31 jähr., $165: 87 \mathrm{~cm}$ lange, $61 \mathrm{~kg}$ schwere, kräftig gebaute, gut genährte, dunkelblonde Ilgr. mit Riesenbecken, ist seit dem 17. J. regelmässig 21 tg., 4-5tg. nicht reichlich ohne Beschwerden menstruirt,

a) hat 2. VI. 972 Uhr 30 Min. Vorm. K., $51 \mathrm{~cm}, 3560 \mathrm{~g}$ (Plac. $650 \mathrm{~g})$ geboren, nachdem die Wehen 1. VI. 4 Uhr Nachm. begonnen batten. Letzte Menstruation Ende VIII. wie sonst. Empfängniss 3. IX. Schwangerschaftsdauer 271 Tage statt 273 Tage offenbar durch Anziehung und Verschiebung der Schwangerschafts- und Menstruationsmonate auf etwa die Mitte ihres ersten Abstandes. Erste Menstruation nach der Geburt (1. VI.) 23. VI.

b) letzte Menstruation um den 20. X., erste Hälfte X. schwächer und 1 tg. Empf. Anf. X. Senkung 28. VI. Wehen Mitte V.

Geb. I., $50 \mathrm{~cm}, 2775 \mathrm{~g}$ (Plac. $700 \mathrm{~g}$ ), 17. IX. $7 \mathrm{Uhr}$ Nachm., nachdem die Wehen 11 Uhr Vorm. begonnen batten.

Beginn der Schwangerschaft ist sicher falsch angegeben. Auch das Ende ist vielleicht nicht das ganz normale, sondern um 2-4 Tage zu früh. Die Schwangerschaftsdauer ist aber, davon abgesehen, offenbar die normale wie bei der ersten Schwangerschaft.

Die Curve umfasst 2 Doppelmonate von 41 und 40 (44) Tagen.

Die Wehen Mitte V. und die Senkung 28. VI. umfassen einen weiteren Doppelmonat von 6 Wochen. Es ist also in der Schwangerschaft der früher dagewesene Menstruationstypus von 21 Tagen von der Wochenperiodicität beibehalten. Es sind nur die Monate doppelt.

Von den beiden letzten 42 tägigen Doppelmonaten der Blutdruckcurve ist nur dẹr letzte ganz nach dem 21 tägigem Periodentypus getheilt, der vorletzte dagegen nach dem 28 tägigen, nämlich: 

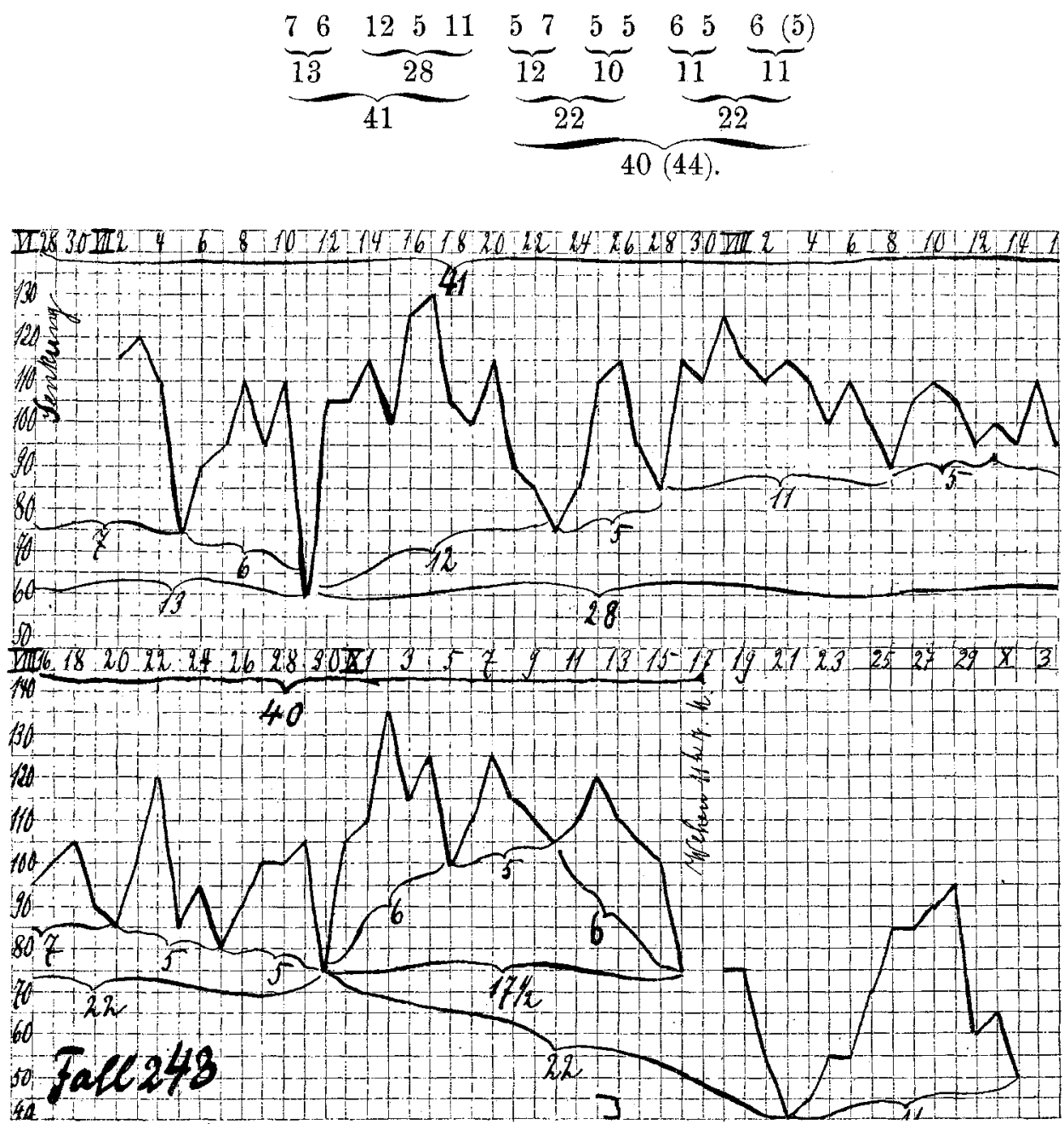

Die Geburt hat nicht am Ende des Blutdruckmonats stattgefunden. Der Blutdruckmonat endet erst am 5. Tage des Wochenbettes. (Fall von Angioneureusthenie.)

Es ist nicht unwichtig, zu erfahren, ob bei Zwillingen verschiedenen Geschlechtes mit ganz getrennten Placenten (welche vorn and hinten im Uterus gesessen haben, so dass die Eier sehr wohl aus beiden Ovarien oder wenigstens aus verschiedenen Follikeln eines Ovariums stammen können) sich die.Periodicitäten anders verhalten als bei Einlingen.

Der folgende Fall von Zwillingsschwangerschaft ist ein solcher. Die Zwillinge waren K. u. M., hatten getrennte Placenten, von denen 
die eine links vorn, die andere rechts hinten sass. Ob beide Eier aus demselben Ovarium stammten, war nicht erkenntlich. Jedenfalls stammten sie nicht aus demselben Follikel. Es mussten also zwei Corpora lutea vera da sein, welche eine besonders starke Wirkung haben konnten.

Fall 249. 1902/3. Geburts-No. 155. Rich., 39jähr., 153:81 cm hohe, $72 \% / 2 \mathrm{~kg}$ schwere, kräftig gebaute, mittelgut ernäbrte, hellblonde VIgr. mit runden Becken, ist seit dem 17. J. unregelmässig 4-12w., 8 tg., reichlich ohne Beschwerden menstruirt,

a) hat vor $18 \mathrm{~J}$, in $13 \mathrm{St}$. K., übertragen?),

b) " " 17 J. $" 6$ "M., $54 \mathrm{~cm}, 4080 \mathrm{~g}$ (Plac. $760 \mathrm{~g}(3 \mathrm{~W}$.

c) hat vor $16 \mathrm{~J}$. in 5//2 St. K., $49 \mathrm{~cm}, 3080 \mathrm{~g}$ (Plac. $600 \mathrm{~g}$ ),

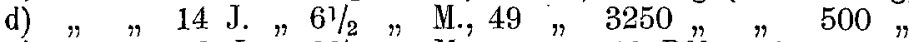

e) " " 2 J. "2 $21 / 2$ M., 10 Pfd, geboren.

f) Letzte Menstruation 2. XII. wie gewöhnlich. Empfängniss 21. XII. Geburt 23. VIII. 3 Uhr 45 Min. Vorm.

II., $48 \mathrm{~cm}, 2870$, in rückenlinker Hauben-Lage,

K., $48 \mathrm{~cm}, 2380$, unter Selbstentwicklung lebend (s. später Geburtsmechanik).

Die Zwillinge sind vielleicht 4 Wochen vor dem normalen Termin geboren. (Conception 21. XII.) Freilich steigt der Blutdruck schon von Mitte VII. ab deutlich und beständig.

Die Mischung des 4- und des 3 wöchentlichen Periodentypus ist ganz deutlich (je 7 und 5 Tage), der Art, dass man zweifeln kann, wie die Monate abzutheilen sind. Ein Unterschied gegenüber den Verhältnissen bei Einlingen lässt sich aber nicht finden.

Siehe noch Fall Mate., Zwillingsschwangerschaft, bei dem 21 und 28 tägiger Typus 2 mal wechseln, unten unter "Empfängniss in der Mitte des Menstruationsmonats".

ad c) Das gleichzeitige Mit- und Durcheinander-Arbeiten der beiden concurrirenden 4- und 3 wöchentlichen Periodicitäten zeigt sich dadurch, dass oft der 4 wöchentliche Monat nach den Periodentheilen des 3 wöchentlichen, also mit 10 und 5 Tagen getheilt wird und der 3 wöchentliche nach den Periodentheilen des 4 wöchentlichen mit 14, 7 und $3 \frac{1}{2}$ Tagen.

Wir haben oben bei Besprechung des physiologischen Monats und der physiologischen Woche gesehen, dass sich die physiologischen Perioden und damit auch Monat und Woche normaler Weise immer fortschreitend halbtheilen und haben dafür auch am Beginn dieses Abschnittes erneut Beispiele vorgeführt (S. 294, 296). Wenn nun die Blutdruckmonate, wie so häufig, trotzdem 

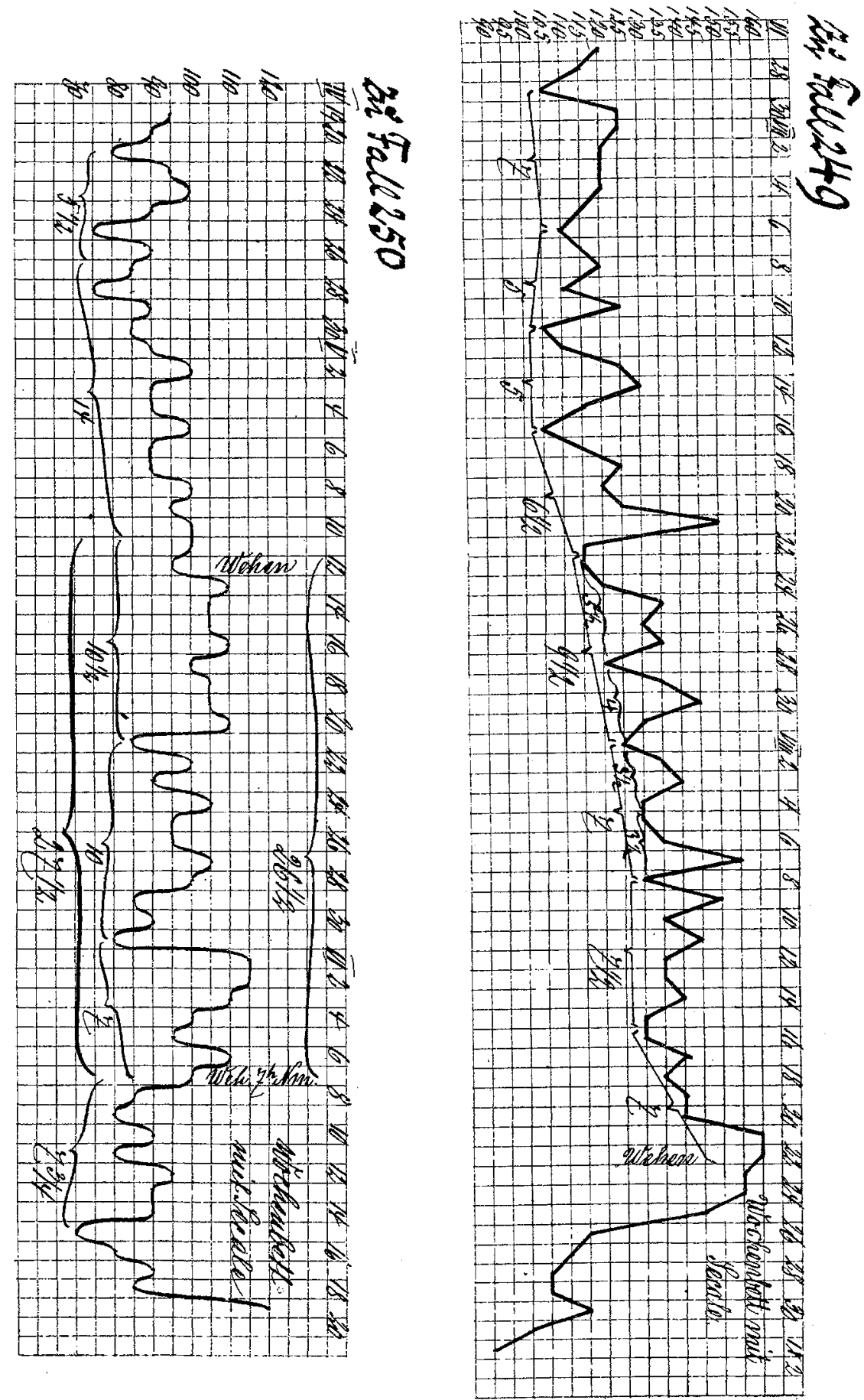
andere Theilungen zeigen, so ist darin die Wirkung von anderen Perioden zu erkennen und vorzugsweise gerade auch diejenige der zweiten concurrirenden Periodicität.

a) Der 28 tägige Monat theilt sich nach den Periodentheilen des 21 tägigen: 10 bis 11 und 5 .

Fall 250. 1908/4. Geburts-No. 127. Bee., 30jähr., $148: 78 \mathrm{~cm}$ lange, $61 \frac{1}{2} \mathrm{~kg}$ schwere, kräftig gebaute, gut genährte, dunkelblonde VI gr., ist seit dem 12. J. regelmässig $28 \mathrm{tg}$., $3-4 \mathrm{tg}$., mässig, mit Rückenschmerz menstruirt,

a) hat vor $14 \mathrm{~J}$. in $4 \mathrm{Std}$. reifen $\mathrm{K}$. geboren,

b) 22. V. $9311 \mathrm{Uhr}$ Nachm. M., $53 \mathrm{~cm}, 3900 \mathrm{~g}$, geboren, nachdem die letzte Menstruation 24. VII. wie sonst, Empfängniss Anf. VIII. stattgefunden und Schwangerschaftswehen

18. IV. 28. IV. 4. V. 5. V. 9 Uhr Vm. bis 6. V. 9 Uhr Vm. 22. V. 6 Uhr. Nm.

$\underbrace{10}_{34}-\frac{18}{6}$

Geburtswehen vom 22. V. 6 Thr Nachm. ab beobachtet waren. Wenn die Empfängniss wirklich Anf. VIII. stattgefunden hat, so war die Schwangerschaftsdauer 289 Tage, d. i. $8^{1 / 2}$ Monate zu je 34 Tagen. Es kann ja aber auch die Empfängniss 17 Tage, d. i. 1/2 Monat später stattgefunden haben, so dass die Schwangerschaftsdauer wäre $8 \times 34=272$ Tage.

c) 28. XI. $951 / 212$ Uhr Vorm. M., $49 \mathrm{~cm}, 3230 \mathrm{~g}$, nachdem letzte Menstruation Anf. IIl. wie sonst, Empf. 1. IV. stattgefunden, die Wehen 28. XI. 3 Uhr Vorm. begonnen hatten. - Die Conception wird wohl Anf. III. und nicht 1. IV. stattgefunden haben, so dass die Schwangerschaftsdauer die gewöhnliche gewesen sein wird.

d) 11. VI. 3 Uhr Vorm. K., 521/2 em, $3875 \mathrm{~g}$ (Plac. 600), nachdem die letzte Menstruation Mitte VII. wie sonst gewesen war, und die Wehen 10. VI. $81 / 4$ Uhr Vorm. begonnen hatten,

e) 12. X. 0211 Uhr Vorm. K., $51 \mathrm{~cm}, 3730 \mathrm{~g}$ (Plac. 565), nachdem die letate Menstruation 3. III. wie sonst (?), Empf. 12. I. stattgefunden und die Wehen 12. X. 3 Uhr Vorm. begonnen, also Schwangerschaftsdauer 273 Tage.

f) Letzte Menstruation Anf. IX. wie sonst, Empfängniss Anf. IX. Erste Kindesbewegung Anf. I., Geburt M., $53 \mathrm{~cm}, 4020 \mathrm{~g}$ (Plac. $750 \mathrm{~g}$ Kantenplacenta), 8. VI. $2^{3 / 4}$ Uhr Vorm., nachdem die Wehen 7. VI. 2 Uhr Vorm. begonnen und von $9^{3 / 4}$ Uhr Nachm. ab betragen hatten: $4,7,11,10,12,8,9,11,11,8,4$. Sehwangerschaftswehen 12. V.

Das Kind ist offenbar reif und rechtzeitig geboren. Nachträglich lassen sich aus der Curve sogar noch letzte Menstruation und Empfängniss genauer feststellen. Die Curve ist eine angioneureusthenische. Bei solchen Fällen finden Geburt und Empfängniss an derselben Strlle des Blutdruckmonats statt. Die Geburt ist hier einen Tag (genauer $7 / 8$ ) zu früh eingetreten (bei der letaten Reihe Schwangerschaftswehen). Sie war erst fällig 27\% Tage nach den Schwangerschaftswehen 12. V. Die Empfängniss hat danach 8. IX. stattgefunden, die Menstruation 7. IX. begonnen. Beides hat die B. Anf. IX. genannt. Wenn man dies aber auch trotz der Beweise, welche ich später geben werde, nicht als 
sicher ansehen wollte, so ist doch die Schwangerschaftsdauer und ihre Construction $273=10 \times 27,3$ sicher.

Nach dieser Periodicität gehen die Blutdruckmonate und die Wehenmonate. Die andere concurrirende Periodicität ist $13 \times 21$. Sie verräth sich durch ihre Periodentheile $5 \frac{1}{2} \cdot 10 \frac{1}{2} \cdot 10$, und diese Periodentheile bilden hier die Theilung des Monats, der hier deshalb nicht wie sonst halb- und viertelgetheilt ist. Diese fremdartige Theilung durch Periodentheile der zweiten Periodicität 21 beweist deren Vorhandensein und Mitwirkung bei der Construction der Schwangerschaftsdauer. Die Periodicität $10 \times 27,3$ gab also die Monatstheilung. Der Monat selbst theilt sich aber nach der Periodicität $13 \times 21$.

Unsere Vorausbestimmung des Geburtstages lautete entsprechend den Wehen 12. V. richtig auf den 8./9. VI. Die Schwängerer waren für die Geburten b) c) e) verschiedene.

Fall 251. 1903/4. Geburts-No. 163. Litsch., 37jähr., $165 \mathrm{~cm}$ lange, $68 \mathrm{~kg}$ schwere, kräftig gebaute, mässig genährte, brünette VIII gr.,

ist seit dem 14. J. regelmässig 31 tg., 3 tg., reichlich, ohne Schmerzen menstruirt, leidet seit Jahren an Asthma,

a) hat vor $10 \mathrm{~J}$. in $12 \mathrm{Std}$. K. ausgetragen,

b) " $" 9$ J. $n 1$, M. reif,

c) " $" 8 \mathrm{~J}, " 1$, 1 M. "

d) " $" 7 \mathrm{~J} . " 1$ M. ausgetragen,

e) $" \# 6 \mathrm{~J} . \quad$ K. reif,

f) $" \# .5 \mathrm{~J} . \quad \mathrm{K}$.

g) $" n \quad 4 \mathrm{~J} . n 1 / 4 \quad n . \mathrm{M} . "$ "geboren,

h) " die letzte Menstruation 4.-6. XI. wie sonst gehabt, und um den 20. XI. empfangen.

Sie gebar M. von $54^{1} / 2 \mathrm{~cm}, 4250 \mathrm{~g}$ (Plac. $740 \mathrm{~g}$ ), 25. VIII. $9 \mathrm{Uhh}$ Nachm., nachdem die Wehen $1 / 27$ Uhr begonnen und von 7 Uhr ab betragen hatten: $3,8,9,9$.

Fall 251.

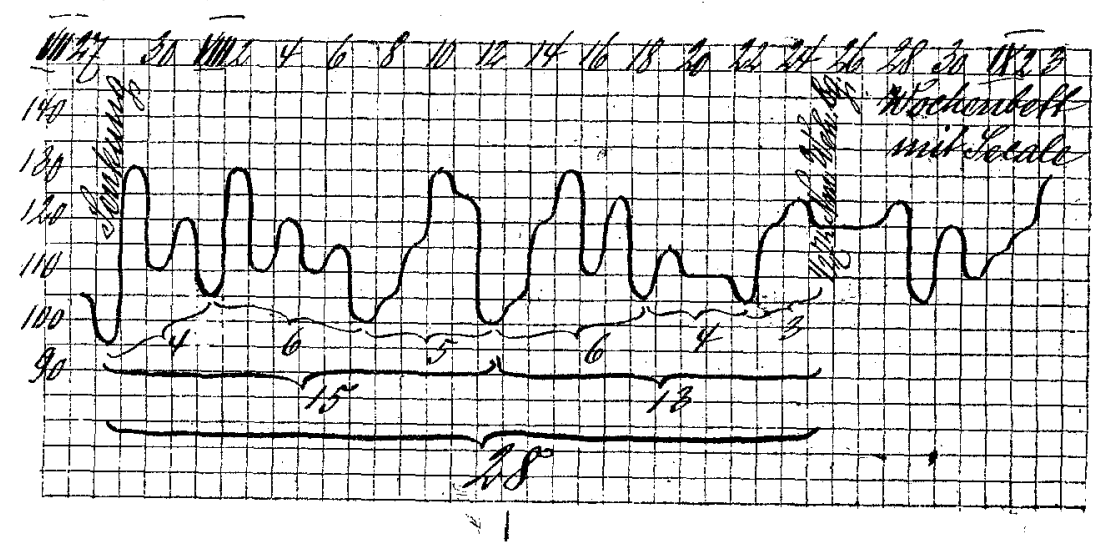


Die Empfängniss hat in der Mitte des Menstruations- (Blatdruck-) monats 4. XI. bis 5. XII. stattgefunden. Blutdruck- und Schwangerschaftsmonate deckten sich von da ab immer mit ihren ungleichnamigen Hälften bis zum 10. Schwangerschaftsmonat (d. i. derjenige der Curve). Dieser ist deshalb als 2 umgekehrte Hälften von Blutdruckmonaten in der Mitte tief getheilt. Schwangerschaftsdauer und Construction ist $280=10 \times 28$. Vom 19.-20. XI. bis zur Geburt 25. VIII. sind 280 Tage.

Die andere concurrirende Periodicität ist $13 \times 21,5$. Sie konnte hier die Halbtheilung des ganzen Blatdruck-Monats nicht hindern, weil derselbe schon von der Empfängniss her halbgetheilt ist. Dafür aber bewirkt sie mit ihren Periodentheilen 10.5 wenigstens die Theilung der Monats-Hälften.

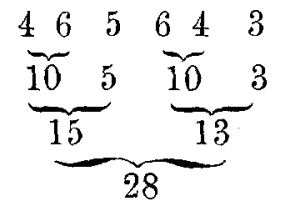

Die richtigen Vorausbestimmung des Geburtstages konnte hier ohne längere Curve nicht gelingen. Von der Senkung 28. VII. ab war der 18. VIII. als der Geburtstag sogar der wahrscheinlichere, weil die Empfängniss am 18. XI. geschehen sein konnte und die Blutdruckcurve 28. VII. bis 7 . VIII. $4 \cdot 6=10$ Tage auf den 21 tägigen Periodentypus hinwies. Es mussten dann die Geburtswehen 21 Tage nach der Senkung, also auf den 18. VIII. fallen.

Fall 252. Polikl. 1901/02. Geburts-No. 241. Til., 25jähr,, I gr., als Kind scrophulös, stets blutarm, menstruirt vom 17. J. 4 w., $2-3$ tg., nicht reichlich, mit Schmerzen und mit Stücken, hatte die letzte Regel Anf. XII. wie sonst, fühlte die ersten Bewegungen 27. IV., gebar mit Extraction nach combinirter Wendung wegen Placenta praev. central. einen eben abgestorbenen Knaben von $48 \mathrm{~cm}$ und $5 \frac{1}{2}$ Pfd. am 24. VIII. 5 Uhr Nachm., nachdem die Wehen 23. VIIL. Abends begonnen hatten. Dem Kinde fehlten offenbar noch 2 Wochen, und die Geburt erfolgte in Folge von Blutung und Tamponade mit halbstündlich 4-8 Wehen bei derjenigen Wehenreihe, welche 2 Wochen vor dem normalen Ende der Schwangerschaft eintrat. Schon vorher waren Blutungen von 200 resp. $300 \mathrm{~g}$ am 10. VIII. $1 / 22 \mathrm{Uhr}$ und 20. VIII. früh $2 \mathrm{Uhr}$ dagewesen.

Die Wehenreihen (=Blutungen) traten also ein:

Geburt Ended.Grav. 10. VIII. 20. VIII. 24. VIII. 7. IX.

\section{d. i. mit einer $Z$ wischenzeit von $\frac{10 \text { Tagen }}{14 \text {. Tage Tagen }} \underbrace{7}_{14 \text { Tage. }}$}

Es ist allerdings nicht sicher, aber sehr wohl möglich, dass die Theilung der ersten 14 Tage in 10 und 4 Tage berentet: $10^{1 / 2}$ und 31/2 Tage, d. i. eine Mischung des 3- und 4-wöchentlichen Periodentypus. Freilich ist es auch möglich, dass nur der 4 wöchentliche Typus vorliegt, indem die Wehenreihe am 20. VIII. $4(31 / 2)$ Tage vor der Wehenreihe 2. Ordnung am 24. VIII. der 4. Ordnung ancehört. ent. 
sprechend dem $17^{1} / 2$. Tag des Schemas für den 4 wöchentlichen Typus, während die Wehenreihe 3 . Ordnung am 21. Tag vor dem normalen Ende der Schwangerschaft ausgefallen ist oder wenigstnns keine Blutung erzeugt hat.

Während die Halbmonate 14· 14 Tage betrugen, wurde der erste davon nicht, wie nach dem 4 wöchentlichen Typus nöthig, in $7 \cdot 7$, sondern nach dem 3 wöchenthichen Typus in $10 \cdot 4$ getheilt.

Als weitere Fälle siehe unten unter "Verschiedene Schwängerer".

Fall Lan. b a. c.

Fall Kraw. a u. $b$.

$\beta$, der 21 tägige Monat theilt sich nach den Periodentheilen des 28 tägigen.

Fall 253. 1903/4. Geburts-No. 70. Ol., 25jähr., $156: 83 \mathrm{~cm}$ lange, $73 \mathrm{~kg}$ schwere, mittelkräftig gebaute, gut genährte, brünette II gr., ist seit dem 15. J. regelmässig 28 tg., $2-3$ tg., nicht reichlich, mit Leibschmerz menstruirt,

a) hat vor 3 Jahren in 4 Stunden ein grosses M. geboren,

b) die letzte Menstruation Ende V. wie sonst gehabt, 25. V. cohabitirt und M., $51^{1 / 2} \mathrm{~cm}, 3760 \mathrm{~g}$ (Plac. $530 \mathrm{~g}$ mit viel Kalk) geboren 28. II. 8 Uhr 55 Machm., nachdem die Wehen 7 Uhr Nachm. begonnen und von $8 \mathrm{Uhr}$ ab 7,8 betragen hatten.

Schwangerschaftswehen waren 16. I. von $1 / 21$ Uhr Nittag ab, d. i. $431 / 2$ statt 42 Tage vor Beginn der Geburtswehen dagewesen. Wie die Wehenperiodicität so zeigt auch die Blutdruckcurve den 21 tägigen Typus: $22 \frac{1}{2}$ und 21 Tage - aber obgleich die 42 tägige Periode regelrecht zu 221 tägigen Hälften halbgetheilt ist, so sind die beiden Hälften nicht wieder halbgetheilt, sondern je zu 14 und 7 Tagen, d. i. nach dem 4 wöchentlichen Typus.

Hier spielt offenbar der 28 tägige Perioden-Typus, obgleich er durch die und in der Schwangerschaft in den 21 tägigen übergegangen ist, doch bei dessen Theilung wieder deutlich eine Rolle.

Unter Berücksichtigung dieser Abweichung und des Conceptionstermins 25. V. konnte nach der Curve der 28. II. richtig als Geburtstag vorausbestimmt werden.

Die Verlängerung der Schwangerschaftsdauer von $27 \%$ auf 278 Tage (25. V. bis 28. II.) kam dadurch zu Stande, dass die Empfängniss um diese 5 Tage oder mehr vor Beginn des Menstruationsmonats eingetreten war (25.-30. V. oder später). Die Menstruations-(Blutdruck-)periodicität zog die Wehenperiodicität um 5 Tage zu sich vorwärts. Mitte I. war dies erst theilweise geschehen. Daher war der vorletzte 21 tägige Monat 221/4 Tage lang und die Schwangerschaftswehen standen ebenfalls noch $11 / 2$ Tage weiter als 42 Tage vom Ende der Schwangerschaft $a b$.

Das Gesetz der Verschiebung siehe unten. 


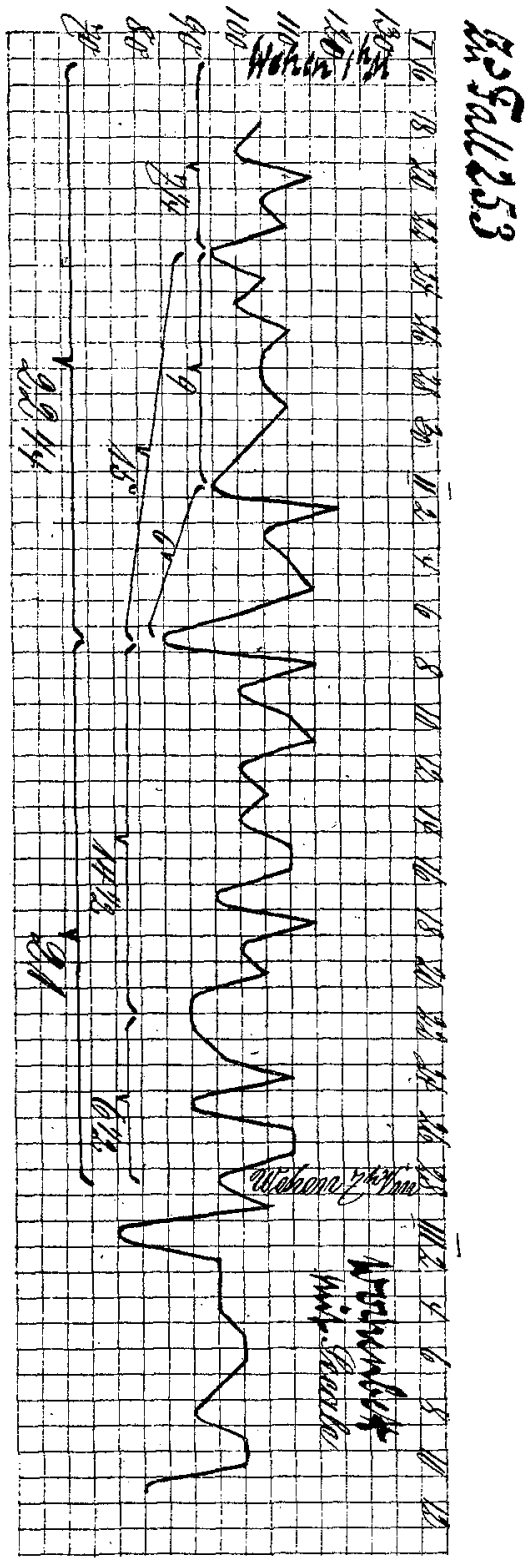

ad d. Das gleichzeitige Wirken der 2. nconcurrirenden" Periodicitäten zeigt sich darin, dass man die Blutdruckeurve sowohl nach der einen als nach der anderen concurrirenden Periodicität abtheilen kann.

Fall 254. 1903/04. Geb--No. 139. Janz., 19 jähr., $159: 86 \mathrm{~cm}$ lange, $68 \mathrm{~kg}$ schwere, kräftig gebaute, gut genährte, blonde I gr.. 
ist seit dem 11. J. unregelm, 4-26 wöchentl, $2-3$ tg., mässig stark, mit Leibschmerzen menstruirt,

hat Anfang IX. die letzte Nenstruation gehabt und Ende IX. kurz vor der ersten ausgebliebenen Menstruation empfangen. Sie gebar M. $50 \mathrm{~cm}, 2470 \mathrm{~g}$ (Plac. $375 \mathrm{~g}$ mit wenig Kalk) 29. VI. Nachm 71/2 Uhr, nachdem die Wehen $8 \mathrm{Uhr}$ Vorm, begonnen und vom 29. VI. 11 Uhr Vorm. betragen hatten: $4,6,7,6,6,7,9,8,8,9,8,9,9,9,8$ (Blase springt), 6, 9 .

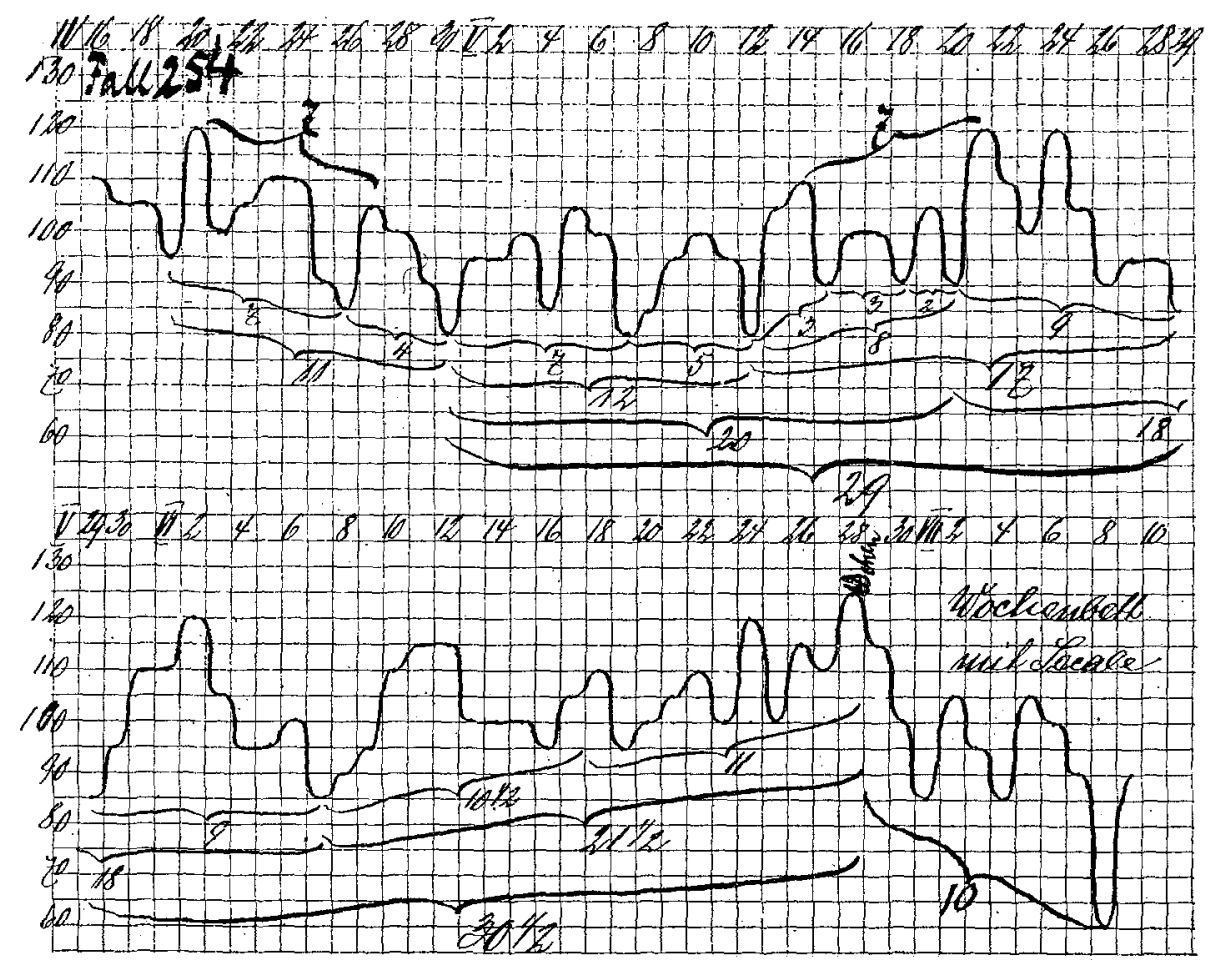

Das Kind ist offenbar zur ganz normalen Zeit geboren und 273 Tage getragen. Der Conceptionstermin war schon bei der Aufnahme, d. i. über 10 Wochen vor der Geburt angegeben worden und stimmt mit der Zeit der Geburt.

Die Blatdruckcurve zeigt 2 Monate von 29 und 301/2 Tagen. Jeder ist aber wieder so unregelmässig getheilt, dass man versucht ist, auch den 21 tägigen Typus daraus zu lesen:

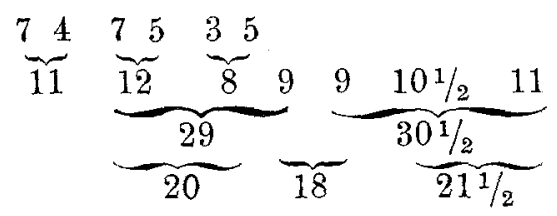


Beide Periodentypen $9 \times 30,3$ und $13 \times 21$ sind etwas gestört, arbeiteten ziemlich gleich stark mit- und durcheinander. Von 30,3 sind die Periodentheile $7-8,4$ von $215 \cdot 10 \cdot 10 \frac{1}{2} \cdot 11$ vertreten.

Fall 255. 1903/04. Geb.-No. 38. Schü., 21 jähr., $155: 83 \mathrm{~cm}$ lange, $661 / 2 \mathrm{~kg}$ schwere, mittelmässig gebaute, gut genährte, blonde I gr., ist seit dem 16. J. regelmässig 21 tägig $2-3$ tg., nicht reichlich, ohne Schmerzen menstruirt,

hat die letzte Menstruation 11. und 12. III. schwächer als sonst gehabt und will 18. II., also gerade bei der letzten normalen Nenstruation empfangen haben. Erste Kindbewegungen Anf. VII. Geburt M. $50 \mathrm{~cm}, 3000 \mathrm{~g}$ (Plac. $480 \mathrm{~g}$ ) 24. XII. 3 Uhr Vorm., nachdem die Wehen 23. XII 4 Uhr Nachm. begonnen und von $81 / 2$ Uhr Nachm. betragen hatten: $5,6,5,6,6,7,7,8,7,8,9,3,10$. Schwangerschaftswehen

$$
\text { 16. XI., 10. XII. Nachm. } 4 \text { Uhr, } \underbrace{23}_{24} \text { XII. } 9 \text { Ubr Vorm. }
$$

\section{zh. Fall 255}

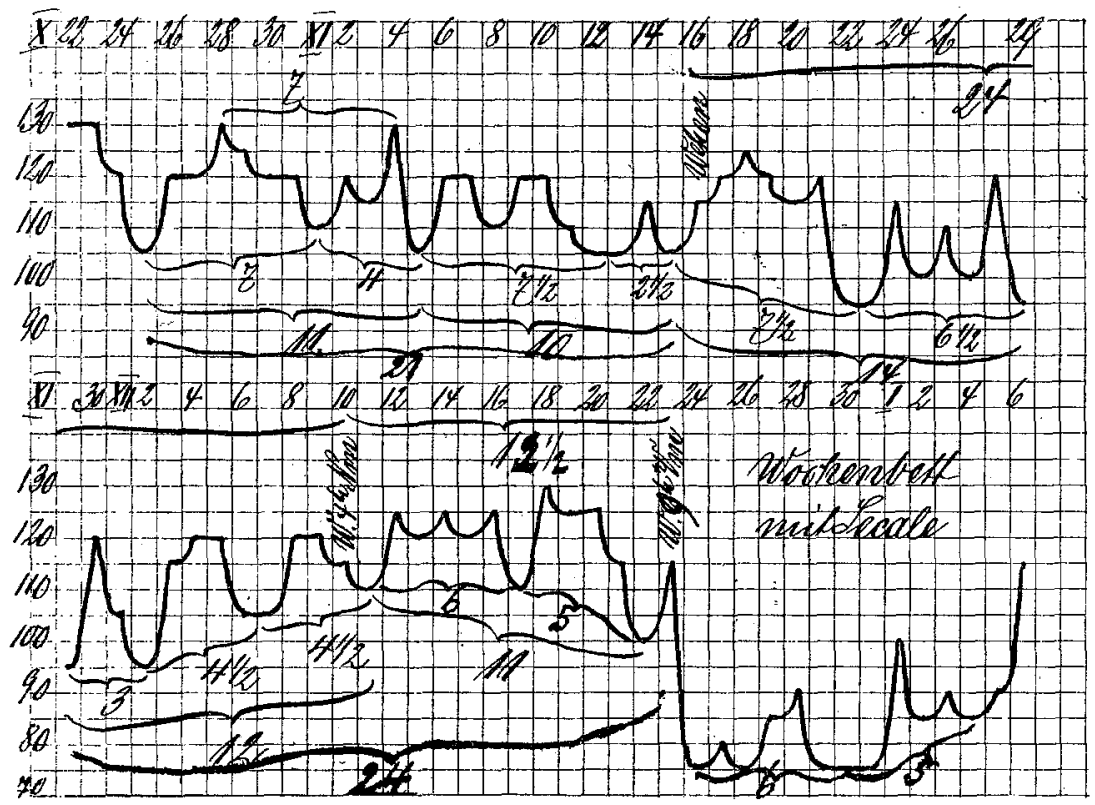

Ob dieses M. von $50 \mathrm{~cm}$ und $3000 \mathrm{~g}$ wirklich 308 Tage getragen, also 35 Tage übertrageu, ist, wie die an sich nicht unwahrscheinlichen Angaben lauten, kann ich nicht entscheiden. Jedenfalls ist es spätestens am 10./11. III. gezeugt, also wenigstens 11-14 Tage (d. i. 1/2, 21 oder 28 tägiger Monat) übertragen. Es waren am 10. XII., also 274 Tage nach dem 11. III., auch Wehen da. Warum da die Geburt njcht und wie überhaupt das Uebertragen hier zu Stande kam, kann ich noch nicht erklären. In der Blutdruckcurve spielen der 4- und der 3-wöchentliche Periodentypus beständig durcheinander 


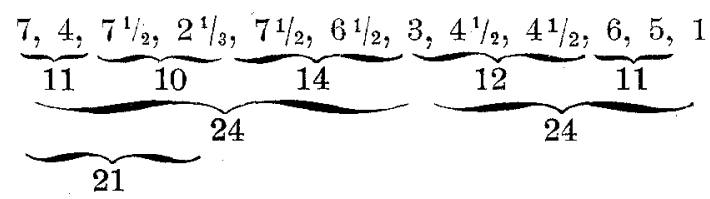

und bei den Schwangerschaftswehen kommt sogar eine Periode von 24 Tagen als Mitte zwischen dem 3 und 4 wöchentlichen Typus zum Vorschein.

Eine Vorausbestimmung des Tages der Geburt gelingt in solchem Falle bei nicht vollständigerer Beobachtung noch nicht.

Vielleicht ist das Verhältniss wie folgt: Vom 10. III., der ersten ausgebliebenen Menstruation (zugleich Conception) bis zur Geburt sind 288 Tage. In der Curve verräth sich bei der Wehenperiode der Periodentypus 24. Dieser wiederholt sich in der Blutdruckcurve 2 mal. Die eine Periodicität ist also wohl $12 \times 24=288$. Die andere wird $20^{1 / 2}$ (verkürzt 21) sein $14 \times 201 / 2=287$.

Die beiden bei der Schwangerschaftsdaner concurrirenden Periodenlängen wären dann allerdings nicht 27,3 und 21 , sondern 24 und $20^{1} / 2$. Das Umspringen bezw. Durcheinanderarbeiten beider wäre aber ebenso deutlich.

Bei dem folgenden. Fall 256 ist die Einwirkung der beiden Periodentypen so gleichmässig, dass man zweifeln kann, zu welchem Typus man ihn mehr rechnen soll. Nach den Maximis und der Wehenperiode gehört er zum 28(27,3)tägigen Typus, nach den Minimis aber zu dem 21 tägigen. Da ist es gar nicht möglich, den 28 tägigen Typus auszuzählen, sondern immer nur den 21 (22)tägigen. Obwohl man aber, wie man auch zählt, immer den Monat zu 22 Tagen erhält, ist derselbe wieder nach dem 28 tägigen Typus getheilt.

oder

$$
\underbrace{71 / 2}_{22} \underbrace{14^{1 / 2}} \underbrace{81 / 213^{1 / 2}}_{22} \frac{813^{1 / 2}}{21^{1 / 2}}
$$

$$
71 / 2 \underbrace{14^{1 / 2} 81 / 2}_{23} \frac{13^{1 / 2} 8}{211 / 2} \quad 13^{1 / 2}
$$

Obwohl also die Blutdruckperiodicität zweifellos hauptsächlich nach dem 3 wöchentlichen Periodentypus arbeitet, arbeitet die Wehenperiodicität deutlich nach dem 4 wöchentlichen -- nur beide um $1 / 4$ Tag pro Woche verlängert -.

Fall 256. 1902/3. Geburts-No. 83. Krase,, 21 jähr., $163: 83 \mathrm{~cm}$ hohe, $61 \mathrm{~kg}$ schwere, gracil gebaute, mittelgut ernährte, dunkelblonde II gr., mit Becken $21 \cdot 24 \frac{1}{1} \cdot 30 \cdot 32$, ist seit dem 17. J. regelm., 4wöchentlich, 3-4 tg., nicht reichlich mit Rückenschmerzen menstruirt

a) hat 6. X. 01 in 38 Stunden M. von 7 Pfd. spontan geboren,

b) hat die letzte Menstruation 27.-29. V. wie gewöhnlich gehabt und von da $a b$ im ganzen Juni geschlechtlich verkehrt. Sie hatte Sehwangerschaftswehen 16. I. 3-8 Uhr Nachm. und 17. I. 7-71/2 Uhr 
Vorm. und wieder 6. II. Abends, war aber 16. I. von der Treppe und am 6. II. von der Leiter auf den Rücken gefallen. Nur am 14. III. stellten sich spontan Schwangerschaftsweben ein.

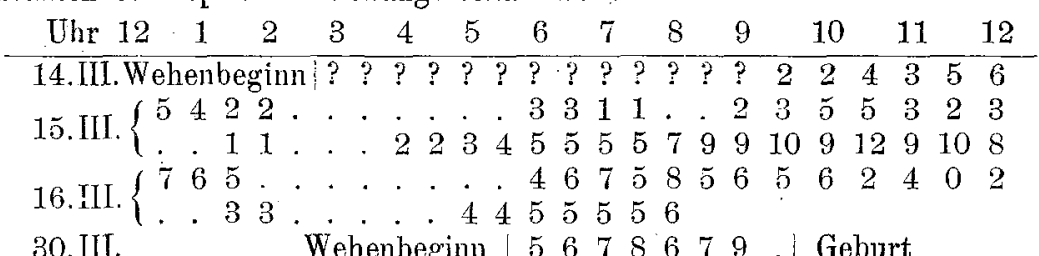

30. III.

Wehenbeginn $\mid$\begin{tabular}{lllllll|l}
5 & 6 & 7 & 8 & 6 & 7 & 9
\end{tabular} . Geburt

Die Geburt des M. $50 \mathrm{~cm} 3350 \mathrm{~g}$ verlief 30 . III. von 6-10 Uhr sehr exact.

Der Beginn der Schwangerschaftswehen am 14. III. steht, vom Beginn der Geburtswehen ab, 15/8 Tage ab.

Die Schwangersehaftswehen am 16./17. I. und 6. II., je nach Unfäll, treffen 36 und 57 Tage $=5$ und 8 Wochen und je 1 Tag vor den Schwangerschaftswehen und $51^{1 / 2}$ und $72^{1 / 2}$ Tag $=7$ und 10 Wochen und je $21 / 2$ Tag vor der Geburt.

Sie würden sicher ohne Unfall nicht eingetreten sein, trafen aber auf Wehentermine und der Fall hat offenbar nur deshalb so stark und dauernd gewirkt. Die Abweichung von 1 und 21/2 Tag erklärt sich aus der Blutdruckeurve.

Die Blutdruckcurve zeigt sowohl bei den Maximis als bei den Minimis die 7 tägige Periodenwehe, nur $z$ wischendurch etwas verlängert und zwar so, dass 8 Schwangerschaftswochen 58 Tage zählen d. i. die Woche 71/4. Tage. Nimmt man an, dass dies die ganze Schwangerschaft hindurch so war, so erhält man eine Schwangersebaftsdauer von $39 \times 7^{1 / 4}=-282^{3 / 4}$ Tage. Demnach müsste die Conception am 24. Juni stattgefunden haben, also gerade vor der fälligen Juniregel. In diesem Falle konnte man also nur mit der Blutdruckcurve den 4 wöchentlichen Typus und damit von den Schwangerschaftswehen am 14. III. ab die Geburt auf den 28. III. voraussagen. Der Fehler, dass die Woche $71 / 4$ Tage, also 2 Wochen 141/2 Tage zäblten und dass die Geburt einen Tag und noch etwas später eintrat, konnte nicht vorher erkannt werden, oder nur dann, wenn man die Blutdruckscurve auch nach dem 21 tägigen Periodentypus eintheilte. Man erhielt da

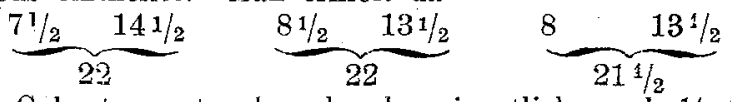

Tage. Die Geburt musste danach also eigentlich noch 1/2 Tag später eintreten. Dass dies nicht geschah, liegt daran, dass dann die Wehenperiode 14. II. bis Geburt, welche schon $15^{1 / 2}$ statt $14^{1 / 2}$ Tag zählte, noch um einen halben Tag verlängert worden wäre. Die Geburt begann in der Mitte des Abstandes von 11/2 Tag, welchen das Eude des letzten Blatdruckmonats und das Ende der letzten Wehenperiode haben sollten. Die letzte Wehenperiode sollte mit $14^{1 / 2}$ Tagen, d. i. 29. III. 6 Uhr, Vorm. der letzte Blutdruckmonat mit 22 Tagen 30. III. 6 Uhr Abends enden. Die Geburtswehen begannen 6 Stunden nach, vielleicht sogar wirklich in der' Mitte vou beiden.

Die Schwangerschaftsdauer ist hier $282^{3 / 4}$ oder rund 283 Tage $=$ $10 \times 28,3$ (verlängert von 27,3 ) $=13 \times 21,77$ (verlängert von 21,0 ) d. i. pro Woche von 7 Tagen um je $1 / 4$ Tag $=39$ Wochen $+39 / 4\left(=9^{3 / 4}\right)$ Tage $=282^{3} / 4$ Tage. 

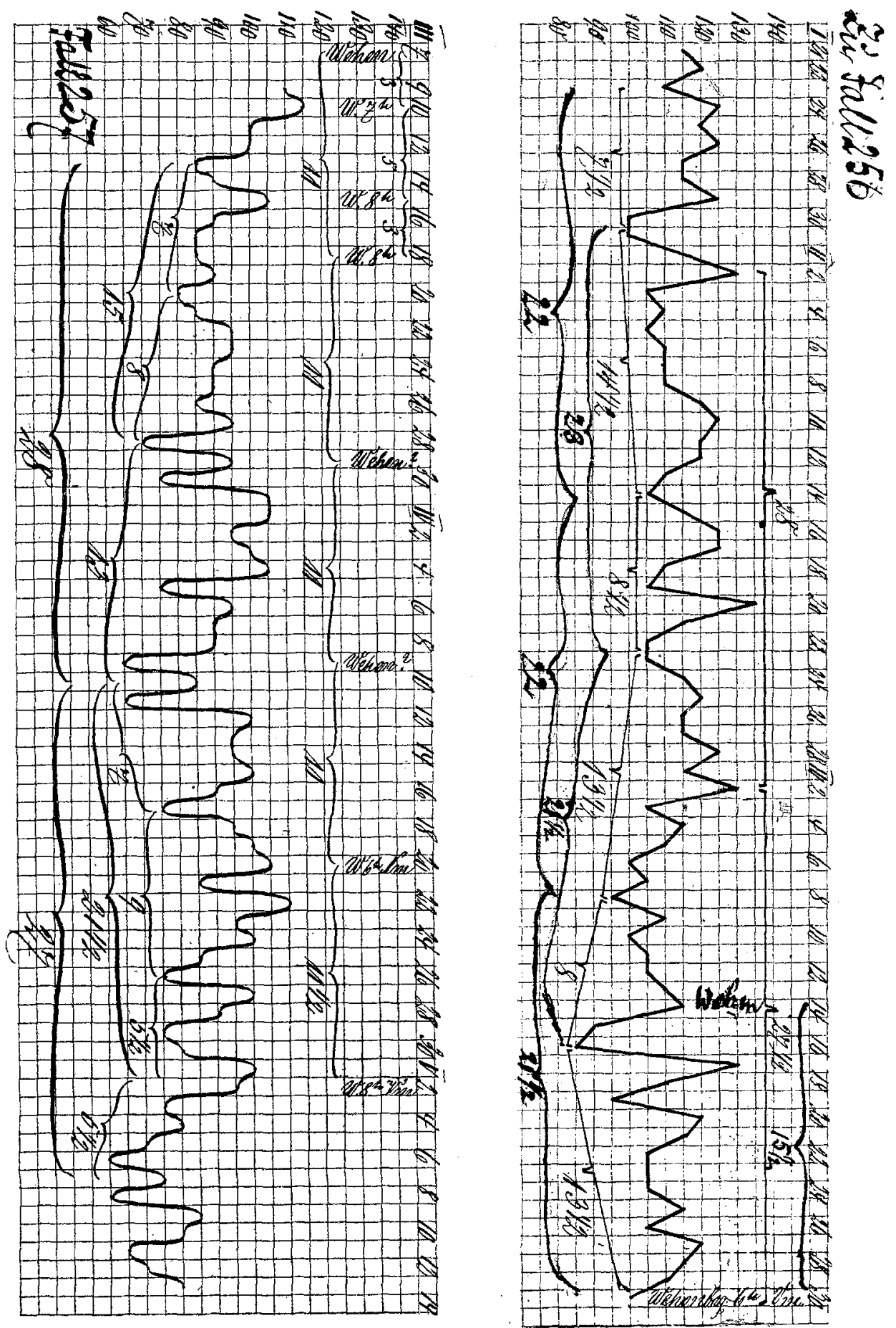
ad. e. Das gleichzeitige Arbeiten der zweierlei Monatstypen (verschieden langerPeriodicitäten) während der Schwangerschaft wird dadurch bewiesen, dass in manchen Fällen die Wehenperiodicität nach dem einen Typus arbeitet, die Blutdruck(Menstruations)periodicität nach dem andern.

Fall 257. 1903/4. Geburts-No. 107. Müll., 27jähr., 1571/2:84 cm lange, $67 \mathrm{~kg}$ schwere, mittelkräftig gebaute, gut ernährte, blonde IIgr., ist seit dem 18. J. 28-30 tg., 3-4 tg., nicht reichlich, ohne Schmerzen menstruirt,

a) hat vor $5 \mathrm{~J}$. in $17 \mathrm{Std}$. kleinen K. geboren,

b) die letzte Menstruation Ende VI. wie sonst gehabt und 26. VII. empfangen. Erste Kindsbewegungen Mitte IX. Sie gebar K., $51 \mathrm{~cm}$, $3800 \mathrm{~g}$ (Plac. $870 \mathrm{~g}$ mit viel Kalk), 2. V. 9 Uhr 20 Min. Nachm., nachdem die Wehen 2. V. 8 Uhr Vorm. begonnen hatten:

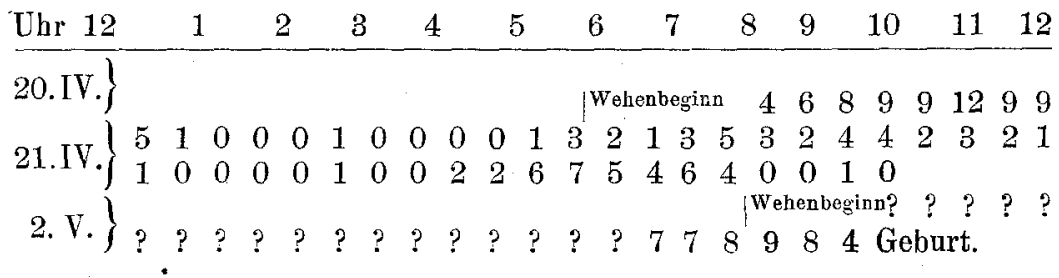

Schwangerschaftswehen waren da jedenfalls am 7. III., denn die M. kam am 8. III. durch sie bewogen in die Klinik, und dann

7. III. 10. III. 15. III. 18. III. 20. IV. 2. V. $7 \mathrm{Uhr} \mathrm{Nm} .8 \mathrm{Uhr} \mathrm{Nm} . \quad 8 \mathrm{U} \mathrm{Nm} .6 \mathrm{Uhr} \mathrm{Nm} .8 \mathrm{Uhr} \mathrm{Nm}$.

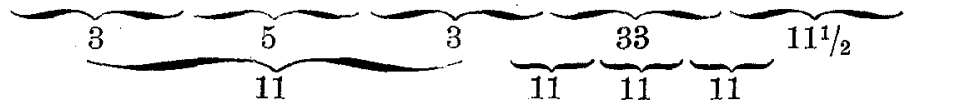

Wenn man als höchstwahrscheinlich annimmt, dass in der Zeit vom 18. IV. bis 20. IV. $=33$ Tage auch 2 Wehenreihen dagewesen sein werden mit einem Abstand von 11 Tagen wie vorher und nachber, so erhält man 5 Wehenperioden von je 11 (statt 101/2) Tagen. Nimmt man weiter an, dass solche Schwangerschaftsperioden von 11 Tagen in der ganzen zweiten Hälfte der Schwangerschaft dagewesen sein werden, d. i. . . . . . . . . . . $13 \times 11=143$ in der ersten Hälfte der Schwangerschaft aber normal lang, d. i.

so erhält man als ganze Dauer der

Schwangerschaft.

$$
13 \times 10^{1} / 2=1361 / 2
$$

In Wirklichkeit war die Schwangerschaftsdauer 26. VII. Abends bis 2. V. früh $2801 / 3$ Tag. Die Verlängerung von $1-11 / 2$ Tag wird davon berrübren, dass die Empfängniss am 26. VII. statt hatte, die Menstruation aber erst etwa 3 Tage später fällig war. Die 2-3 Tage Abstand ergaben bei späterer Verschiebung und Deckung von Wehenmonaten und Blutdruckmonaten, Verhältnisse, als ob die Schwangerschaft 1-11/2 Tage kürzer gewesen wäre, als sie wirklick war (s. später). 
Das Verhältniss bezw. die versehiedene Periodenlänge war etwa gerade so wie bei Fall 170 (s. oben S. 295), wo sich die erste und zweite Hälfte der Schwangerschaft ebenso verhält, nur dass es sich dort um den 4 wöchentlichen Typus handelte, während hier der dreiwöchentliche vorliegt.

Die Blutdruckperiodicität hat aber entgegen der Wehenperiodicität bis zum 10. IV. den 4 wöchentlichen Typus, und erst der letzte Monat ist nur 21 tägig mit 7 tägiger Theilung. Warum? Ist hier noch im letzten Monat der 4 wöchentliche Typus in den 3 wöchentlichen umgesprungen, so dass die Geburt am Ende eines Blutdruckmonats erfolgt ist, oder ist die Geburt wohl am Ende eines kurzen 22 tägigen Schwangerschaftsmonats, aber auch eine Woche vor dem Ende des letzten ( 4 wöchentlichen) Blutdruckmonats in der Schwangerschaft erfolgt? Mir ist letzteres wabrscheinlicher, weil sich die $21 \frac{1}{2}$ Tage dieses Monats mit den $51 / 2$ ersten Tagen des Wochenbettes zu einem gut construirten Blutdruckmonat von 27 Tagen vereinigen.

Sicher hat in diesem Falle die Wehenperiodicität nach dem 21 tägigen, die Blutdruckperiodicität nach dem 28 tägigen Typus gearbeitet.

Schwangerschaftsdauer $18 \times 211 / 2=10 \times 28=280$ Tage.

Fall 258. 1904/5. Geburts-No. 36. Sawa., 30jähr., $156: 80 \mathrm{~cm}$ lange, $63 \mathrm{~kg}$ schwere, kräftig gebaute, gut ernährte, hellblonde VII gr., ist seit dem 18. J. unregelmässig $4-5$ wöchentlich, 3-4 tg., wenig, ohne Beschwerden menstruirt,

a-f) hat vor $10,9,6,4,3,1^{1 / 2} \mathrm{~J}$. geboren,

g) die letzte Menstruation 6.-9. II. wie sonst gehabt und im III. empfangen. Senkung des Tterusgrundes 9.-10. XI. bemerkt. Sie gebar M., $48 \mathrm{~cm}, 2950 \mathrm{~g}$, 14. XII. 8 Uhr 30 Min. Nachm., nachdem die Wehen 5 Uhr Nachm. mit Fruchtwasserabgang begonnen und von 6 Uhr ab betragen hatten: $7,7,7,8,7$.

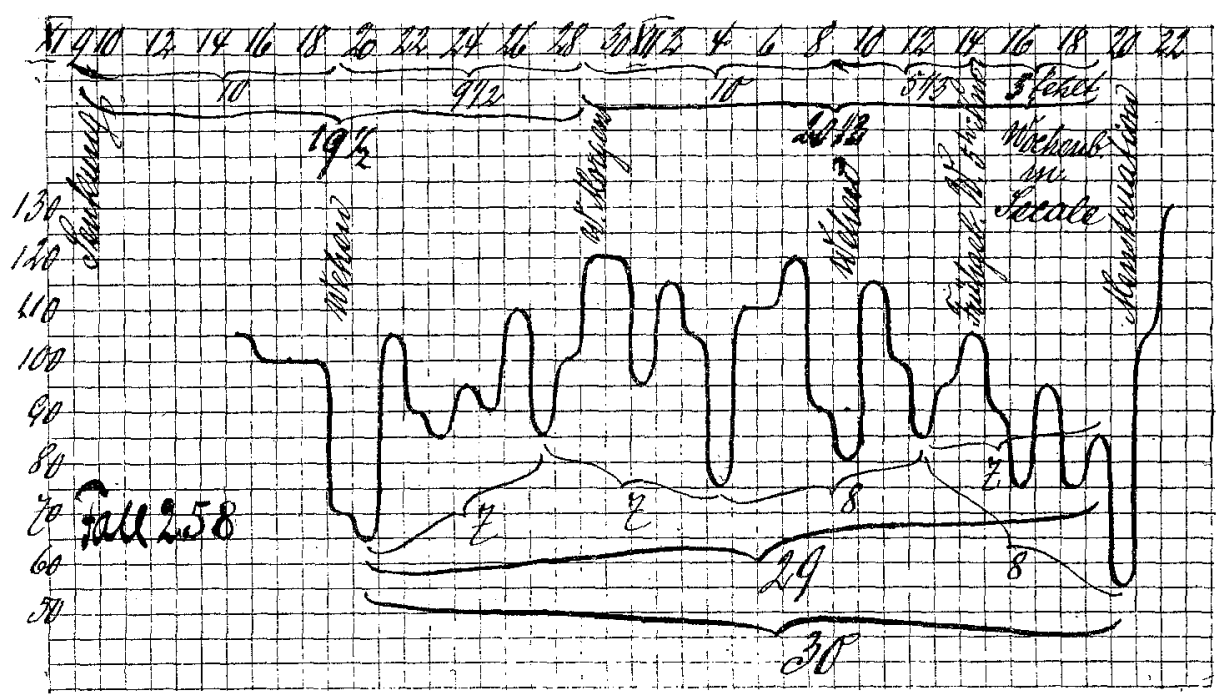


Das Kind ist offenbar 5-6 Tage zu früh geboren, dadurch, dass die Fruchtblase bei der letzten Reibe Schwangerschaftswehen hoch sprang, indem das Chorion am unteren Placentarande abgerissen wurde und nun die Wehen nicht wieder zur Ruhe kommen konnten. Die Wehenperioden gingen nach dem 21 tägigen Periodentypus:
9. XI.
19. Xl.
29. XI.
9. XII.
14. XII.
19.-20. XII.

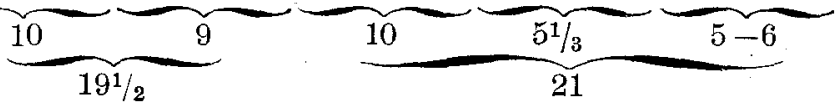

Die Blutdruckeurve aber ging nach dem $30^{1 / 3}$ tägigen Periodentypus:

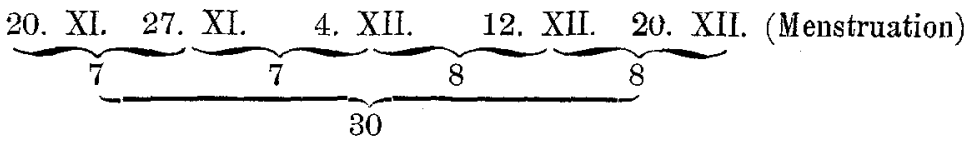

Die Schwangerschaftsdauer war offenbar $13 \times 21=9 \times 30,3$, endete aber um 5-6 Tage zu früh.

Fall 259. 1903/4. Geburts-No. 81. Dre., 23jähr., $167: 90 \mathrm{~cm}$ lange, $71 \mathrm{~kg}$ schwer, kräftig gebaute, gut ernäbrte, blonde II gr., mit Becken $20 \cdot 24 \cdot 30 \cdot 33$. ist seit dem 15 . J. regelmässig 28 tg., 3-4tg., reicblich ohne Schmerzen menstruirt, geboren,

a) hat vor 2 Jahren in 20 Stunden durch Zange grosses $M$.

b) hat die letzte normale Menstruation Anf. V., eine schwächere Anf. VI. gehabt, hat empfangen Ende V., d. i. kurz vor der VI-Menstruation (?), und K., $51 \frac{1 / 2}{\mathrm{~cm}}, 3500 \mathrm{~g}$, geboren 29. II. 7 Uhr 15 Min. Nachm., nachdem die Wehen 6 Uhr Vorm. begonnen und von $2 \mathrm{Uhr}$ Nachm. betragen batten: 2, 3, 4, 4, 4, 2, 4, 5, 7, 9 .

Die letzten 3 Blutdruckhalbmonate von $14 \cdot 14 \cdot 151 / 2$ Tagen sind deutlich nach dem 4 wöchentlichen Typus construirt, wie es die Menstruationsperiode vor der Schwangerschaft war. Aber sie sind selbst nicht mehr nach dem 4 wöchentlichen, sondern schon nach dem dreiwöchentlichen Typus getheilt

$$
\underbrace{81 / 2+51 / 2}_{14} \underbrace{9+5}_{14} \frac{\frac{5+6}{11+4^{1 / 2}}}{151 / 2}
$$

und die einzige erkennbare Wehenperiode 18.-29. II. von $10^{1 / 2}$ Tagen richtet sich auch nach dem 3 wöchentlichen Typus.

Unzweifelhaft arbeitete also die BIutdruckperiodicität in ihren ganzen und halben Monaten exact nach dem vierwöchentlichen (27,3 tägigen) Periodentypus, die Wehenperiodicität aber nach dem 3 wöchentlichen (21 tägigen).

Schwangerschaftsdauer $273(=10 \times 27,3=13 \times 21$ Tage $)-$ $1^{1 / 2}$ Tage Verschiebung.

Der Geburtstermin war zunächst auf 14 Tage nach dem 13. II. zu bestimmen, d. i. auf 27. II. Die Geburtswehen traten aber erst 11/2 Tage später ein. Die Ursache dafür liegt wahrscheinlich darin, dass die Empfängniss nicht bei oder kurz vor Beginn der letzten und schwächeren Menstruation eintrat, sondern 3 Tage nach Beginn, also etwa 31. V., während die Menstruation erst ${ }_{n}$ Anf. VI." zu Ende ging. 


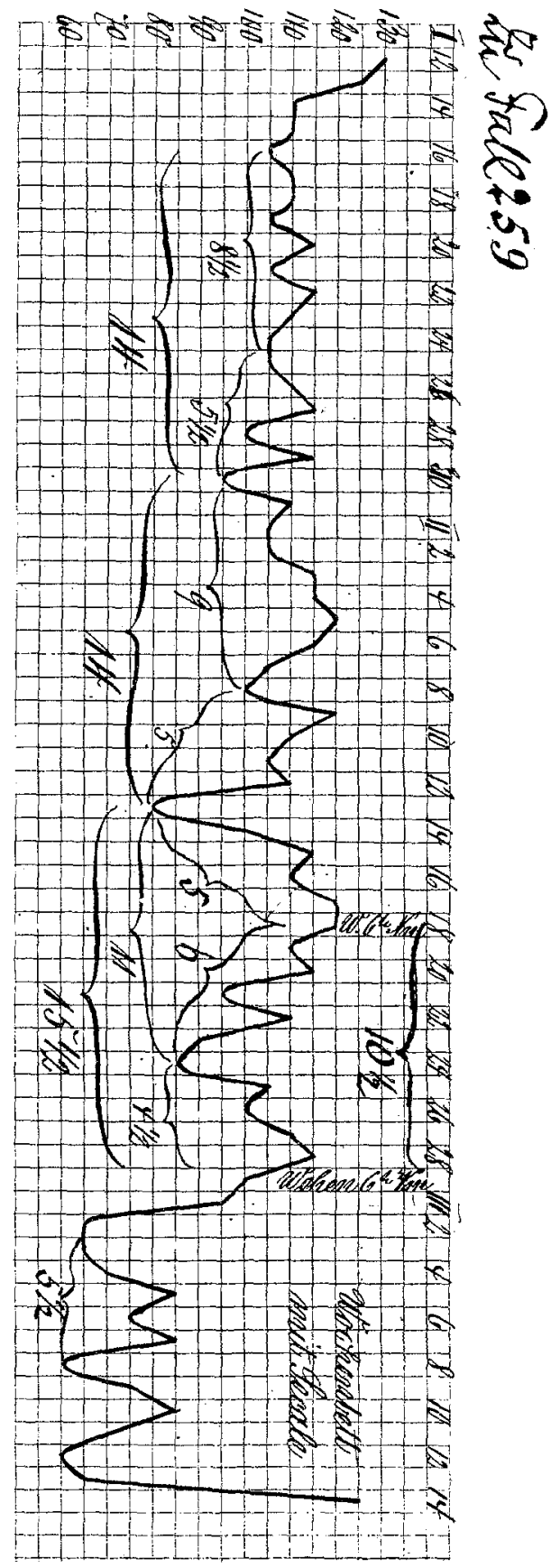


Entsprechend der Zwischenzeit von 3 Tagen zwischen Anfang der Menstruation und Empfängniss trat Anziehung und zuletzt Vereinigung von Blutdruck- und Schwangerschaftsmonat auf die Hälfte der anfänglichen Entfernung, d. i. vor 3 auf 11/2 Tage ein. Danach ist die Angabe der Dr. zu corrigiren. Sie mag schon vor Beginn der Menstruation cohabitirt haben, ist aber erst am 3. Tag der Menstruation wirklich schwanger geworden und die Menstruation wurde dadurch kürzer, was sie weniger kannte.

ad f. Das gemeinschaftliche Arbeiten der beiden nooncurrirenden" Periodicitäten während der Schwangerschaft wird bewiesen dadurch, dass der Uebergang von einem Periodentypus zum andern bei den Wehenmonaten früher oder später erfolgt, als bei den Blutdruck(Menstruations)monaten.

Fall 260. 1903/4. Geburts-No. 50. Wies., 23jähr., 156:86 cm lange, $75 \mathrm{~kg}$ schwere, kräftig gebaute, gut genährte, blonde I gr., ist seit dem 15. J. regelm. 20-22 tg., 8tg., reichl. mit Leibschmerz menstruirt (ohne Weissfluss)

hat die letzte Menstruation Anfang IV. gehabt und 14. IV. empfangen. Sie gebar K. $52 \mathrm{~cm}, 3620 \mathrm{~g}$. (Plac. $570 \mathrm{~g}$ mit viel Kalk). 13. I. 1 Uhr 20 Min. Nachm., nachdem die Wehen 12. I. 7 Uhr Nachm. begonnen und von $10^{1 / 2}$ Uhr ab betragen hatten: $4,4,4,9,9,8,9$, $9,8,8,7,7,7,8,6,7,8,6,6,8,7,7,6,6,6,6,5,9,9,12,10,6$. Schwangerschaftswehen 6.-7. XII. Nachts, 17. XII. Vorm., 29. XII. 7 Uhr Vorm.

Das Kind ist 14. IV. jedenfalls in der Mitte eines Menstruationsmonates empfangen und ist 273 Tage getragen. In den beobachteten 3 letzten Monaten verhalten sich Blutdruckmonate und Wehenmonate versehieden. Blutdruckmonate $\underbrace{10 \quad 11}_{21} \underbrace{10 \quad 15}_{25}$

Wehenmonate $11 \quad 12 \quad 14$

Der Periodentypus war vor der Schwangerschaft 21 tägig. In der Schwangerschaft ist der letzte Monat als Blutdruckmonat deutlich $28 \mathrm{tg}$., der vorletzte Monat als Blutdruckmonat in seiner 2. Hälfte auch 4wöchentlich, in seiner ersten Hälfte aber 3 wöchentlich, der drittletzte Monat durchweg 3 wöchentlich. Als Wehenmonat ist nur der letzte Monat in seiner 2. Hälfte 4 wöchentlich. Die erste Hälfte wie der vorletzte Monat ist 3 wöchentlich. Die früheren Monate werden jedenfalls alle, sowohl als Blutdrucks- als auch als Wehenmonate 21 tägig sein.

Rechnet man von der Empfängniss 14. IV. bis zum 30. XI., bis wo die beobachteten Blutdruckmonate 21 tägig sind, so sind es 230 Tage $=11$ Monate zu je 21 Tagen, an welche sich dann ein halber vierwöchentlicher Monat mit 15 und ein ganzer vierwöchentlicher mit 28 Tagen anschliessen d. i. $230-15+28=273$ Tage.

Man muss sich fragen, ob nicht die als 28 tägig angesehenen und berechneten $1 \frac{1}{2}$ Nonate mit 43 Tagen auch einfach als zwei 21 tägige Monate gerechnet werden können wie die voraufgegangenen 11. Aber die Blutdruckcurve verbietet es. 
Bei den Wehenmonaten ist die Anordnung bis zum 6. XII. sicher weniger einfach gewesen. Man kommt auf 273 Tage, wenn man rechnet $(10 \times 21=)$ $210+12+14+11+12+14$, wenn sich also der beobachtete Rhythmus $11 \cdot 12 \cdot 14$ vorher einmal wiederholt hätte. Doch das ist nur Vermuthung.

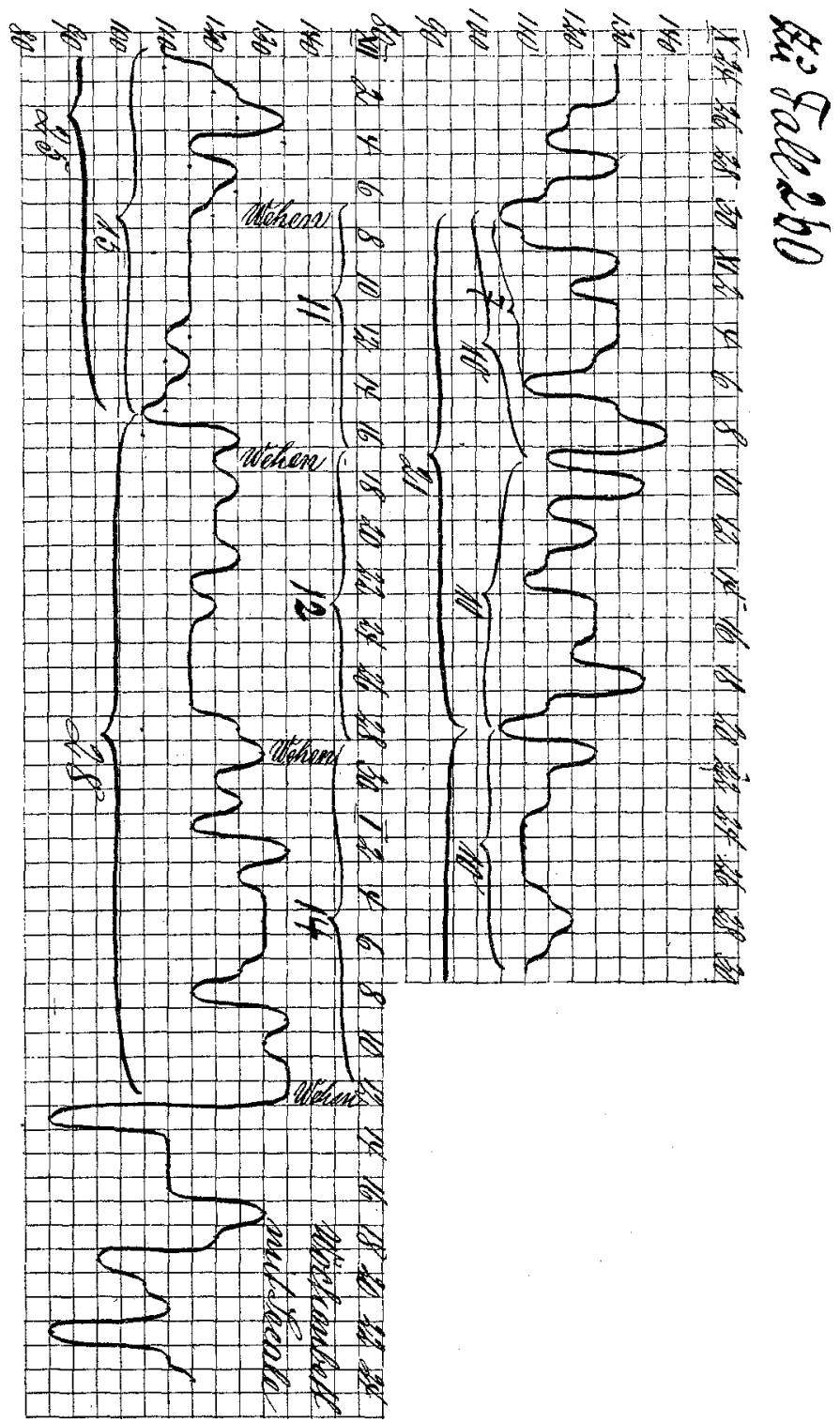

In diesem Falle hat sich der 4wöchentliche Periodentypus gegenüber dem von vor der Schwangerschaft her bestandenen 3wöchentlichen erst sehr spät in der Schwangerschaft zur Geltung 
gebracht und $z$ war bei dem Blutdruckmonat um einen ganzen Monat früher als beim Wehenmonat. Mitgewirkt haben muss er natürlich schon während der ganzen Schwangerschaft, sichtbar aber nur in Form der Theilung des 21 tägigen Monats wie z. B. 30. X. bis 6. XI, und 9 . XI. nämlich $7 \cdot 3$

Fall 261. 1903/4. Geburts-No. 78. Stroy., 26jähr., 151:81 cm lange, $61 \mathrm{~kg}$ schwere, mittelkräftig gebaute, gut genährte, dunkelblonde II gr., ist seit dem 15. J. regelm. 28tg., 3-4 tg., reichl., ohne Schmerz menstruirt

a) hat vor $2 \mathrm{~J}$. in $21 \mathrm{St}$. einen ausgetragenen K. geboren,

b) hat die letzte Menstruation Anf. V. wie sonst gehabt, 1. VI., also kurz vor der ersten ansgebliebenen Menstrution, empfangen und Anf. X. die ersten Bewegungen gefühlt.

Schwangerschaftsweben haben begonnen 20. I. 4 Uhr Nachm.

Uhr 12
20. I.

27.II. $\{$ ? ? ? ? ? ? ? ? ? 58887899111212118 Geburt

Zwischen 21. I. und 27. II. sind noch Schwangerschaftswehen 4. II. $1 / 23$ Uhr Vorm., 14. II. $1 / 26$ Uhr Nachm. und 25. II. 9 Uhr Vorm. bemerkt worden.

Diese Curve bildet mit ihren Minimis vom 21. T. bis 23. II. einen einzigen Bogen, welcher bis 11./12. II. $21 \frac{1 / 2}{2}$ Tag aufsteigt und offenbar auch bis 1. III., dem von dem Conceptiontermin ab berechneten Geburtstermin .29 Tage abfallen würde, wenn die Geburt nicht $31 / 2$ Tag zu früh erfolgt wäre. Warum die Geburt zu früh erfolgte, blieb unklar. Dass sie aber soviel zu früh erfolgte, ergiebt sich auch aus den Wehenperioden $10^{3} / 4,10^{3} / 4$, auf welche, wemn nicht nochmals $10^{3} / 4$, so doch die Hälfte $51 / 4$ folgen musste, d. i. bis 1 . III.

Die Schwangerschaftsdauer ist offenbar die normale, 273 Tage, und zwar $=10$ Monate zu 27,3 Tagen; denn die Menstruationsperiode vor der Schwangerschaft war 28 tg., was ja gewöhnlich 27,3 bedeutet, und in der Curve findet sich dieser Periodentypus sowohl bei der Wehenperiodicität vertreten: $20 . \mathrm{I}$. bis 4 . II. $=141 / 2$ Tage, wie in der Blutdruckperiodicität: 12 . bis 27 . II $=15$ Tage. Die Schwangerschaftsdauer von 273 Tagen ist aber auch $=13$ Monate zu je 21 Tagen; denn diese Zahl, wie ihre Hälfte, ist bei den Wehenperioden: $10^{3 / 4}$, $10^{3} / 4$, wie bei der Blutdruckcurve: $21 \frac{1}{1} / 2 \cdot 10 \cdot 11 \frac{1}{2}$ vertreten. Beide Periodicitäten, die 27,3 und die 21 tägige arbeiten, wenn auch scheinbar ohne Regel, mit- und durcheinander und es ist zweifellos eine Regel da. Das Umspringen zwischen den beiden Monatstypen geschah bei der Wehenperiodicität früber als bei der Blutdruckperiodicität.

Bei folgendem Fall arbeiten der 4- und der 3 wöchentliche Periodentypus sowohl bei den Wehenmonaten wie bei den Blat- 

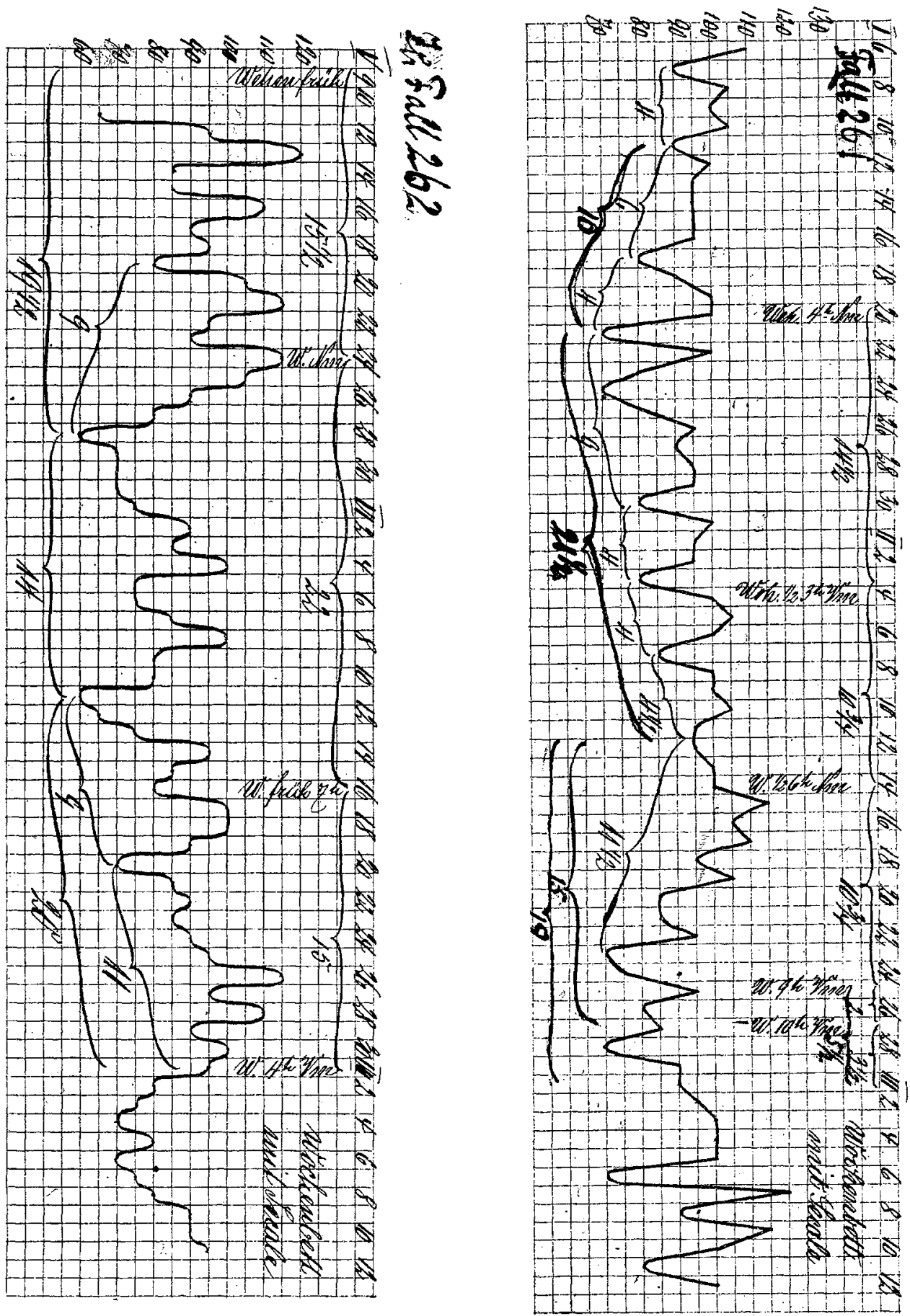
druckmonaten durcheinander, aber nicht bei beiden gleich - sondern wechselzeitig verschieden, also deutlich unabhängig voneinander.

Fall 262. 1903/4. Geburts-No. 142. Folt., $26 \mathrm{jähr}$., $156 \frac{1}{1 / 2}: 83 \mathrm{~cm}$ lange, $74 \mathrm{~kg}$ schwere, gracil gebaute, gut genährte, dunkelblonde IV gr., ist seit dem $16 \mathrm{~J}$. $31 / 2-4$ w., später $28 \mathrm{tg}$., 3 tg. mässig; ohne Schmerz menstruirt, bat

a) 1897 Geburts-No. 78. Il. $47 \frac{1}{2} \quad \mathrm{~cm}^{2} 2600 \mathrm{~g}$ (Plac. $430 \mathrm{~g}$ ) 15. IV. $21 / 2$ Uhr Vorm. geboren, nachdem die Weben 14. IV. 3 Uhr Nachm. begommen hatten und das Fruchtwasser 2 Uhr 20 Min. Vorm. abgegangen war. Schwangerschaftswehen 18. III., d. i. 28 Tage vorher. Empfängniss wurde auf Ende VII., letzte Menstruation auf Ende VIII. schwächer angegeben. Die Geburt scheint 2 Wochen zu früh stattgefunden zu haben.

b) 1900 . Geburts-No. 89 b. Letzte Menstruation Mitte IX. schwächer. Empfängniss Mitte IX. Erste Kindsbewegungen Mitte I. Geburt M. $49 \mathrm{~cm}, 3210 \mathrm{~g}$ (Plac. $570 \mathrm{~g}$ ) 15. V. $21 / 2 \mathrm{Jhr}$ Nachm., nachdem die Wehen $1 / 210$ Uhr Vorm. begonnen hatten und die Fruchtblase unmittelbar vor Austritt des Kindes gesprungen war. Hier hat die Empfängniss jedenfalls schon Mitte VIII. gleich nach der letzten normalen Menstruation stattgefunden und die Schwangerschaftsdauer war, die gewöhnliche.

c) 1902. Geburts-No. 44. Letzte Menstruation 3. VI. schwächer und nur 1 tägig. Empfängniss 16. oder 19. oder 27. V., Uebelkeit seit 16. V., Erbrechen seit dem 20. V. Geburt M. $481 / 2 \mathrm{~cm}, 3010 \mathrm{~g}$, (Plac. 560 g) 25. II. $1 / 22$ Uhr Vorm., nachdem die Weben vom Blasensprung $1 / 21$ Uhr ab gefüblt waren. Schwangerschaftswehen 14. JI. d. i. 101/2 Tag vor der Geburt. Die Empfängniss scheint erst am 22. V., d. i. 7 Tage vor der scbwächsten Juniregel stattgefunden zu haben. Dann war die Schwangerschaftsdauer (bis 25. X.) richtig 273 Tage.

d) Hat die letzte Menstruation Anf. IX. wie sonst, Anf. X: schwächer und nur 1 tägig gehabt und hat am 4. X., also kurz vor der Menstruation empfangen. Sie gebar K. $51 \frac{1 / 2}{\mathrm{~cm}}, 3600 \mathrm{~g}$ (Plac. 490) 2. VII. $61 / 2$ Uhr Vorm., nachdem die Wehen begonnen hatten 4 Ular Vorm. Schwangerschaftswehen waren da 9. V. Vorm., 24. V. Nachm., 16. VI. 7 Uhr Vorm.

Die Schwangerschaftsdauer war 4 . X. bis 2. VII., d. i. 272 Tage (Schaltjahr!) $=10 \times 27,3=13 \times 21$ Tage. Während der letzten 53 Tage sind die Wehenperioden $15 \frac{1}{2} \quad 22 \quad 15$

die Blutdruckperioden $191 / 2 \quad 14 \quad \underbrace{911}_{20}$

In beiden Periodicitäten arbeiten der 3- und der 4 wöchentliche Periodentypus durcheinander und zwar bei jeder in anderer Weise:

bei der Wehenperiodícität $2,3,2$ Wochen

Dadurch "wird" Blutdruckperiodicität $3,2,3$ gleichzeitige Wirken beider "Periodentypen im selben Falle um so dentlicher.

Durch die vorstebenden Beispiele und Erläuterungen ist es äusserst wahrscheinlich gemacht, wenn nicht schon bewiesen, dass die gewöhliche Schwangersehaftsdauer von 273 Tagen bestimmt wird von der gemeinschaftlichen 
Wirkung der beiden häufigsten und kräftigsten Periodicitäten von 27,3 und 21 Tagen, indem dieselben vou der Empfängniss ab sich am 273. Tag wieder in derselben Phase wie bei der Empfängniss -- im Knotenpunkt treffen, sich dadurch verstärken und die Geburt veranlassen.

Den Hauptbeweis aber dafür, dass der Eintritt der Geburt und damit die Dauer der Schwangerschaft durch den Knotenpunkt der beiden "concurrirenden Periodicitäten" bestimmt wird, finde ich in dem Umstand, dass die Wehenperiodicität, welche immer mit einem Monatsende bei der Geburt abschliesst, das eine Mal sich nach der einen, das andere Mal nach der andern concurrirenden Periodicität richtet. Es treffen sich also die dadurch gekennzeichneten Enden beider Periodicitäten regelmässig im Beginn der Geburt.

Leider weiss ich noch nicht, warum die Wehenperiodicität nicht immer ein- und derselben Periodicität folgt, sondern scheinbar regellos einmal der einen, das andere Mal der anderen. Aber gerade dadurch, dass trotzdem immer derselbe bestimmte Knotenpunkt getroffen wird, wird bewiesen, dass die beiden concurrirenden Periodicitäten sich immer. und selbst dann im Knotenpunkt bei der Geburt treffen, wenn eine von beiden concurrirenden Periodicitäten sonst ganz latent bleibt.

Der Sinn der Construction der Schwangerschaftsdauer aus zwei verschiedenen Periodicitäten (Monatstypen) scheint mir folgender zu sein: Die eine Periodicität bestimmt das Auftreten der Schwangerschafts-Wehenreiben in bestimmten, gegen das Ende der Schwangerschaft hin durch fortschreitende Halbtheilung immer kürzeren Abständen. Die andere Periodicität wählt dann durch Bildung des Knotenpunktes diejenige Wehenreihe aus, welche zur Geburt führt. Man würde zweckmässig und gern jene Periodicität immer die "erste", die andere die "zweite" nennen, wenn in der Schwangerschaft immer Schwangerschaftswehen bemerkt würden, welche die "erste" Periodicität kenntlich machten. Da dies aber nicht der Fall ist, so bezeichnet man lieber diejenige Periodicität, nach welcher sich die Abendminima der Blutdruckcurve richten, als Blutdruck- bezw. Menstruationsperiodicität und diejenige, nach welcher sich die Schwangerschaftswehen richten, als Webenperiodicität. Beide können freilich dieselbe sein. Die zugehörige andere Periodicität heisst dann die "andere" oder 
"zweite" oder enventuell "latente" - immer ohne Rücksicht darauf, ob sie diejenige mit den längeren oder kürzeren Monaten ist.

\section{Schema.}

Die beiden concurrirenden Periodicitäten $10 \times 27,3$ und $13 \times 21$ ausser der Schwangersohaft

nicht (deutlich) besetzt:

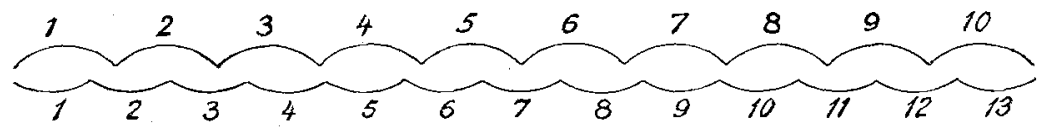

Die längere $(27,3)$ von der Blutdruckperiodicität besetzt:

Blutdruckmonate Latente Periodicität

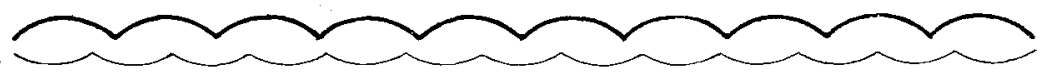

Die kürzere (21) von der Blutdruckperiodicität besetzt:

Latente Periodicität

Blatdruckmonate

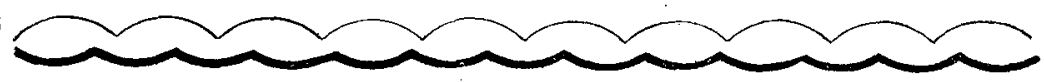

In der Schwangerschaft:

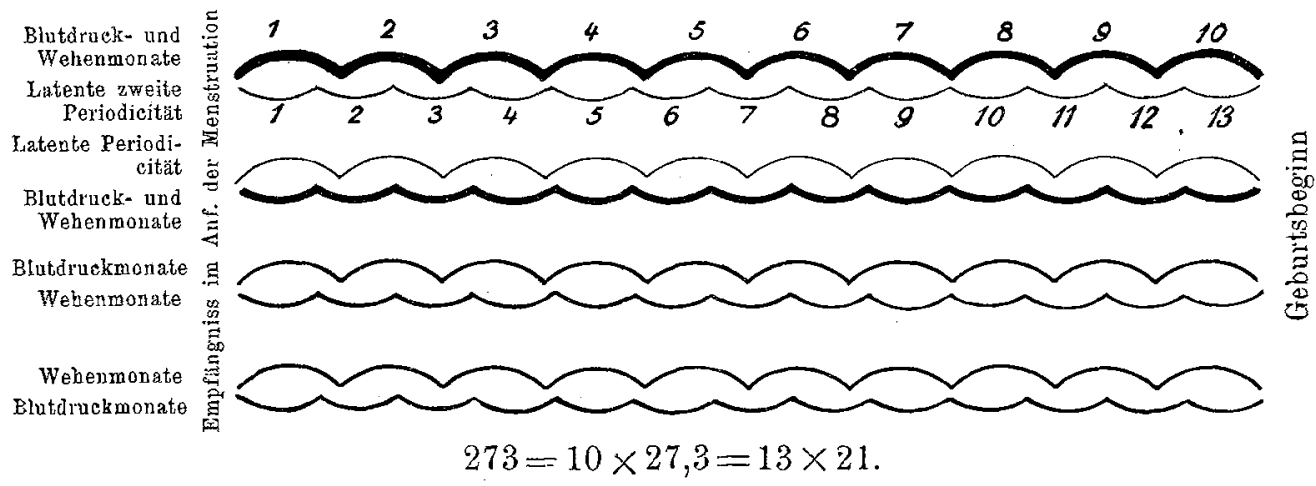

Schwangerschafsdauler von 273 Tagen construirt mit nur einer der beiden gewöhnlichsten concurrirenden Periodicitäten 27,3 und 21 .

Die normale (häufigste) Schwangerschaftsdauer von 273 Tagen ist aber nicht auf die Entstehung aus den beiden concurrirenden Periodicitäten $10 \times 2 \pi, 3$ und $13 \times 21$ Tage beschränkt. Bei einer nicht geringen Zahl von Fällen wirkt nur eine dieser beiden häufigsten (und kräftigsten) Periodicitäten mit, und die zweite wird durch eine andere - seltenere - ersetzt, welche ebenfalls mit einem Monatsende bei 273 Tagen endet. 
Die Zahl 273 Tage ist überhaupt für die Periodenbildung a) besonders günstig und b) von der Natur bei Periodenbildung besonders reichlich benützt worden und stellt deshalb äberhaupt die häufigste und normale Geburtsdauer dar.

ad a) Neben den beiden wiederholt erörterten Periodentypen $10 \times 27,3$ und $13 \times 21$ sind für das Multiplicat 273 rechnerisch noch möglich:

$(5 \times 54,6=10 \times 27,3)$.

$\left(6 \times 45^{1 / 2} ; 45^{1 / 2}=\right.$ die dritte Halbtheilung des Jahres: $\left.\frac{36 \tilde{0}}{8}\right)$.

$7 \times 39$.

$8 \times 34^{1 / 8}$

$9 \times 30^{1 / 3}$ (Sonnenmonat $=$ Kalendermonat).

$(10 \times 27,3$ periodischer Mondmonat und [langer] elektrischer Monat). $11 \times 24,9$.

$12 \times 22,75 \Leftrightarrow 12 \times 23) 22,75=$ vierte Halbtheilung des Jahres: $\frac{365}{16}$.

$(13 \times 21$ kurzer [? elektrischer] Monat).

$(14 \times 19,5=7 \times 39)$.

$15 \times 18,2$.

$(16 \times 171 / 16=8 \times 34 \%)$.

$17 \times 16,1$.

$\left(18 \times 15,17=9 \times 30^{1} / 3\right)$.

Davon scheiden allerdings eine Anzahl Combinationen aus dadurch, dass sie nur Theilungen oder Verdoppelungen von anderen darstellen. Solche müssen nach dem oben dargelegten Gesetz der Halbtheilung und der Verdoppelung der Perioden als zusammengehörig angesehen werden und sind deshalb hier nur einmal gerechnet, die übrigen eingeklammert. Anderseits beweisen aber diese Hälften und $Z$ weifachen gerade weiter die grosse Anwendbarkeit der Zahl 273.

ad b) Wenn man die wegen Theilung oder Verdoppelung ausfallenden (hier eingeklammerten) Combinationen fortlässt, so erkennt man, dass ron der Natur so gut wie alle möglichen Combinationen auch wirklich benutzt werden.

Es wird manchem Leser zunächst lächerlich erscheinen, solche "Zahlenspielerei" auf Naturvorgänge wie die Dauer der Schwangerschaft anwenden zu wollen. Aber die Natur kennt keinen Zufall und hält viel mehr Ordnung, als manche sich träumen lassen, welche Complicirtheit für Zufall ansehen und welche mit den so schwierigen elastischen Grössen nichts zu thun haben wollen. In Wirklichkeit benutzt die Natur nicht nur die beiden häufigsten Combinationen $10 \times 27,3$, und $13 \times 21$, sondern auch die andern möglichen Combinationen, vielleicht sogar alle. Von der grösseren Hälfte wenigstens kann ich es nachweisen.

Einige davon sind in der Natur -- meteorisch - ebenso be- 
gründet wie die Periodicitäten 27,3 und 21 , nämlich $9 \times 30,3$, d. i. der Sonnenmonat, $12 \times 22,57$ (oder 23 ), d. i. die vierte Halbtheilung des Jahres: $\frac{365}{16}$. Für sie bedarf es also keiner weiteren Erklärung. Die andern Combinatinnen $7 \times 39,8 \times 34 \frac{1}{8}, 11 \times 24,9,15 \times 18,2$, $17 \times 16,1$ sind vielleicht wirklich nur Quotienten von 273 .

Es ist dieser Gedanke durchaus nicht so absurd, wie er erst erscheinen mag. Wir sahen oben, Bd. 80, S. 583, dass sich die physiologischen Perioden ähnlich theilen, wie die Schwingungen eines Seiles, einer Saite, der Luftsäule einer Orgelpfeife etc. und zwar auch durchaus nicht nur nach dem Gesetz der Halbtheilung, sondern auch nach anderen Theilungen, wenn relative oder absolute Fixpunkte vorliegen, welche eine andere Theilung begünstigen.

Wenn, wie oben als Vermuthung ausgesprochen worden, die Schwangerschaftsdauer von 273 Tagen, obgleich zuerst selbst aus einzelnen Perioden zusammengesetzt, im Laufe der Tausende oder Millionen - von Jahren schliesslich auch eine gewisse feste Eigenschaft (Individualität) als selbständige Periode erlangt hat, so kann diese wieder für sich rückwärts durch absolute oder relative Fixpunkte in verschiedene Perioden getheilt werden. Solche Fixpunkte kann z. B. der Empfängnisstag abgeben, so dass sein Abstand von dem vergangenen oder künftigen Menstruationsbeginn für die zweite Periodicität einen halben oder ganzen Monat bestimmt, s. Bd. 80 S. $634-643$. Ich werde später noch eine Anzahl Fälle vorführen, wo dies meiner Meinung nach auch geschehen ist. Die Fixpunkte können aber offenbar auch anders erzeugt sein.

Ich will nun die folgenden Beispiele danach eintheilen, je nachdem von den beiden häufigsten und kräftigsten Periodicitäten 21 u. 27,3

$\alpha$, die Periodicität $13 \times 21$ oder

$\beta$, die Periodicität $10 \times 27,3$ mit einer anderen selteneren Periodicität sich zu der Geburtsdauer 273 verbunden hat oder gar

$\gamma$, zwei andere seltenere Periodicitäten, ohne Mitwirkung einer der beiden 21 und 27,3 sich gepaart haben.

Für $\alpha$ kommen in Betracht

$$
\begin{aligned}
& 13 \times 21=7 \times 39=273 \\
& 13 \times 21=8 \times 54=272 \\
& 13 \times 21=9 \times 30^{1 / 3}=273 \\
& 13 \times 21=11 \times 25=275 \\
& 13 \times 21=12 \times 22^{3} / 4=273
\end{aligned}
$$


Normale Schwangerschaftsdauer $273=10 \times 27,3=7 \times 39$ $(=13 \times 21)$.

Fall 263. 1903/4. Geburts-No. 70. Schmäh, 25jähr., 159:82 cm lange, $601 / 2 \mathrm{~kg}$ schwere, gracil gebaute, ziemlich gut genährte II gr., ist seit 15. J. regelmässig $28 \mathrm{tg}$., 7 tg., reichlich, mit Leibschmerz menstruirt,

a) hat vor $2 \mathrm{~J}$. in $22 \mathrm{St}$. grossen K. geboren,

b) hat die letzte Menstruation 15.-21. V. wie gewöhnlich gehabt, 24. V. empfangen und die ersten Kindsbewegungen Anf. X. gefühlt. Sie gebar K., $51 \mathrm{~cm}, 3100 \mathrm{~g}$ (Plac. $370 \mathrm{~g}$ mit viel Kalk), 21. II. $12 \frac{1}{2}$ Uhr Nachm., nachdem die Wehen 21. II. 3 Uhr Vorm. begonnen und von $10 \mathrm{Uhr}$ ab betragen hatten: $6, \overline{7}, 9,9,4$.

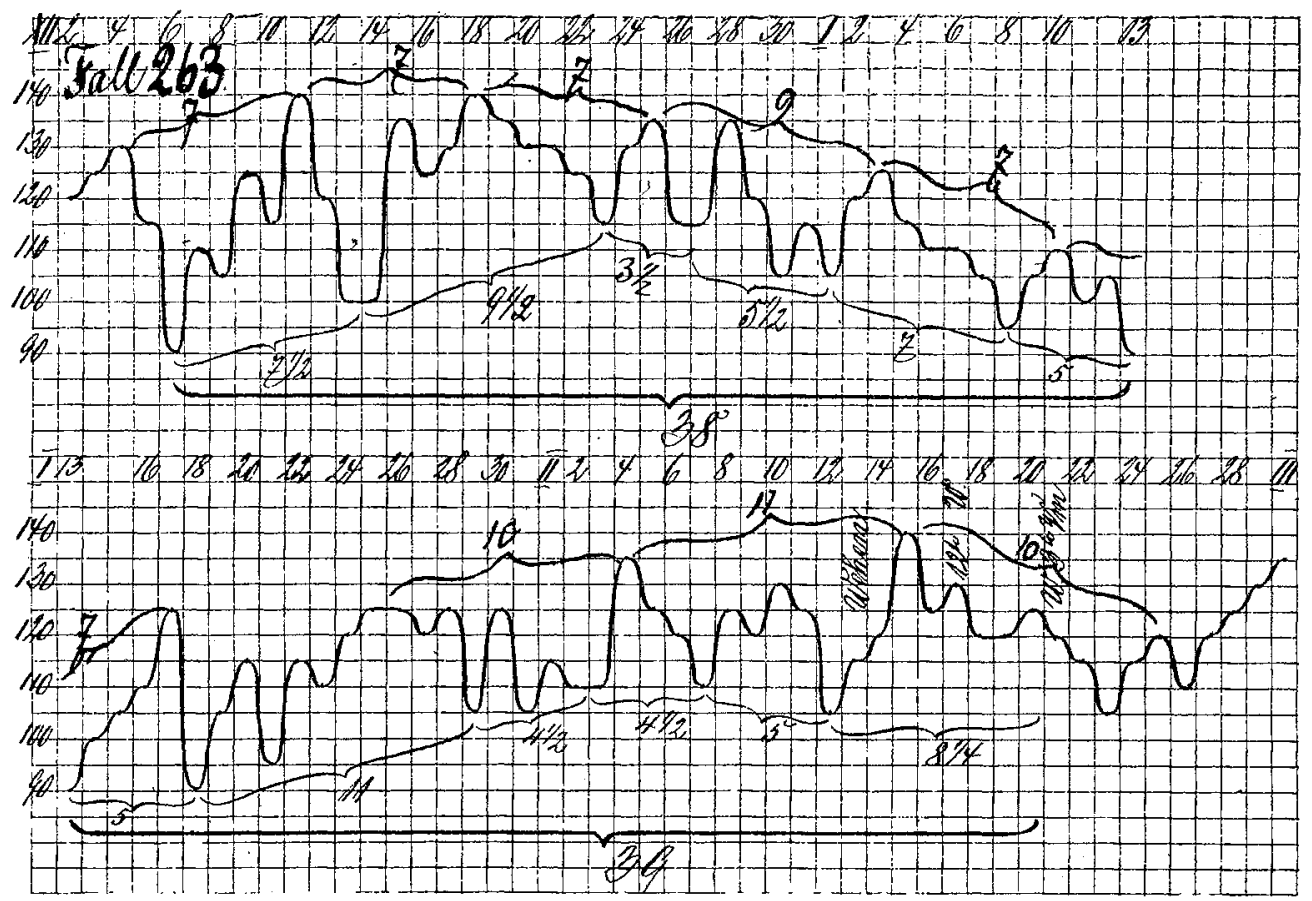

Die sehr bemerkenswerthe Curve zeigt zwei grosse, von den Verbindungslinien der Abendminima gebildete Monatsbogen von 38 und 39 Tagen (vom 6. XII. bis 13. I. und vom 13. I. bis zur Geburt 21. II.). Die ganze Schwangerschaft dauerte vom 24. V. bis 21 . II. = 273 Tage $=7 \times 39$. Diese (Blutdruek-) Periodicität ist böchstwahrscheinlich erzeugt durch den Abstand der Empfängniss 24. V. (früh) von der nächstfälligen Menstruation 12. VI. $=191 / 2=$ der Hälfte eines Monats von 39 Tagen. Die andere concurrirende Periodicität war $10 \times 27,3$ wie vor der Schwangerschaft und wurde in dieser von der Wehenperiodicität benützt: 


\section{II. früh 17. II. 21. II. früh

und zeigt sich auch in der Curve in den Periodentheilen: $31 / 2 \cdot 7 \cdot 71 / 2$ und besonders bei den Abendmaximis: 5 mal 7 . Schliesslich scheint aber auch noch als 3 . concurrirende Periodicität dazu zu kommen $13 \times 21$, denn in der Curve finden sich als Periodentheile $5: 5^{1 / 2}: 5: 5: 11: 5$. und bei den Maximis 10:11:10. Das Vorhandensein der beiden gewöhnlichen Periodicitäten 27,3 und 21 weist noch mehr darauf hin, dass die seltene Periodicitat $7 \times 39$ hier eine neue und erst durch den Abstand $z$ wischen Conception und Menstruation erzeugte ist.

Für die Vorausbestimmung des Geburtstages kounten die beiden Enden des Bogens 6. XII. und 13. I. als Maassstab für einen noch folgenden Bogen benützt werden, und da die Länge des Bogens von der Zeit vom Empfängnisstermin 24. V. bis zum Ende des folgenden Bogens (273) 1:7 war, so musste die Geburt am Ende des folgenden Bogens, d. i. 21. II., erfolgen.

Normale Schwangerschaftsdauer $273=13 \times 21=8 \times 34$ Tage.

Fall 264. 1903/4. Geburts-No. 23. Baa., 19 jähr., 156:85 cm hohe, $66 \mathrm{~kg}$ schwere, kräftig gebaute, gut genährte, blonde I gr.,

ist seit dem 16. J. regelmässig 30-32 to., 7 tg., menstruirt, hat die letzte Menstruation Anf. V. (?) gehabt und empfangen Ende V. Sie gebar M., $48 \mathrm{~cm}, 2370 \mathrm{~g}$ (Plac. 640), 2. XII. Nachm. 3 Uhr, nachdem die Wehen 1. XII. 6 Uhr Nachm. begomen hatten. Schwangersebaftswehen werden wobl, wie so oft, am Tage vor dem Eintritt in die Klinik oder am selben Tage dagewesen sein und den Eintritt veranlasst haben.

\section{tófall 264}

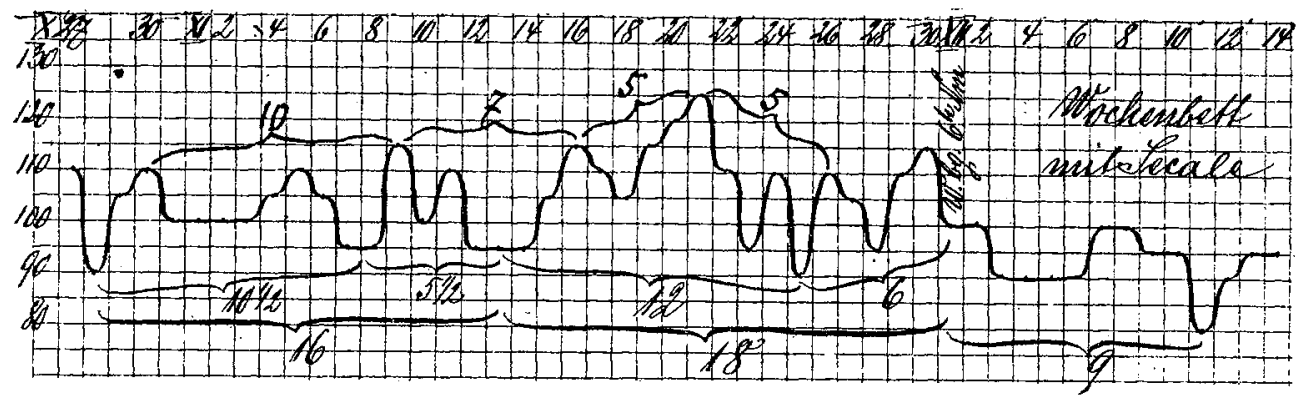

Die Curve stellt wahrscheinlich nur einen einzigen, 34 Tage langen letzten Blutdruckmonat dar, den achten der ganzen Schwangerschaft. Die Schwangerschaftsdauer ist $8 \times 34=272=13 \times 21$ Tage. Die Theilung des ersten Halbmonats $10^{1 / 2} \cdot 5^{1 / 2}$ und die Maxima verrathen, dass der 21 tägige Typus mit im Spiele war. Einen sicheren Beweis für die Richtigkeit meiner Deutung kann ich freilich nicht geben, weil 
der richtige Conceptionstermin fehit. Weitere Beobachtungen müssen entscheiden, ob die Combination $8 \times \mathbf{3 4}=13 \times 21=273$ Schwangerschaftsdauer wirklich offter vorkommt. Dies wird bejaht durch die folgenden Fälle Rein. und Hol.

Fall 265. 1904/05. Geb.-No. ? Rein., 28 jähr,, $162: 82 \mathrm{~cm}$ lange, $75 \mathrm{~kg}$ schwere, sebr stark gebaute, gut genährte, dunkelblonde II gr, ist seit dem 21. J. unregelmässig, 3-6 wöchentlich, in der letzten Zeit 34 tg. $6 \mathrm{tg}$. reichlich, mit Leib- und Kreuzsehmerz menstruirt,

a) hat 22. VIII. K. durch Kunsthülfe geboren,

b) hat die letzte Menstruation 24. II. wie sonst gehabt, sodass die nächste 29./30. III. fällig war, hat aber vorher 27. LII. empfangen. Sie gebar K. $51 \mathrm{~cm} 3500 \mathrm{~g}$ (Plac. $635 \mathrm{~g}$ mit reichl. Kalk) 27. XII. Nachm. 7 Uhr 12 Min., nachdem die Wehen mit dem Fruchtwasserabgang $1 \mathrm{Uhr}$ $15 \mathrm{Min}$. begonnen und von $1 \mathrm{Uhr}$ ab betragen hatten: $2,8,8,7,8,9$, $11,9,9,10,9,10,6$.

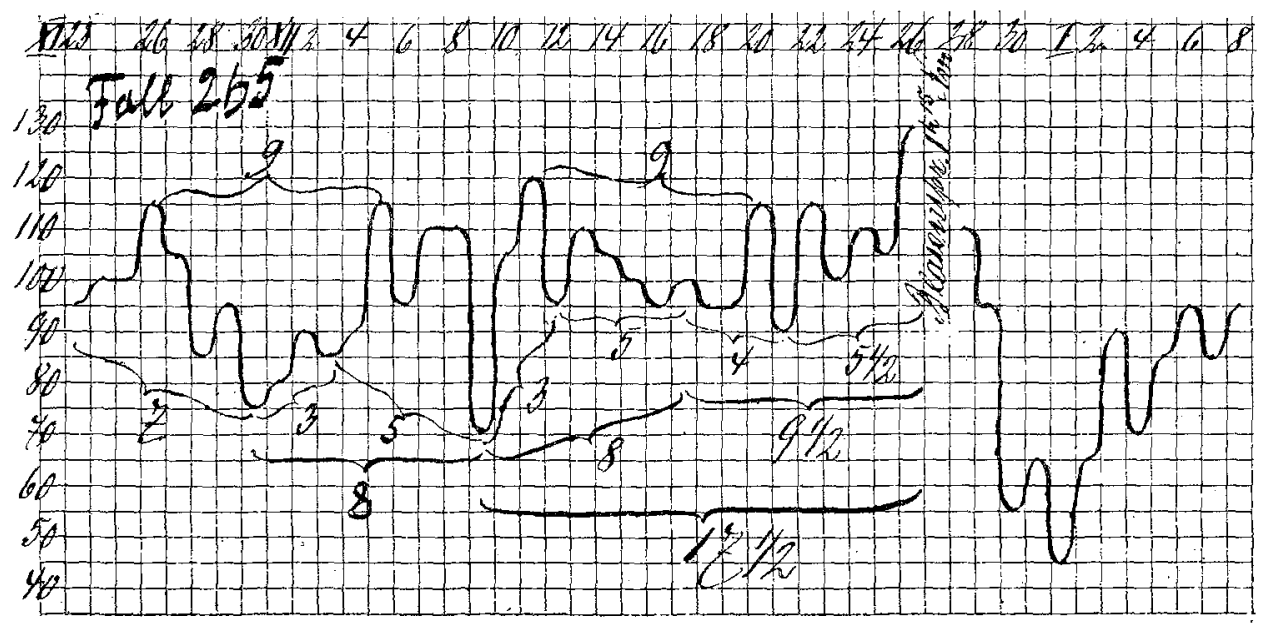

Die Schwangerschaftsdauer war vom 27. III. Abends bis 27. XII. Mittag $=274 \frac{1}{2}$ Tage. Diese bedeuten aber nur 273 Tage, weil die Empfängniss vom Beginn der zu erwartenden Vlenstruation 2-3 Tage entfernt war und so eine Anziehung und damit Verschiebung der Beginn der Menstruations- und der Schwangerschaftsmonate um je 1 bis $1_{1 / 2}^{1 / 2}$ Tag zu Stande kamen, sodass es also war, als ob Empfängniss und Menstruationsbeginn zugleich 29. III. stattgehabt hätte (s. später). Die Schwangerschaftsdauer 273 bedentet hier $8 \times 34,1$; denn das Minimum am 9. XII. bedeutete die litte des letzten Monats. Die zweite Hälfte des letzten Monats ist also $17 \frac{1}{2}$ Tage lang, die erste jedenfalls 16 Tage; denn die Wehen am 22. XI. haben die R. in die Klinik getrieben. Die zweite concurrirende Periodicität war jedenfalls $13 \times 21$; denn die Theilung der $8 \%$ tägigen Wochen zeigt fast überall den Periodentheil 5-51/2 Tage.

Die Schwangerschaftsdauer war also $273=8 \times \mathbf{3 4 , 1}=13 \times 21$.

Die Vorausbestimmung des Geburtstages war gut möglich, weil man ron der Conception 27. III. (oder 1-2 Tage später) ab bis zum Mini- 
mum 9. XII. 257 (oder our 255) hatte und weil diese nach der früheren Periodenlänge 15 halbe Monate zu je 17 Tagen betragen mussten. Man brauchte also vom 19. XII. ab nur 17 Tage weiter zu zäblen, um auf den Tag der Geburt zu kommen. Sie begann freilich wirklich erst einen halben Tag später.

Fall 266. 1904/5. Geburts-No.? Hol., 36jähr., $149: 80 \mathrm{~cm}$ lange, $64^{1} / 2 \mathrm{~kg}$ schwere, kräftig gebaute, ziemlich gut genährte, dunkelblonde II gr., ist seit dem 15. J. 4-6 wöchentlich, $3 \mathrm{tg}$., reichlich, ohne Schmerz menstruirt,

a) hat 17. VI. $1893 \mathrm{~K}, 47 \mathrm{~cm}, 2800 \mathrm{~g}$ in 16 Std. geboren,

b) 1904, kann über den Beginn der Schwangerschaft Angaben nicht machen, gebar K., $50 \mathrm{~cm}, 2800 \mathrm{~g}$ (Plac. $540 \mathrm{~g}$ obne Kalk), 27. XII. 1 Uhr Vorm., nachdem die Wehen 27. XII. 9 Uhr Vorm. begonnen und von $12 \mathrm{Uhr}$ ab betragen hatten: 9, 12.

Die Curve ist vor dem Druck verloren gegangen.

Leider fehlte der Curve ein Theil vom vorletzten Monat. Der letzte Monat war aber sehr vollständig und betrug vom 17. XI. bis 21. XII. 34 Tage. Der vorletzte Monat wird gerade so gewesen sein. Wenn man an der Curve die ersten 5 Tage, 14.-18. X., wie 17. bis 21. XI. ergänzte, so war er anch 34 Tage lang und ebenso construirt. Weitere Schlüsse liessen sich nicht daraus ziehen, als dass die Schwangerschaftsdauer wird gewesen sein $272=8 \times \mathbf{3 4}$, und dass die Empfängniss 29.-30. III. stattgefunden haben wird, 6 Tage nach Beginn der letzten Menstruation, die also am 24. III. begonnen haben wird.

Die andere concurrirende Periodicität war njcht sicher zu erkennen. Sie wird $10 \times 27,3$ oder $13 \times 21$ gewesen sein, weil die $\mathrm{H}$. ihre Menstruation ,4-6 wöchentlich" hatte.

Normale Schwangerschaftsdaver $273=13 \times 21$ (oder $10 \times 27,3$ ?) $=\mathbf{9} \times \mathbf{3 0}, \mathbf{3}$.

Diese Combination von Periodicitäten ist offenbar recht häufig. Wir erfahren bei entsprechender Aufmerksamkeit täglich, dass eine nicht kleine Anzahl Frauen ihre Menstruation nicht wirklich alle 4. Wochen $=28(27,3)$ Tage hat, sondern alle Monate, am selben Monats-Datum. Es ist dies natürlich nicht ganz wörtlich zu nehmen, weil die Monate nicht gleich viel Tage haben. Aber es zeigt, dass der Periodentypus $30,3 \quad(=27,3+3)$ Tage, wobei jede Woche $73 / 4$ Tag hat, doch recht häuffg ist. Er trifft, weil $9 \times 30,3$ $=273$ Tage geben, mit der Construction der Schwangerschaftsdauer $13 \times 21$ so häufig zusammen, dass man im gewöhnlichen Leben sich des wirklichen Unterschiedes ob $13 \times 21$ mit $10 \times 27,3$ oder mit $9 \times 30,3$ als Schwangersehaftsdauer gar nicht recht bewusst wird.

Ich führe nur 1 Beispiel vor, weil sich unter den übrigen Fällen reichlich weitere finden.

Fall 267. 1903/4. Geburts-No. 162 . Dah., 19jähr., $161: 85 \mathrm{~cm}$ lange, $74 \mathrm{~kg}$ schwere, kräftig gebaute, gut genährte, blonde I gr., ist seit dem 14. J. regelmässig 27-29 tg., 4-5 tg., reichlich, ohne Beschwerden menstruirt, 
hat die letzte Menstruation gegen Mitte XI. wie gewöhnlich gehabt, hat 22. XI. empfangen, die ersten Kindsbewegungen Anf. IV. bemerkt und hat M., $52 \mathrm{~cm}, 3830 \mathrm{~g}$ (Plac. $737 \mathrm{~g}$ ) geboren 24. VIII. $1 \frac{1 / 2}{2}$ Uhr Nachm., nachdem die Wehen 6 Ubr Vorm. begonnen und von $9 \mathrm{Uhr}$ Vorm. ab betragen hatten: $3,4,6,8,9,10,9$.

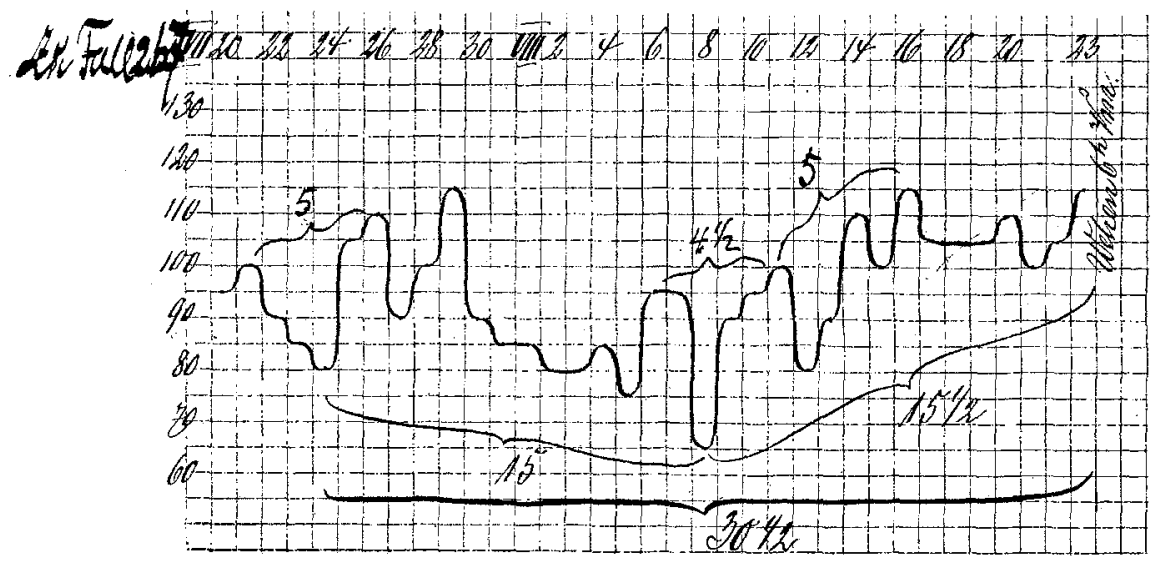

Die Curve zeigt 2 Halbmonate von 15 und $15 \frac{1}{2}$ Tagen. Sie ist dentlich angioneureusthenisch. Wie die Geburt in der Mitte eines Blutdruckmonats und auf dessen Höbe stattgefunden hat, so hat auch die Empfängniss auf solcher Monatsmitte, wahrscheinlich mit dem bei der Zwischenovulation ausgetretenen Ei, stattgefunden. Die Schwangerschaft ging also von Mitte zu Mitte eines Blutdruckmonats und betrug $9 \times 301 / 3=273$.

Die andere concurrirende Periodicität lässt sich nicht recht erkennen, wird aber wahrscheinlich nicht $10 \times 27,3$ gewesen sein, obgleich die Menstruation vor der Schwangerschaft $27-29 \mathrm{tg}$. war, sondern wohl $13 \times 21$, weil es scheint, dass sich so nahe stehende Periodicitäten wie 27,3 und 30,3 nur sehr selten zur Bestimmung der Schwangerschaftsdauer paaren.

Die Vorausbestimmung des Geburtstages gelang am 7. VIII. noch nicht richtig. Da erschien es, als ob die Mitte des letzten Monats schon am 5. VIII. gewesen wäre. Es wurde also der 22. VIII. als Geburtstag bestimmt, Nachdem aber 8. VIII. die tieftse Druckerniedrigung eingetreten und damit die Mitte des letzten Monats bezeichnet war, brauchte nur die erste Hälfte des Monats von 15 Tagen vom 8. VIII. ab weiter gezählt zu werden, um auf den richtigen Geburtstag zu führen.

$\beta$. Für die Paarung von ungewöhnlichen Periodicitäten mit der Periodicität 27,3 kommen in Betracht

$$
\begin{aligned}
& 10 \times 27,3=7 \times 39=273 \\
& 10 \times 27,3=8 \times 34=272 \\
& 10 \times 27,3=9 \times 30=273
\end{aligned}
$$


Schatz, Die Construction der Sehwangerschaltsdauer.

$$
\begin{aligned}
& 10 \times 27,3=11 \times 25=275 \\
& 10 \times 27,3=12 \times 22^{3} / 4=273 \\
& 10 \times 27,3=\left(14 \times 19^{1 / 2}=7 \times 39\right) \\
& 10 \times 27,3=15 \times 18,2=273 \\
& 10 \times 27,3=17 \times 16,1=273
\end{aligned}
$$

Offenbar kommen diese Paarungen alle vor. Ich führe hier nur die Fälle davon vor, welche anderswo nicht untergebracht werden konnten.

Normale Schwangerschaftsdauer $273=8 \times 34=10 \times 27,3$ Tage.

Fall 113 (Bd. 72 S. 231). Dort war mir diese Combination der concurrirenden Periodicitäten noch nicht bekannt. Nachträglich zeigt die dortige Wehenperiode von 17 Tagen, dass der Fall als Construction der Schwangerschaftsdauer hat $273(2)=10 \times 27,3=$ $8 \times 34$.

Normale Schwangersehaftsdaver $273=10 \times 27,3=\mathbf{1 5} \times \mathbf{1 8 , 2}$,

Fall 269. 1903/4. Geburts-No. 106. Krü., 23jähr., $158: 84 \mathrm{~cm}$ lange, $69 \mathrm{~kg}$ schwere, kräftig gebaute, gut genährte, blonde I gr., ist seit dem 14. J. regelmässig $28 \mathrm{tg}$., 5 tg., reichlich mit Rückenschmerz menstruirt, hat die letzte Menstruation Ende VII. wie sonst gehabt und hat Ende VII. empfangen. Sie gebar K., $48 \mathrm{~cm}, 2900 \mathrm{~g}$ (Plac. $500 \mathrm{~g}$ ), 1. V. 3 Uhr Vorm., nachdem die Wehen 30. IV. 3 Uhr Nachm. begomnen und von $10 \frac{1}{2}$ Uhr ab betragen hatten: 2, 2, 4, 6, 6, 7, 7, $9,9,10$.

Schwangerschaftswehen sollen 3. IV. 8 Uhr Vorm. und 12. IV. 5 Uhr Nachm. dagewesen sein.

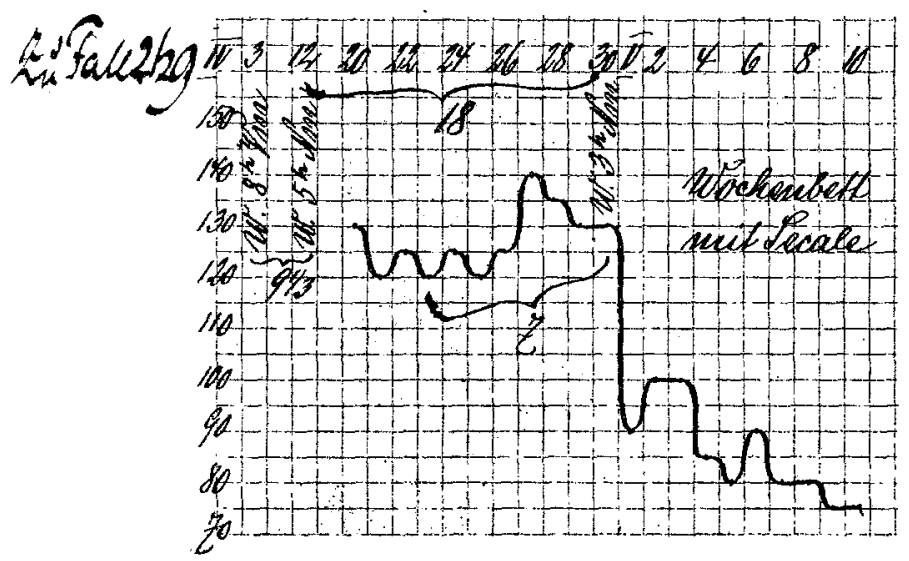

Das Kind ist trotz $48 \mathrm{~cm}$ und $2900 \mathrm{~g}$ ausgetragen. Die Geburt erfolgte exact 273 Tage nach dem bei der Aufnahme angegebenen Empfängnisstermin. Die allerdings nur kurze Blutdruckeurve zeigt den 4 wöchentlichen Periodentypus, die Wehenperioden aber sind $9^{1 / 3}$ und 18 Tage. 


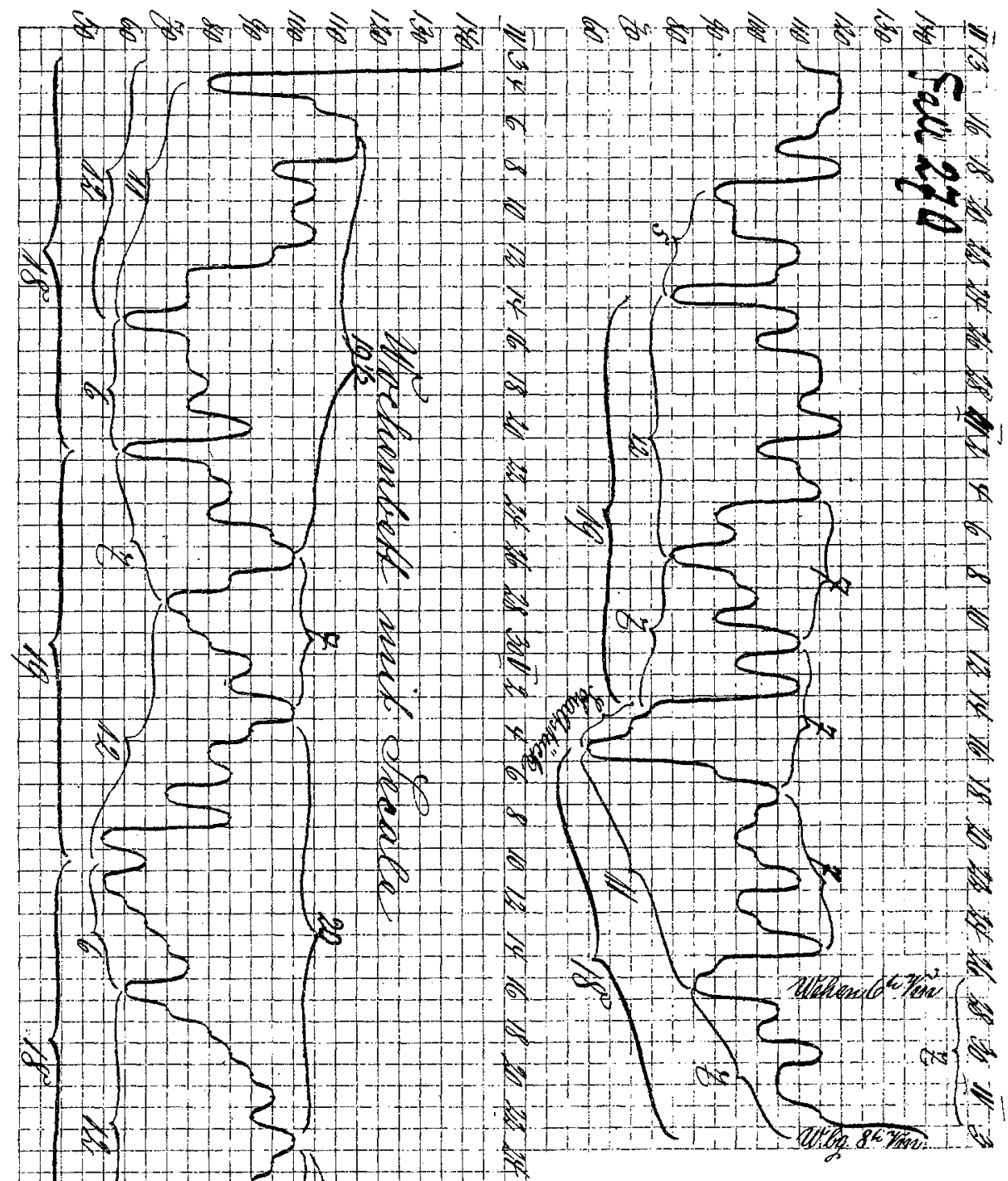


3. IV. 12. IV. 30. IV. 8 Uhr Vm. 5 Uhr Nm. 3 Uhr Nm. $91 / 3$ Tage.

Danach ist die Schwangerschaftsdauer von 273 Tagen aus 10 (Menstruations-) Perioden von je 27,3 Tagen und zugleich aus 30 WehenPerioden zu je 9,1 Tagen oder 15 zu je 18,2 Tagen entstanden.

Solche Combination der Schwangerschaftsdauer $273=10 \times 27,3$ $=\mathbf{1 5} \times \mathbf{1 8 , 2} \mathrm{kommt}$ ofter vor. Hier ist aber die Besonderheit, dass die Blutdruck(Menstruations)periode exact nach der einen 27,3 , die Wehenperiodicität aber nach der anderen der beiden Periodicitäten arbeitet, welche zusammen mit ihrem Knotenpunkt dann deutlich den Geburtstag bestimmen.

Fall 270. 1903/4. Geburts-No. 99. Stick., 18jähr., 159:84 cm lange, $671 / 2 \mathrm{~kg}$ schwere, mittelkräftig gebaute, mittel ernährte, brünette I gr., ist vom 14. J. regelmässig 4w., 4 to., reichlich, ohne Schmerz menstruirt, weiss über den Beginn ihrer Schwangerschaft gar nichts auszusagen. Sie gebar K., $51 \mathrm{~cm}, 3600 \mathrm{~g}$ (Plac. 680), 3. IV. $6 \mathrm{Uhr}$ Nachm., nachdem die Wehen 8 Uhr Vorm. begonnen und vou $31 / 2 \mathrm{Uhr}$ ab betragen hatten: $5,6,10,11,14$. Schwangerschaftswehen 27. III. 6 Uhr Vorm., d. i. 7 Tagè vor Beginn der Geburtswehen.

Die St. bekam im Wochenbett eine Thrombose des Plex. pampiniform. erst links, dann rechts, und musste deshalb 2 Monate das Bett hüten.

Die Curve vor der Entbindung wäre nicht recht verständlich, wenn nicht eine so lange Curve $\mathrm{nach}$ der Entbindung zur Verfügung stände. Beide zusammen zeigen aber, dass durchweg ein 18-19tägiger Monatstypus da war mit ungleicher Theilung zu 12 6 . Man muss annebmen, dass dieser Typus in der ganzen Schwangerschaft vorhanden war. Es bedeutet eine Schwangerschaftsdauer $15 \times 18=270$. Diese Formel erklärt vielleicht auch das Schaltstück von 2-3 Tagen, 14.-16. III., vor dem letzten kurzen Monat der Schwangerschaft. Es trat ein, um die andere 4 wöchentliche Periodicität, wie sie bei der Wehenperiodicität zu Tage trat (Schwangerschaftswehen 7 Tage vor dem Geburtsbeginn), $10 \times 27,3=273$ Tage voll auszufüllen (s. später unter "Verschiebungen").

Die Construction der Schwangerschaftsdauer ist hier also $273=10$ Wehenperioden zu 27,3=15 Blutdruckperioden zu 18 Tage $=270$ Tagen + Schaltstück von 3 Tagen .

Man muss annehmen, dass die Empfängniss erfolgt ist am Begimn einer Menstruationsperiode oder mindestens, dass die Menstruationsperiodicität die Schwangerschaftsperiodicität so an sich gezogen hat, dass sich beide schliesslich ganz decken (s. später).

Der Fall ist besonders auch darin lehrreich, dass er zeigt, wie die Blutdruckperioden sich nach der Schwangerschaft ebenso fortsetzen oder fortsetzen können, wie sie in der Schwangerschaft waren.

Normale Schwangerschaftswehen $273=10 \times 27,2=17 \times 16,1$.

Fall 271. 1901/2. Geburts-No. 74. Dett., 35jähr., $159 \mathrm{~cm}$ lange, $60 \mathrm{~kg}$ schwere, mittelkräftig gebante, gut genährte, blonde IV gr., ist seit dem 14. J. 4 w., 2-3 tg., reichl., ohne Schmerzen menstruirt 

boren,

a u. b) hat vor 15 und $12 \mathrm{~J}$. je $1 \mathrm{~K}$. von $7-8$ Pfd. normal ge-

c) 1994/5. Geburts-No. 91. Letzte Menstruation Ende VII., sehwach, Geburt K. $51 \mathrm{~cm}, 3150$ g, 19. IV. 6 Uhr 20 Min. Nachm., nachdem die Wehen 10 Uhr Vorm. begonnen und von $3 / 41$ Mittag ab betragen hatten: $4,5,6,4,4,6,6,7,6,7,6$,

d) letzte Menstruation 16. VIII. schwächer und nur kurz. Conceptionsmöglichkeit 13. VIII. Geburt M. $491 / 2 \mathrm{~cm}, 3020 \mathrm{~g}$ 13. 5 . $11^{3 / 4}$ Uhr Vorm., nachdem die Wehen $61 / 2$ Uhr früh begannen und von $71 / 2$ Uhr ab betragen hatten: $3,5,5,2,4,3,5,7,7$. Sehwangerschaftswehen waren am 10. IV. Nachm. 4-8 Uhr und 9. V. $4 \mathrm{Uhr}$ Morgens, also $321 / 2$ und 4 Tage vor Beginn der Geburtswehen beobachtet worden.

Da die Geburten a-c keinen Aufschluss geben, welchen Periodentypus der Fall hat und da in der 4. Schwangerschaft eine Blutdruckcurve nicht angefertigt worden, so ist man auf die Aussagen über letzte Menstruation, Empfängniss und auf die Schwangerschaftswehen angewiesen. Bei der gegründeten Annahme, dass das Kind reif und rechtzeitig geboren und, weil Empfängnis am 13. VIII. möglich, auch wirklich da gezeugt, also 273 Tage getragen ist, muss die Wehenperiode von $321 / 2$ Tag, deren Ende ja auf das Ende der ganzen Schwangerschaftsdauer fallen muss, aufgefasst werden als $2 \times 16^{1} / 4$ und die Wehenperiode 4 als der 4. Theil solchen Monats. Die Construction der Schwangerschaftsdauer ist also $17 \times 16=272$. Die andere concurrirende Periodicität entspricht jedenfalls der normalen Menstruationsperiode von früher n28 tägig" $=27,3$ also $10 \times 27,3$.

$0 b$ hier eine Verschiebung zwischen Schwangerschafts- und Menstruationsmonat stattgefunden hat, weil die Empfängniss 3 Tage vor Beginn der Menstruationswoche fällt, lässt sich bei den sonstigen geringen Unterlagen nicht sagen, besonders da sie bei Halbtheilung des primären Abstandes von 3 Tagen nur $11 / 2$ Tag betragen baben würde.

Die Vorausbestimmung musste ohne Blutdruckeurve den Geburtstag auf den 13. $\mathrm{V}$. ohne Verschiebung, 15. V. mit Versehiebung ansetzen.

$\gamma$. Bei $\alpha$ und $\beta$ wurde die normale Schwangersehaftsdauer 273, wenigstens noch durch eine der beiden häufigsten und stärksten Periodicitäten 27,3 und 21 bestimmt oder gehalten, während die zweite concurrierende Periodicität von einer selteneren Periodicität gebildet wurde. Es kann die Schwangerschaftsdauer aber auch normal, also wenigstens um 273 Tage lang sein, ohne dass dabei eine der beiden häufigsten und kräftigesten Periodicitäten 27,3 und 21 vertreten ist, sondern nur 2 andere, aber freilich auch solche mit dem Schlusswert von wenigstens annähernd 273 Tagen:

$$
\text { d. i. } \left.\left.\begin{array}{l}
7 \times 39 \\
8 \times 34^{1 / 4}-34 \\
9 \times 30^{1 / 3}-30 \\
11 \times 24,9-25 \\
12 \times 22,75-23
\end{array}\right\} 1\right\} 1
$$




$$
\left.\begin{array}{c}
(14 \times 19,5) \\
15 \times 18,2-18 \\
\left(16 \times 17^{1} / 6-17\right) \\
17 \times 16,1-16
\end{array}\right\} 1
$$

Ich habe bisher nur die mit $\}$ verbundenen Combinationen gesehen, s. ausserdem unten Fall Men. und Fall Wer. unter "constructive Frügeburten" und Fall Matt. unter "Chorea und Sehwangerschaftswehen".

\section{Schwangerschaftsdauer $275=7 \times 39(-40)=11 \times 25$.}

Fall 272. 1903/4. Geburts-No. 148. Er., 22jähr., 160:85 cm lange, $70 \mathrm{~kg}$ schwere, gracil gebaute, gut genährte, dunkelblonde II gr., hat in der Jugend an Scrophulose gelitten (Eltern an Schwindsucht gestorben), ist seit dem $19 \mathrm{~J}$. unregelm. $2-6 \mathrm{w} ., 6-7 \mathrm{tg}$, reichlich, obne Schmerzen menstruirt,

a) hat vor $3 \mathrm{~J}$. K. von $8 \mathrm{Pfd}$. in 3 Std. leicht geboren,

b) hat die letzte Menstruation Anf. X. wie sonst gehabt, hat Mitte $X$. empfangen, die ersten Kindsbewegungen Anf. III. und die Senkung des Uterusgrundes 29. V. bemerkt.

Sie gebar M. $48 \mathrm{~cm}, 3100 \mathrm{~g}$ (Plac. $600 \mathrm{~g}$ mit viel Kalk) 18. VII. 5 Uhr Vorm., nachdem die Wehen 12 Uhr Mitternacht begonnen und von 3 Uhr ab betragen hatten: 4, 8, 9, 9, 3 .

Die Blutdruckeurve bietet mit ihren Minimis vom 7. VI. bis 17./18. VII., d. $i$. in 40 Tagen einen einzigen schön gebauten Bogen, welcher nur dịe 5 Tage (1 kurze Woche) vor der Geburt stark (auf 150 Mon.) erhöht ist. Der Periodentypus scheint deutlich 6 oder 3 wöchentlich zu seim, die Geburtswehen traten aber schon 40 Tage nach dem tiefsten Minimum ein.

Die Schwangerschaftsdauer war offenbar nabezu oder ganz die normale und war $=7 \times 39$ bis $40=273$ bis 280 .

Es wird sich der 40 tägige Monat in der Schwangerschaft siebenmal in gleicher Weise wiederholt haben. Die Senkung des Uterusgrundes am 29. V. bedeutet eine Reihe Schwangerschaftswehen. Diese müssen recht deutlich gewesen sein, weil sie die Veranlassung gaben, die Klinik aufzusuchen. Dieser Wehentermin liegt 50 Tage vor der Geburt und passt nicht zu der Periodicität $7 \times 39-40$. Er verrät die andere concurrirende Periodicität, nämlich $11 \times 25=275$, so dass die Schwangerschaftsdauer als $\mathbf{7} \times \mathbf{3 9}(\mathbf{- 4 0})=\mathbf{1 1} \times \mathbf{2 5}=\mathbf{2 7 5} \mathrm{zu}$ bezeichnen ist. Diese beiden Periodicitäten, so sonderbar ihre Combination erscheinen mag, sind bei der E. offenbar schon bei der Menstruation vor der Schwangerschaft dagewesen. Die Menstruation war bis 6 wöchentlich. Dies stimmt wohl mit 40 tägig. Sie war aber auch 2 wöchentlich. Dies kann auch $12^{1 / 2}$ tägig heissen. So genau hat die E. nicht aufgemerkt.

Die Empfängniss geschah 2 Wochen nach Beginn der letzten Menstruation. Es wird da, wenn die nächste Menstruation da gerade eintreten solite, Beginn des 1. Menstruation-Blutdruckmonats mit dem Beginn des 1. Schwangerschaftsmonats zusimmengefallen sein. 


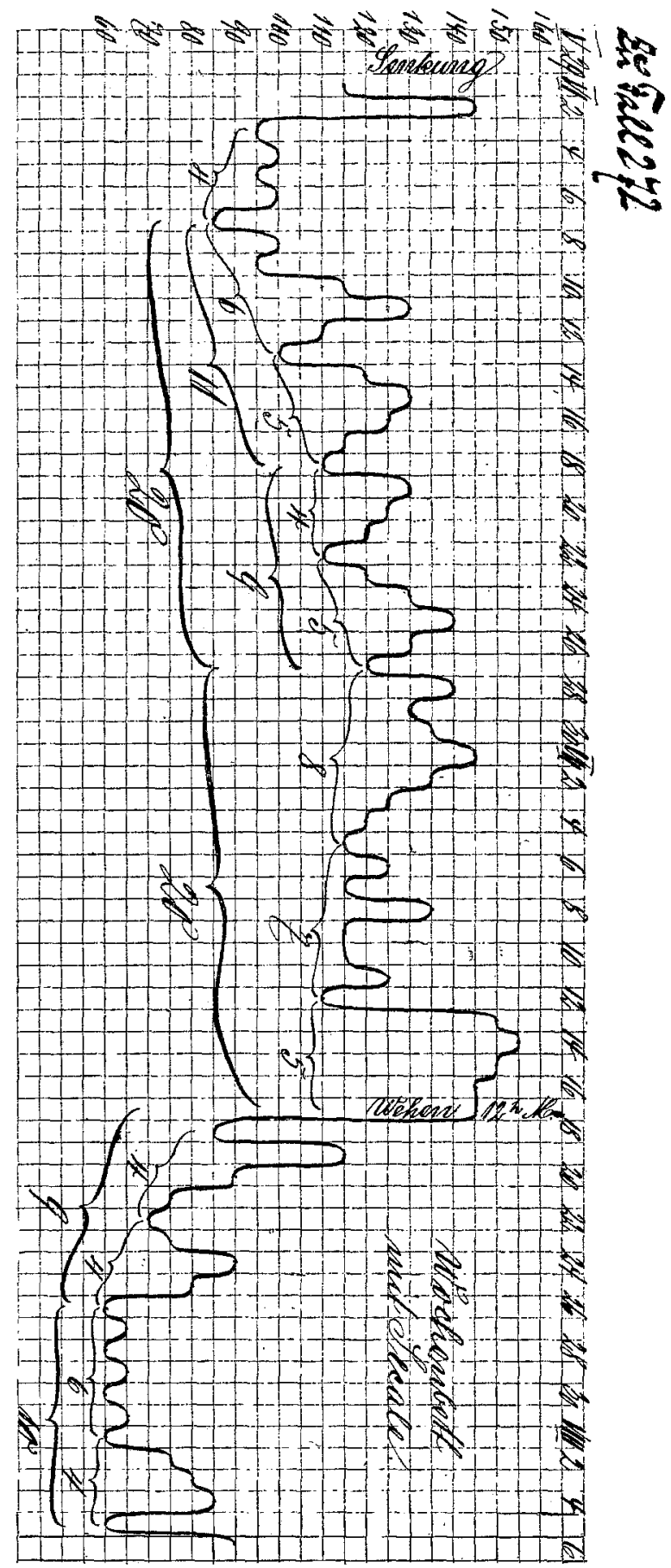


Normale Schwangerschaftsdauer $2761 / 2=7 \times 39^{1 / 2}\left(=9 \times 30^{2} / 3\right.$ ? $)$ Tage.

Fall 273. 1903/4. Geburts-No. 101. Lie., 19jähr., $155: 82 \mathrm{~cm}$ lange, $62 \mathrm{~kg}$ schwere, gracil gebaute, mittel genährte, blonde I gr., ist vom 13 J. unregelm., 4-5w., 4 tg., nicht reichl., ohne Schmerz menstruirt,

hat die letzte normale Menstruation in der zweiten Hälfte VI. gehabt und 5. VII. cohabitirt. Sie gebar K. $52 \mathrm{~cm}, 3200 \mathrm{~g}$ (Plac. $650 \mathrm{~g}$ mit viel Kalk) 8. IV. 8 Uhr 40 Min. Nachm., nachdem die Wehen 7. IV 6 Uhr Vorm. begonnen hatten.

Schwangerschaftswehen 19. III. Vorm.

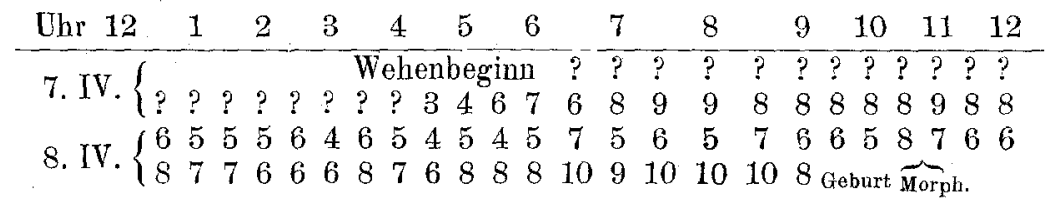

Zu Fall 273.

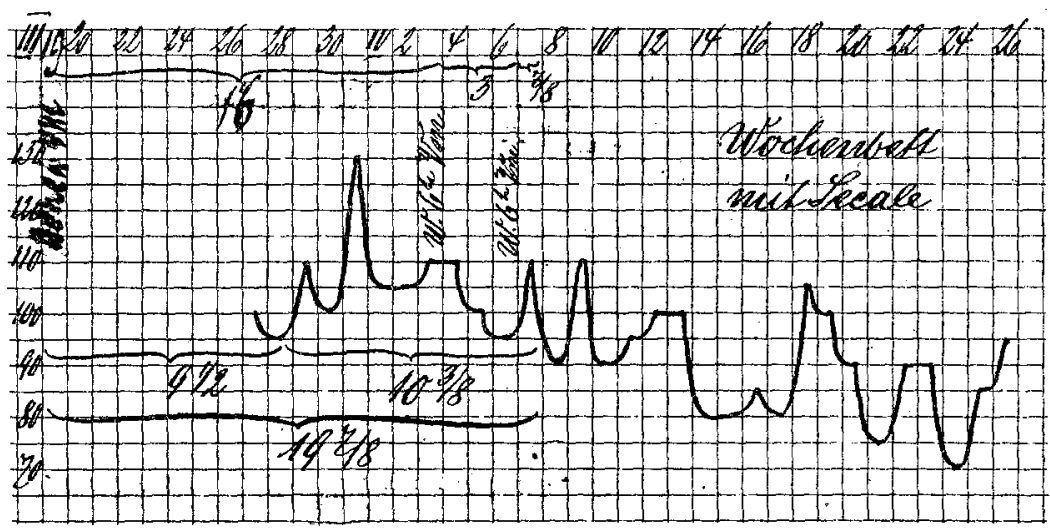

Der Fall hat eine Schwangerschaftsdauer vom 5. VII. Ab. bis 7. IV. früh, d. i. von $276 \frac{1}{2}$ Tag oder, wenn das $\mathrm{Ei}$ einer Zwischenovulation befruchtet worden ist, etwa 275 Tage. Diese (nahezu) normale Schwangerschaftsdauer ist eigenthümlich construirt. Von den Schwangerschaftswehen 19. III. Vorm. bis zu Beginn der Geburtswehen 2. IV. 6 Uhr früh sind $19^{3} / 4$ Tage. Von der Empfängniss 5. VII. Ab. bis zu den Schwangerschaftswehen 19. III. Vorm. sind 257 Tage, d. i. $13 \times 19,78$. Die ganze Schwangerschaftsdauer ist also $14 \times 19 \% / 4$ oder $7 \times 391 / 2=2761 / 2$ Tag. So sonderbar diese Construction erscheint: es kann doch kaum ein Zufall sein, dass die Wehenperiode von Beginn der Schwangerschaftswehen 19. III. bis zum Beginn der Geburtswehen gerade den 14. Theil der ganzen Schwangerschaftsdauer darstellt.

Die andere concurrirende Periodicität, welche den Knotenpunkt mit bestimmte, ist nicht ersichtlich. Es könnte sein: $8 \times 34^{1 / 2}, 9 \times 30^{2} / 3$, $10 \times 27,6,11 \times 25,12 \times 23$. Nach der Menstruationsperiode vor der Schwangerschaft, welche als $4-5$ wöchentlich angegeben wurde, kommt 
in Betracht $8 \times 341 / 2$ oder $\mathbf{9} \times \mathbf{3 0 2 / 3}$. Letztere ist wahrscheinlich, weil viel häufiger. Die Vorausbestimmung des Geburtstages konnte wegen der Kürze der Blutdruckcurve nur annähernd und nur unter Zuhülfenahme des Empfângnisstermines und der Schwangerschaftswehen geschehen.

Nach der Cohabitation am 5. VII. Ab. war das Ende der Schwangerschaft um den 5 . IV. oder vielleicht etwas später, wenn das befruchtete

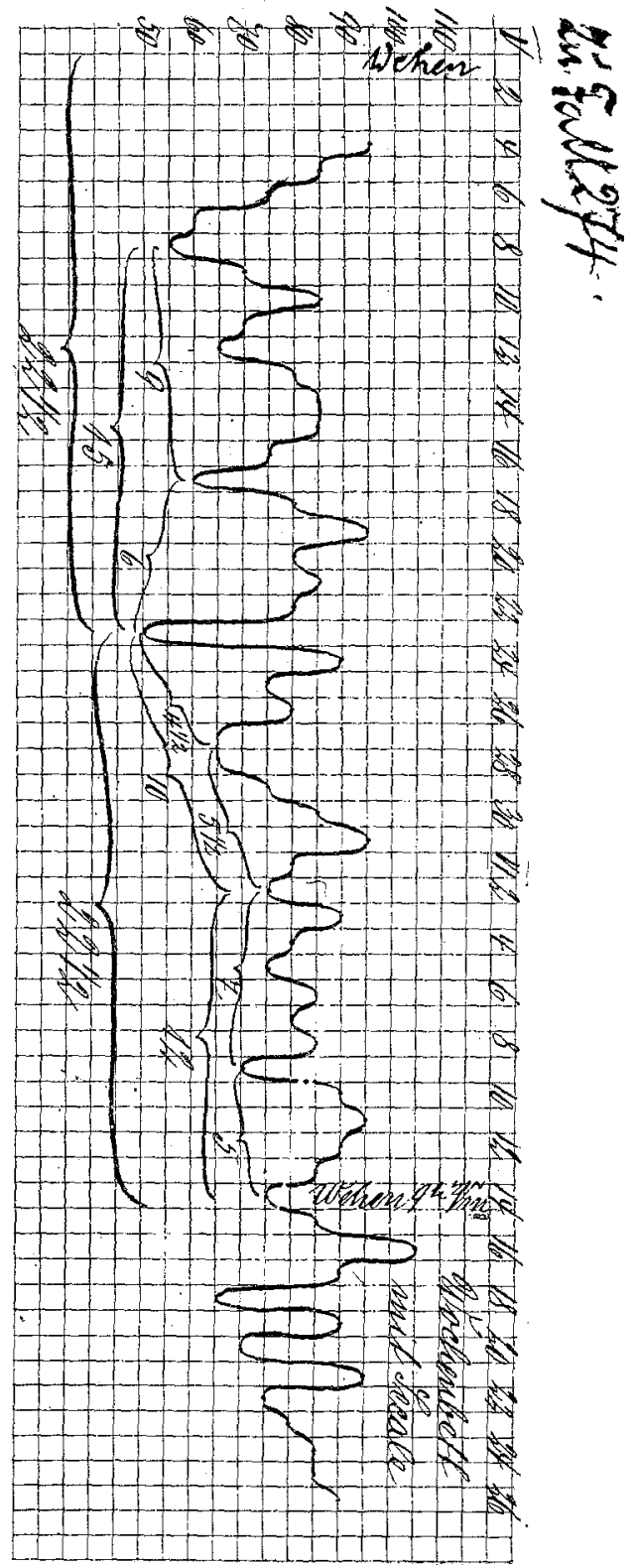




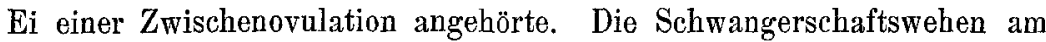
19. III. konnten 2 Wochen vor der Geburt liegen, diese also am 2. IV. erfolgen, wenn der Periodentypus 4 wöchentlich war, aber auch $21 / 2$ Wochen vor der Geburt liegen und diese 5. IV. Nachm. erfolgen, wenn der Wehenmonat 5 wöchentlich war wie vor der Schwangerschaft der Menstruationsmonat. Nachdem der 2. IV. ohne Wehen vorüber gegangen war, musste der 5 wöchentliche Periodentypus angenommen and die Gebart am 5. IV. Ab. erwartet werden. Sie trat aber erst 7. IV. ein. Der Wehenmonat war eben nicht 35 (oder $341 / 2$ ), sondern $391 / 2$ Tag lang. Das hätte man nur bei längerer Beobachtung wissen könven.

Normale Schwangerschaftsdauer $273=9 \times 30,3=12 \times 22,75$.

Fall 274. 1903/4. Geburts-No. 132. Ho., 21 jähr., $157: 81 \mathrm{~cm}$ lange, $64 \mathrm{~L} / 4 \mathrm{~kg}$ schwere, mittelkräftig gebaute, dunkelblonde $\mathrm{I} \mathrm{gr}$,

ist seit dem 15 . J. regelmässig $28 \mathrm{tg}$., $3 \mathrm{tg}$., reichlich, mit Leibschmerz menstruirt,

will die letzte Menstruation Ende X. wie sonst gehabt haben, ist aber auf sich sehr unachtsam gewesen. Sie gebar K., $51 \mathrm{~cm}, 3300 \mathrm{~g}$ (Plac. $680 \mathrm{~g}$ ), 15. VI. 6 Uhr Nachm., nachdem die Wehen $9 \mathrm{Uhr}$ Vorm, begonnen und von 2 Uhr Nachm. betragen hatten: 4, 6, 9, 9, 10 (Blase springt), 8, 8, 10.

Schwangerschaftswehen waren in der Nacht vom 30. IV. zum 1.V., d. i. $45^{7} / 2$ Tage vor der Geburt, dagewesen, und deshalb war die Schwangere in die Klinik geschickt worden.

Die Blutdruckeurve vom 1.V. (Wehen) bis 15. VI. wird in die Mitte am 23. V. vom grössten Minimum getheilt. Sie stellt also zwei Monate von je 222/3 oder 223/4 Tagen dar. Leider ist der Conceptionstermin nicht bekannt. Wenn die Monate in der ganzen Schwangerschaft gleich lang gewesen sind, dann hat dieselbe aus 12 Monaten zu je $223 / 4$ Tagen $=273$ Tagen bestanden

Ich halte diesen Periodentypus hier aber nicht für als entstanden aus der verkürzten (23 stündigen) Tagesperiode (s. oben die „verschiedenen Perioden etc." [Arch. Bd. 80 S. 622 ff.]) und auch nicht aus der 21 tg., d. i. 6- oder 3 wöchentlichen Periode, sondern für entstanden als 4. Halbtheilung des Jahres $\frac{365}{16}=22,83$. Der Fall entspricht den (Arch. Bd. 80 S. $625-631$ ) vorgeführten 3 Fällen mit 23 to. Periodentypus. Es sind damit 4 sichere Fälle.

Die andere neben der $12 \times 22^{3 / 4}$ concurrirende Periodicität wird wahrscheinlich $9 \times 30,3$ sein, weil der Periodentheil 15 vertreten ist. Es ist aber nicht ausgeschlossen, dass es $13 \times 21$ ist, -weil die Periodentheile 5 und 10 mehrfach vertreten sind. Dann würde der Fall nicht hierher, sondern unter die Combinationen mit einer der kräftigsten Periodicitäten gehören, und es würde damit seine Erlklärung leichter sein.

$\mathrm{Da}$ ich den Fall erst für einen mit $28 \mathrm{tg}$. Periode ansah, so bestimmte ich den Geburtstag auf 28 Tage nach dem 23. V., also auf 20. VI. Der Monat 1.-23. V. war aber allein richtig, and vom 23. V. wieder 23 Tage weiter gerechnet, würde richtig den 15. VI. als Geburtstag ergeben haben. 


\section{Nachschrift bei der Correctur.}

Bei dem grossen Widerstand, welchen die Periodenlehre sogar in Kreisen von Gynäkologen findet und besonders auch die Construction der Schwangerschaftsdauer als 2 Periodicitäten finden wird, mache ich, als diese Lehre von anderer Seite her unterstützend, darauf aufmerksam, dass nach Leopold und Ravano (Dieses Archiv Bd. 83, S. 585) zwar die Periodicität der Ovulation meistens mit derjenigen der Menstruation zusammenfällt, bisweilen aber einem eigenen periodischen Cyclus folgt. Bei Fall 2 der 3. Gruppe war die Menstruation 4wöchig, die letzte 6. I. 96. Ovariotomie 13. I. Corpus luteum wenig über 2 Wochen alt, ein reifer beinahe sprungfertiger Follikel vorhanden. Die Ovulation hatte also eine Periode von etwa $21 / 2-3$ Wochen, die Menstruation von 4 Wochen. Beide werden in der Blutdruckcurve an den Minimis zu erkennen sein, weil auch das Springen des Follikels mit einer Hyperämie des Ovariums verbunden ist. Würden diese beiden Periodicitäten bei einer Schwangerschaft zur Anwendung kommen, so würde deren Dauer construirt sein können $273=10 \times 27,3=14 \times 19,5(7 \times 39,0)$. - Ich sah bei einem Manne Prostatablutungen und Prostataneuralgien, verschiedene Periodicitäten also am selben Organ einhalten. 